Universidad de Lima

Facultad de Economía

Carrera de Economía

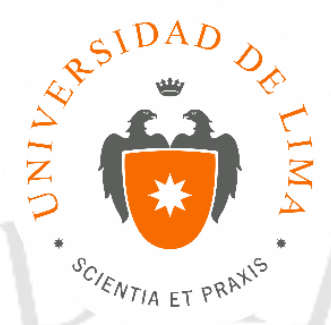

\title{
EMISIÓN DE BONOS FORMATO 144A/REG S DE ABENGOA TRANSMISIÓN SUR: UN HITO EN EL MERCADO FINANCIERO PERUANO
}

Trabajo profesional teóricamente fundamentado (Proyecto profesional) para optar el título profesional de Economista

\author{
Amelia Natalia Viñas Luna \\ Código 20061201 \\ Asesor \\ Lila Patricia Cancino Cebrián
}

$$
\text { Lima - Perú }
$$

Octubre de 2016 


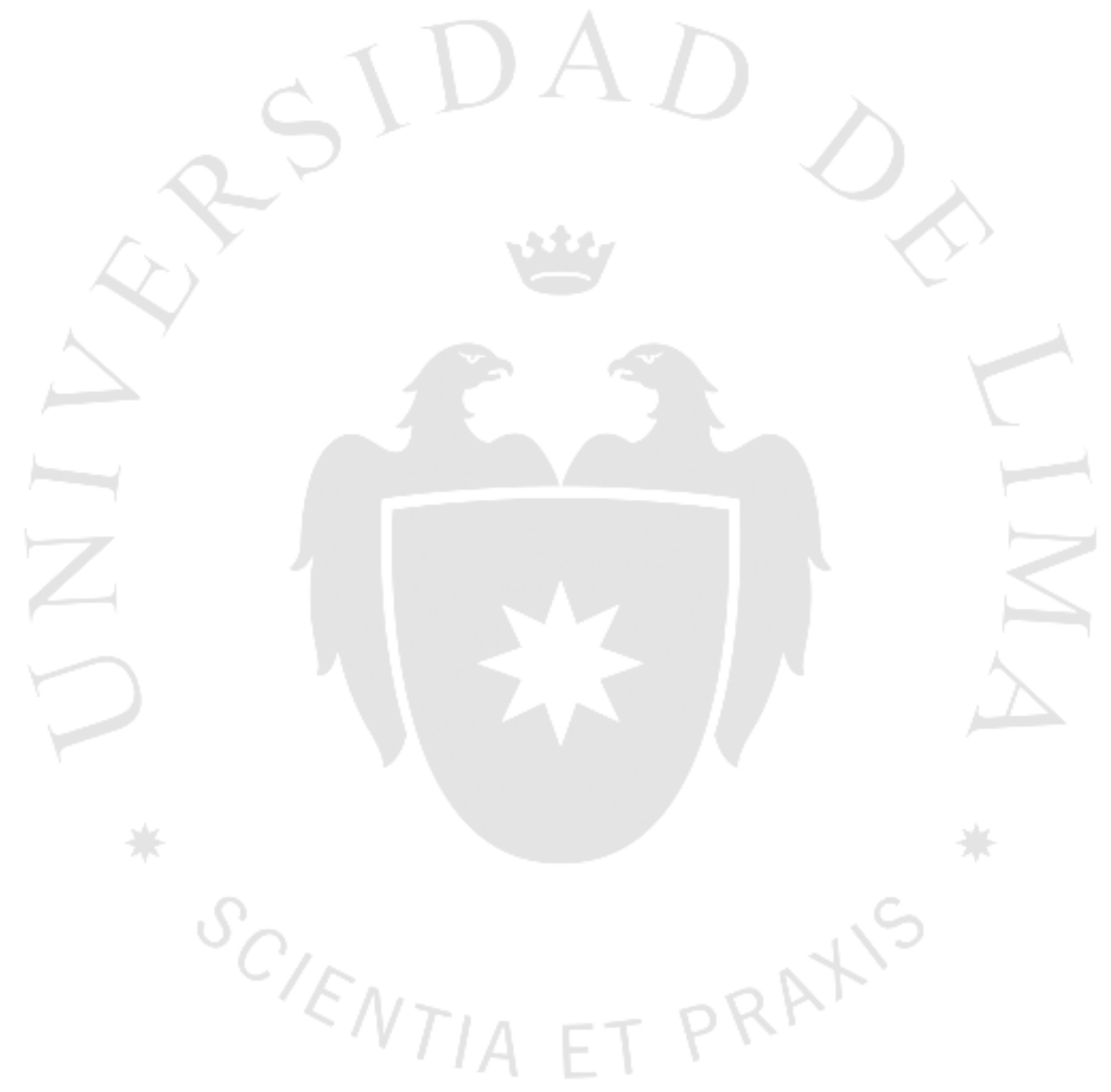


EMISIÓN DE BONOS FORMATO 144A/REG S DE ABENGOA TRANSMISIÓN SUR: UN HITO EN EL MERCADO FINANCIERO

\section{PERUANO}




\section{TABLA DE CONTENIDO}

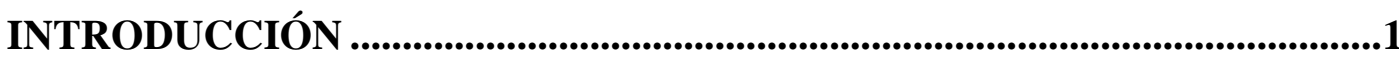

CAPÍTULO I: ALCANCE GENERAL DE LAS EMISIONES PRIVADAS DEL TIPO 144A/REGULACION S Y EL PROJECT FINANCE .............................3

1.1 LOS BONOS DENTRO DEL MERCADO DE CAPITALES .........3

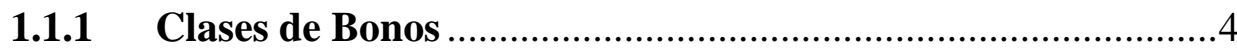

1.1.2 Los participantes en el mercado de capitales ........................6

1.1.3 Categorías de Clasificación Crediticia ...................................8

1.1.4 Emisiones Públicas y Privadas..............................................12

1.1.5 Oferta privada Regla 144A/Reg S ......................................16

1.2 SOBRE EL PROYECTO DE INVERSIÓN ....................................20

1.2.1. Descripción del proyecto de inversión ........................................20

1.2.2. Composición del Sector Eléctrico Peruano …............................22

1.2.3. Funcionamiento del Sistema Garantizado de Transmisión .......25

1.2.4. La modalidad de Project Finance ..........................................22

CAPÍTULO II: DESCRIPCIÓN DE LA ESTRUCTURACIÓN DEL BONO Y SU IMPLEMENTACIÓN

2.1 PRINCIPALES PARTICIPANTES DEL PROYECTO ATS ...........34

2.2 FORTALEZAS DEL PROYECTO DE INVERSIÓN ....................38

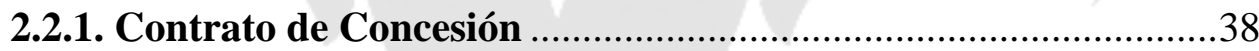

2.2.2 Contratos EPC ............................................................46

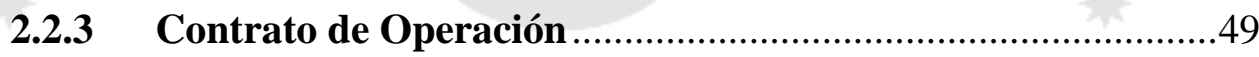

2.2.4 Sector Transmisión ..........................................................51

2.2.5 Experiencia del Promotor y compañías afiliadas...................51

2.3 MATRIZ DE RIESGOS DEL PROYECTO DE INVERSIÓN .......53

2.4 ESTRUCTURACIÓN DE LA EMISIÓN ........................................56

2.4.1. Participantes del Bono 144A/Reg. S de ATS .......................57

2.4.2. Principales Términos Financieros del Bono 144A/Reg. S ......62

2.4.3. Análisis financiero de la sociedad concesionaria ATS ...........65

2.4.4. Principales documentos y garantías ......................................69

CAPÍTULO III: EVALUACIÓN DE RESULTADOS Y ÉXITO DE LA EMISIÓN DEL BONO . .115 


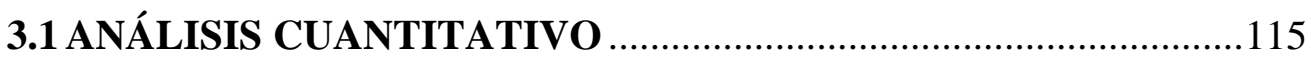

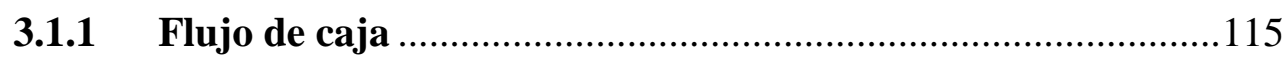

3.1.2 Costo All-In ....................................................................116

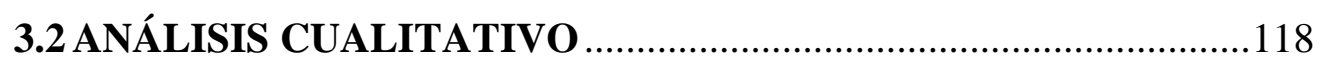

CONCLUSIONES .......................................................................................119

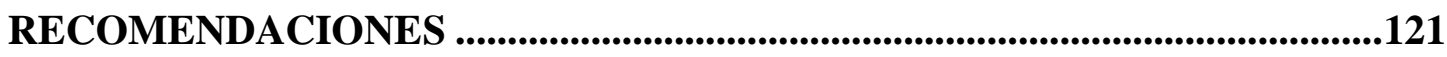

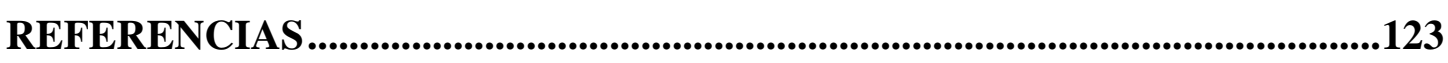

BIBLIOGRAFÍA ….................................................................................126

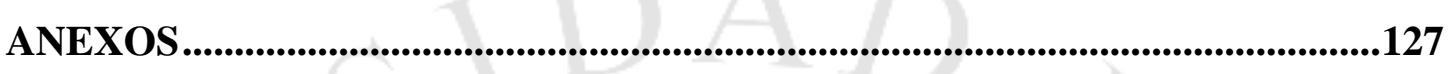




\section{ÍNDICE DE TABLAS}

Tabla 1.1 Tipos de Bonos.....................................................5

Tabla 1.2 Clasificaciones de Riesgo Equivalentes por Agencias de Rating.............10

Tabla 1.3 Diferencias entre Colocaciones Privadas bajo normativa de la SEC..........15

Tabla 2.4 Concesiones de transmisión de Abengoa en Perú otorgadas por el Estado.. 52

Tabla 2.5 Matriz resumen de riesgos del proyecto de inversión......................55

Tabla 2.6 Principales términos financieros de la emisión..........................63

Tabla 2.7 Estado de Resultados..................................................66

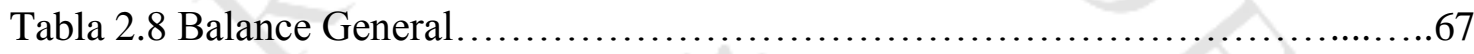

Tabla 2.9 Listado de los documentos del bono de ATS .............................71

Tabla 2.10 Cronograma de amortización de la emisión............................76

Tabla 2.11 Distribución de emisión entre Compradores Iniciales.......................97

Tabla 2.12 Proyecciones del Modelo Financiero aplicado.........................111

Tabla 3.13 Comparativo de Proyecciones de Flujo de Caja Bono vs. Préstamo

Sindicado.....................................................116

Tabla 3.14 Consideraciones para el cálculo del Costo All-In..................... 117 


\section{ÍNDICE DE FIGURAS}

Figura 1.1 Proceso de la asignación de capital en el mercado de capitales.....................7

Figura 1.2 Extensión de la Línea Chilca-Marcona-Montalvo.......................21

Figura 1.3 Composición del Sector Eléctrico Peruano ................................................23

Figura 1.4 Tipos de Sistemas de Transmisión..................................25

$\begin{array}{llllll}\text { Figura } & 1.5 & \text { Estructura } & \mathrm{y} & \text { Participantes dentro del Project }\end{array}$ Finance.......................30

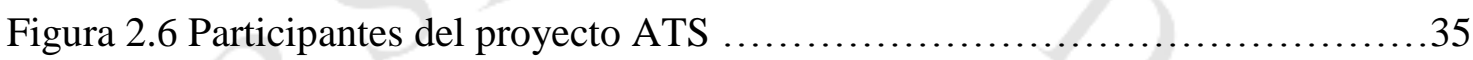

Figura 2.7 Participantes del Bono 144A/Reg S de ATS ...........................58

Figura 2.8 Garantías ofrecidas bajo el bono de ATS .......................... 98

Figura 2.9 Cascada de Flujos entre Cuentas..................................... 103 


\section{INTRODUCCIÓN}

En la última década, las políticas macroeconómicas estables aplicadas en diversos países de América Latina, así como la mayor participación de estos en la economía mundial, han causado que dichos mercados emergentes se vuelvan más atractivos para los inversionistas. Esto ha permitido una evolución favorable de los mercados de capitales de América Latina y el crecimiento de las emisiones corporativas, que para el período de los años 2000 a 2011 aumentaron más de 8 veces, incluyendo el Caribe (Bustillo y Velloso, 2013, p. 59). En este escenario expansivo de los mercados de capitales en Latinoamérica, muchas empresas dedicadas a la construcción de obras de infraestructura han aprovechado el apetito de los inversionistas internacionales para obtener financiamiento a fin de desarrollar sus respectivos proyectos.

Valiéndose de este contexto, la sociedad concesionaria Abengoa Transmisión Sur S.A., establecida en el Perú y encargada de la construcción, operación y mantenimiento de la línea de transmisión eléctrica Chilca-Marcona-Montalvo, realizó el 16 de abril de 2014, una emisión privada de bonos internacional por USD 432000000 a una tasa cupón de 6,875\% por un plazo de 29 años, convirtiéndose en el Project Bond con el vencimiento más largo en Perú (International Financial Law Review, 2014, Expected Model, párr. 1) al cierre del año 2014. El impacto en el mercado de deuda que tuvo este bono fue el de demostrar que, si bien los proyectos de infraestructura en países emergentes acarrean bastantes riesgos, los inversionistas parecen estar aceptando este tipo de estructuras en sus portafolios, aún en aquellos bonos colocados mediante ofertas privadas y por tanto, menos regulados.

El presente documento tiene como objetivo general exponer el proceso de estructuración detrás de la emisión del bono de Abengoa Transmisión Sur S.A. (ATS) y evaluar la emisión como caso de éxito en el Perú para proyectos de inversión de similar naturaleza. Los objetivos específicos del trabajo son:

i. Explicar la adecuación del bono a la estructura contractual y financiera del proyecto de inversión desarrollado por Abengoa Transmisión Sur S.A. 
ii. Describir los mecanismos aplicados a la emisión para mejorar su atractivo hacia los inversionistas.

iii. Diagnosticar el grado de éxito de la emisión en el público inversor.

iv. Analizar las implicancias de este tipo de emisión en el mercado de bonos para proyectos de infraestructura en el Perú.

Cabe destacar, que este trabajo se realiza en base a la experiencia obtenida durante el proceso de estructuración de la emisión y sobre la información pública disponible de esta. Mi papel en el proceso de estructuración de la emisión abarcó la revisión y negociación de todos los contratos de la emisión con los estructuradores, la revisión del funcionamiento del modelo financiero aplicado, el llenado de los formatos necesarios para proceder con la emisión, la coordinación con asesores legales, consultores de los estructuradores y agencias de rating y atender eventuales consultas de los potenciales inversionistas. El sondeo de precio del bono y la determinación de la tasa de interés cupón aplicable al bono fueron realizados por los estructuradores. Por tanto, se hace el énfasis de que el presente trabajo se expone desde la perspectiva del emisor y no del inversionista.

Para realizar la explicación de este proceso, se ha dividido el presente documento en tres capítulos: el primer capítulo incluirá un marco teórico con una descripción general de los bonos y las ofertas privadas; asimismo, se realizará una explicación del marco normativo del sector de transmisión eléctrica y un resumen del proyecto de la línea de transmisión; y, por último, se explicará el esquema Project Finance como tipo de financiación para proyectos de infraestructura. En el segundo capítulo se entrará en mayor detalle respecto a la emisión y los términos financieros, al contrato de concesión que sustenta el proyecto, así como a las fortalezas financieras del mismo y aquellos mecanismos y provisiones usados en el bono para mitigar los posibles riesgos que podría presentar la estructura. Finalmente, en el tercer capítulo, se diagnosticará el grado de éxito de la emisión mediante la mejora de los resultados para la empresa en términos de costos y gestión adecuada del flujo de caja y las implicancias de un bono de esta magnitud en el mercado peruano de bonos del tipo Project Finance.

Finalmente, se destaca que en abril de 2016, la empresa cambió el nombre de su razón social a ABY Transmision Sur. 


\section{CAPÍTULO I: ALCANCE GENERAL DE LAS EMISIONES PRIVADAS DEL TIPO 144A/REGULACION S Y EL PROJECT FINANCE}

\subsection{LOS BONOS DENTRO DEL MERCADO DE CAPITALES}

El mercado de capitales es el mercado financiero en el que se realizan transacciones de compra y venta de valores o títulos de renta fija o variable cuyo vencimiento es mayor a un año, por lo cual es una fuente de financiamiento importante a mediano y largo plazo para aquellas empresas que buscan una alternativa distinta a la banca. Parte de estos valores, son los bonos, también conocidos como títulos de renta fija, los cuales son negociados en el mercado primario y secundario ${ }^{1}$. En esta sección se presenta una breve descripción sobre las principales características de los bonos y aquellos conceptos relacionados con este tipo de valores.

Los bonos son títulos de deuda que representan una obligación financiera asumida por una entidad para pagar cupones (intereses) y capital en fechas predeterminadas. La entidad que asume esta obligación se llama "emisor" y puede ser una compañía, una entidad gubernamental (como una municipalidad), el gobierno central de un país o un organismo multilateral como el Banco Mundial. A los inversionistas que adquieren dichos títulos de deuda se les reconocen también como "tenedores de bonos".

Existen diversos tipos de bonos, pero en general, las distintas clases comparten un grupo de características comunes tales como el cupón, el valor nominal, la tasa cupón, el plazo y el precio.

Otro concepto importante relacionado a los bonos y la fluctuación de las tasas de interés en el mercado, es el de rendimiento al vencimiento o, en inglés, yield to maturity (YTM). El YTM es la tasa de interés requerida actualmente en el mercado para un bono de similares características al que se está analizando y permite realizar valorizaciones

\footnotetext{
1 El mercado primario es aquel mercado en el cual las nuevas emisiones de bonos (también aplicable a acciones) son vendidas por primera vez. Por otro lado, en el mercado secundario se realizan la reventa de un bono cuya emisión inicial ya fue vendida en el mercado primario.
} 
de estos instrumentos de deuda y tener una idea aproximada del precio al que se podría negociar el bono en el mercado secundario.

\subsubsection{Clases de Bonos}

Como se mencionó anteriormente, existen diversas clases de bonos actualmente y no hay un consenso unánime sobre cómo clasificarlos.

Según Fabozzi (2012), una forma de clasificación es mediante los sectores existentes en el mercado de bonos. Según la perspectiva de un país dado, existen los mercados de bonos interno y externo (p. 37):

a) El mercado de bonos interno o mercado nacional de bonos se divide en dos: (i) el mercado doméstico y (ii) el mercado extranjero. En ambos se emiten bonos dentro de un país, pero en el doméstico el emisor está domiciliado en el país, y en el extranjero el emisor no es domiciliado.

b) El mercado de bonos externo, o mercado internacional de bonos, alberga a aquellos bonos que cuentan con las siguientes características:

- Los bonos son emitidos fuera de la jurisdicción de un país dado.

- $\quad$ No se encuentran registrados.

- $\quad$ Existe un underwriting bajo un sindicato internacional.

- La emisión es ofrecida simultáneamente a inversores de distintos países.

Asimismo, otras clasificaciones de bonos se basan en las características mencionadas anteriormente y en el tipo de emisor de estos instrumentos. Entre los tipos más conocidos de bonos, podemos resumir los siguientes en la Tabla 1.1: 
Tabla 1. 1

Tipos de Bonos

\begin{tabular}{|c|c|}
\hline Tipos de Bonos & Descripción \\
\hline \multicolumn{2}{|l|}{ Por tipo de emisor } \\
\hline Bono Corporativo & La obligación es emitida por una empresa o compañía. \\
\hline Bono Soberano & $\begin{array}{l}\text { Emitidos por el gobierno de un país, por lo que se consideran los más seguros, aunque } \\
\text { dependerá de qué país se esté evaluando para determinar si efectivamente el riesgo será bajo. }\end{array}$ \\
\hline Bonos Municipales & Emitidos por entidades gubernamentales que no son del gobierno central. \\
\hline \multicolumn{2}{|l|}{ Por tipo de amortización } \\
\hline Bono Bullet & Pagan periódicamente los intereses pero la amortización se realiza sólo al vencimiento. \\
\hline Bono con amortización hecha a medida & El cronograma de amortización se diseña de acuerdo a los flujos esperados del emisor. \\
\hline \multicolumn{2}{|l|}{ Por tipo de cupón } \\
\hline Bono Cupón Cero & $\begin{array}{l}\text { Este tipo de bono no paga intereses periódicos sino que solo se devuelve su valor nominal al } \\
\text { vencimiento }\end{array}$ \\
\hline Bonos Perpetuos & $\begin{array}{l}\text { Pagan una perpetuidad en forma de cupones de manera periódica y sin una fecha de } \\
\text { vencimiento }\end{array}$ \\
\hline Bonos Step-up & La tasa cupón de estos bonos aumenta conforme a un cronograma fijado. \\
\hline Bono de cupón diferido & $\begin{array}{l}\text { No existen pago de intereses por un período. Luego de terminado este período, se comienza } \\
\text { el pago contabilizando los intereses diferidos hasta ese momento. }\end{array}$ \\
\hline Bono de tasa variable o flotante & $\begin{array}{l}\text { Se realiza el pago de cupones aplicando una tasa referencial (ejemplo: Libor a } 3 \text { meses) más } \\
\text { un margen aplicable }\end{array}$ \\
\hline \multicolumn{2}{|l|}{ Con opciones } \\
\hline Bono con opción de Call & Permite al emisor retirar total o parcialmente de la emisión antes de la fecha de vencimiento. \\
\hline Bono con opción de Put & $\begin{array}{l}\text { Permite al bonista revenderle al emisor la emisión a un precio específico en fechas } \\
\text { determinadas. }\end{array}$ \\
\hline \multicolumn{2}{|l|}{ Por tipo de moneda } \\
\hline Bono denominado en Dólares & Los pagos son realizados en dólares americanos. \\
\hline Bono no denominado en Dólares & Los pagos son realizados en una moneda distinta a los dólares americanos. \\
\hline Bono de denominación dual & Los pagos de cupón se realizan en una moneda distinta a los pagos de principal. \\
\hline \multicolumn{2}{|l|}{ Otros tipos } \\
\hline Bono Convertible & El bono es convertible a un número específico de acciones comunes de la empresa emisora. \\
\hline Bono Estructurado & Existe un activo suby acente al bono que determina la rentabilidad de este. \\
\hline Bonos de arrendamiento financiero & $\begin{array}{l}\text { Emitidos por bancos, financieras y empresas de arrendamiento financiero para financiar } \\
\text { exclusivamente este tipo de arrendamiento. }\end{array}$ \\
\hline Bonos VAC & Se asegura una rentabilidad real al tenedor del bono al indexar el valor nominal a la inflación. \\
\hline Bonos de titulización & $\begin{array}{l}\text { Son aquellos bonos emitidos con el respaldo de un patrimonio titulizado autónomo de la } \\
\text { empresa que cedió sus activos para constituirlo. }\end{array}$ \\
\hline
\end{tabular}

Fuente: Fabozzi (2012), p. 4-6, 13-14; Fabián (2014), p. 12.

Debido a las diversas clasificaciones, el bono en estudio cae dentro de varios de los tipos mencionados anteriormente. Según la perspectiva de países, el bono de ATS es del mercado intercional al haberse emitido fuera de Perú, no estar registrado en la SEC y haber sido ofrecido a inversionistas a través del globo. Por otro lado, se trata de un bono corporativo, con amortización hecha a la medida, con opción de call y 
denominado en dólares. Más detalles sobre estas características, se produndizarán en el segundo capítulo.

\subsubsection{Los participantes en el mercado de capitales}

La relevancia del mercado de capitales radica en que es una fuente importante de financiamiento y canalización de recursos de los agentes económicos que cuentan con ahorros o riqueza extra (agentes superavitarios) y entre aquellos con necesidad de fondos (agentes deficitarios). El concepto de la asignación de recursos o capital toma alta relevancia en el mercado de capitales y puede explicar de manera simplificada cómo funciona el proceso de emisión de valores. La asignación de recursos entre agentes superavitarios y deficitarios puede ocurrir de tres formas (Ehrhardt y Brigham, 2011, p. 14):

1. Transferencias Directas: En este escenario, el emisor (sea una compañía, gobierno, etc.) vende sus valores directamente a un agente superavitario y recibe dinero a cambio. No existe un intermediario o banco de inversión de por medio en la transacción.

2. Transferencias Indirectas mediante un Banco de Inversión: En este caso, el emisor vende los valores a un Banco de Inversión y recibe el dinero de este último. Así, el Banco de Inversión actúa como underwriter de las emisiones de bonos o acciones. El rol de underwriter es comprar las primeras emisiones de un bono o acciones de una empresa y luego venderlas a los inversionistas en el mercado secundario. El bono emitido por ATS es un claro ejemplo de este tipo de transferencias.

3. Transferencias Indirectas a través de un Intermediario Financiero: El intermediario financiero obtiene fondos de los agentes superavitarios vendiendo sus propios valores y, con ese dinero, compra valores a las compañías o entidades gubernamentales. En esta forma de asignación de recursos es que se realiza la creación de nuevas formas de títulos y valores. Como ejemplo se tiene la Emisión de Bonos Titulizados Estructurados - TIANA cuyo emisor es Credicorp Capital Sociedad Titulizadora (Class y Asociados S.A. Clasificadora de Riesgo, 2015). 
Figura 1.1

Proceso de la asignación de capital en el mercado de capitales

Transferencias Directas
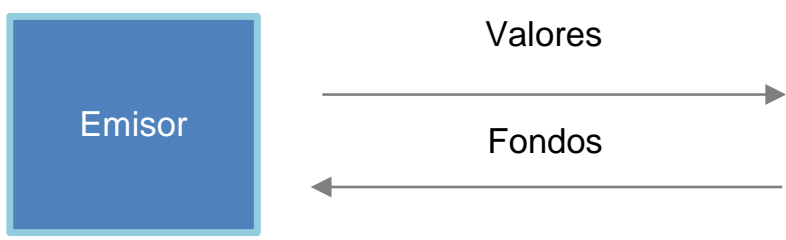

Agentes

Superavitarios

Transferencias Indirectas a través de un Banco de Inversión

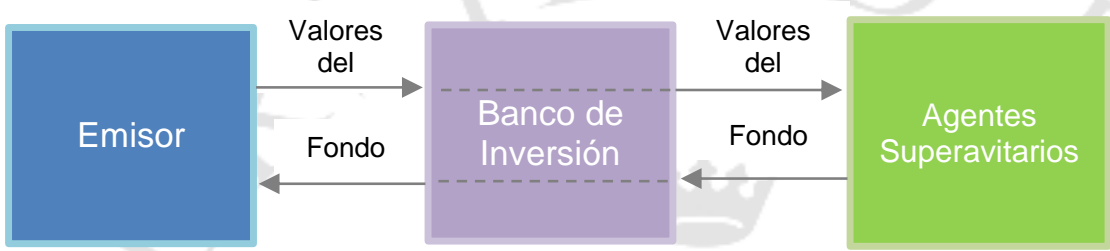

Transferencias Indirectas a través de un Intermediario Financiero

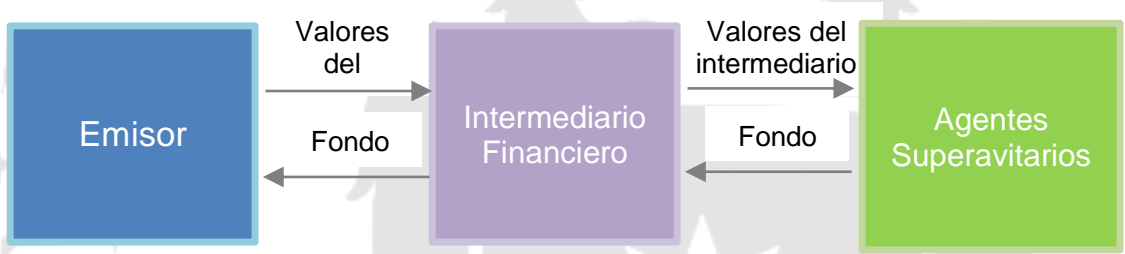

Fuente: Ehrhardt y Brigham (2011), p. 14

En el caso de las emisiones de bonos pueden existir muchos más agentes envueltos en el proceso de asignación. La cantidad e importancia de cada uno de estos agentes variará de acuerdo a la complejidad de la emisión y el negocio de la compañía. Más adelante, se profundizará sobre los participantes envueltos en la emisión del bono en estudio.

Lo más destacable a en este proceso es la importancia de atraer a los inversores adecuados que financien los propósitos de la empresa que emitirá deuda. Para ello, los emisores deben recurrir a las herramientas disponibles en el mercado con el fin de mandar las señales adecuadas respecto al valor a ser emitido y así apuntar a su público objetivo. 


\subsubsection{Categorías de Clasificación Crediticia}

Un concepto importante en tema de bonos es el riesgo crediticio. El riesgo crediticio puede clasificarse en tres tipo según Fabozzi (2012, p.28):

a) Riesgo de incumplimiento o default: Es aquel riesgo de que el emisor no cumpla con las obligaciones de pago de cupones y principal de un bono.

b) Riesgo de spread de crédito: Aún cuando no exista riesgo de incumplimiento, el inversionista debe considerar el riesgo de disminución en el precio del bono si es que las tasas del mercado suben. El rendimiento del bono (o el YTM) está conformado por dos componentes: (1) el rendimiento de un bono libre de riesgo de incumplimiento de características comparables (ejemplo: un bono del Tesoro de EUA) y (2) y la prima por encima del rendimiento del bono libre de riesgo necesaria para compensar el riesgo asociado con el bono, llamada spread de rendimiento (yield spread). Aquella parte del spread de rendimiento proveniente del riesgo de default se llama spread de crédito. Si el riesgo de default de un bono aumenta, afecta su YTM, lo que ocasiona que el precio del bono decline. Este riesgo de caída de precios ocasionada por el aumento del spread de crédito se llama riesgo de spread de crédito.

c) Riesgo de baja de categoría o downgrade: Una de las herramientas utilizadas por los inversionistas para tener una idea del riesgo crediticio de una emisión son las clasificaciones de riesgo otorgadas por las Agencias de Rating. En el mundo, las más reconocidas por su prestigio y metodología de clasificación son Moody’s Investors Service Inc. (Moody's), Standard \& Poor's Global Ratings (S\&P) y Fitch Ratings (Fitch). En el Perú, existen dos empresas clasificadoras de riesgo respaldadas por estas compañías internacionales que son Apoyo \& Asociados (con el respaldo de Fitch) y Equilibrium (con el respaldo de Moody's). Las otras empresas clasificadoras son Class \& Asociados S.A., Pacific Credit Rating y Microrate Latin América S.A.

Las clasificaciones crediticias son usadas como indicador del riesgo potencial de incumplimiento de un bono o un emisor. Es por ello que el rating crediticio otorgado por las clasificadoras de riesgo trata de simplificar la complejidad de la medición del riesgo crediticio del emisor mediante una nomenclatura sencilla.

En la Tabla 1.2, se pueden apreciar las clasificaciones usadas por Moody’s, S\&P y Fitch para el caso de los bonos. Los modificadores “+” y “-“ (en el caso de Fitch y 
S\&P) y los números "1", "2" y “3” en el caso de Moody's, pueden ser añadidos a una calificación para indicar una posición relativa dentro de las categorías de clasificación.

Debido a que el rating de un bono es un indicador del riesgo de default, el rating tiene una directa y medible influencia en el YTM de un bono (Erhardt y Brigham, 2011, p. 199), lo cual es importante cuando el bono se comercializa en el mercado secundario. Un bono con grado de inversión es considerado con un riesgo de default bajo por lo que será más atractivo para aquellos inversionistas con una alta o moderada aversión al riesgo. Por otro lado, los bonos con calificaciones por debajo del grado de inversión presentan un retorno inseguro por lo que pagan una rentabilidad mucho más alta debido al riesgo implícito, es por ello que se les llama "especulativos" o bonos basura. Esto está ligado al concepto de spread de rendimiento explicado líneas arribas, donde la prima de rendimiento es medida mediante la prima de riesgo país, la cual es el diferencial en el YTM de dos bonos de dos países distintos que tengan la misma moneda y el mismo plazo. Comúnmente se compara el riesgo país de un bono de un mercado emergente con el de los bonos del Tesoro de Estados Unidos. Por lo tanto, un país con un rating crediticio más alto, presentará una menor prima de riesgo país en los YTM de los bonos emitidos en dicho país y por tanto, un menor riesgo de spread de crédito y menor sensibilidad en su precio ante las variaciones de la tasas del mercado.

Los países emisores de deuda soberana, como es el caso del Perú, también reciben clasificaciones por estas agencias de rating. En el caso del Perú, su clasificación crediticia de deuda a largo plazo en moneda extranjera es de BBB+ según Fitch y S\&P y de A3 con perspectiva estable para Moody's. En el mercado internacional de bonos, se espera que el máximo rating crediticio que puede alcanzar una emisión sea equivalente al rating del país en donde la empresa realiza sus operaciones. 
Tabla 1.2

Clasificaciones de Riesgo Equivalentes por Agencias de Rating

\begin{tabular}{|c|c|c|c|}
\hline Moody's & S\&P & Fitch & Descripción breve \\
\hline Aaа & AAA & AAA & $\begin{array}{lcc}\text { De primera calidad, máxima } \\
\text { seguridad } \\
\text { obligaciones financieras }\end{array}$ \\
\hline Aa1 & $\mathrm{AA}+$ & $\mathrm{AA}+$ & \multirow{3}{*}{$\begin{array}{l}\text { Alta calidad crediticia, muy fuerte } \\
\text { capacidad para cumplir con } \\
\text { obligaciones financieras }\end{array}$} \\
\hline $\mathrm{Aa} 2$ & AA & AA & \\
\hline Aa3 & AA- & AA- & \\
\hline A1 & $A+$ & $A+$ & \multirow{3}{*}{$\begin{array}{l}\text { Alta calidad crediticia, fuerte } \\
\text { capacidad } \\
\text { obligaciones } \\
\text { financieras pero es } \\
\text { algo más susceptible a efectos } \\
\text { adversos } \\
\text { económicas }\end{array}$} \\
\hline $\mathrm{A} 2$ & A & A & \\
\hline A3 & A- & A- & \\
\hline Baa1 & $\mathrm{BBB}+$ & $\mathrm{BBB}+$ & \multirow{3}{*}{$\begin{array}{l}\text { Media calidad, capacidad adecuada } \\
\text { para cumplir con obligaciones } \\
\text { financieras pero condiciones o } \\
\text { cambios adversos podrían dirigir a } \\
\text { un detrimento en el cumplimiento } \\
\text { de obligaciones. }\end{array}$} \\
\hline Baa2 & $\mathrm{BBB}$ & $\mathrm{BBB}$ & \\
\hline Baa3 & BBB- & BBB- & \\
\hline$\overline{\mathrm{Ba}} 1$ & $\overline{\mathrm{BB}}+$ & $\overline{\mathrm{B}} \overline{\mathrm{B}}+$ & \multirow{3}{*}{ 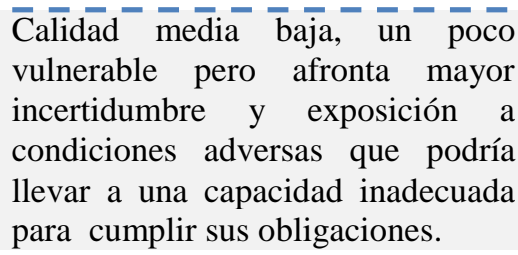 } \\
\hline $\mathrm{Ba} 2$ & $\mathrm{BB}$ & $\mathrm{BB}$ & \\
\hline $\mathrm{Ba} 3$ & BB- & BB- & \\
\hline B1 & \multirow[t]{3}{*}{ B } & $\mathrm{B}+$ & \multirow{3}{*}{$\begin{array}{l}\text { Calidad media baja, más vulnerable } \\
\text { a cambios y condiciones adversas } \\
\text { que muy probablemente afectará su } \\
\text { capacidad o voluntad de cumplir } \\
\text { sus obligaciones. }\end{array}$} \\
\hline B2 & & B & \\
\hline B3 & & B- & \\
\hline \multirow{3}{*}{$\mathrm{Caa}$} & $\mathrm{CCC}+$ & & \multirow{3}{*}{$\begin{array}{l}\text { Pobre calidad, actualmente } \\
\text { vulnerable y dependiente de } \\
\text { condiciones favorables para } \\
\text { cumplir sus obligaciones. }\end{array}$} \\
\hline & $\mathrm{CCC}$ & $\mathrm{CCC}$ & \\
\hline & $\mathrm{CCC}-$ & & \\
\hline $\mathrm{Ca}$ & $\mathrm{CC}$ & $\mathrm{CC}$ & $\begin{array}{l}\text { Probable impago de sus } \\
\text { obligaciones. }\end{array}$ \\
\hline \multirow[t]{4}{*}{$\mathrm{C}$} & $\mathrm{C}$ & $\mathrm{C}$ & \multirow{2}{*}{$\begin{array}{l}\text { El impago es inminente y las } \\
\text { expectativas de recuperación son } \\
\text { por debajo de la media o } \\
\text { deficientes. }\end{array}$} \\
\hline & $\mathrm{C} 1$ & & \\
\hline & & DDD & \multirow{2}{*}{$\begin{array}{l}\text { Entidades con impago de todas sus } \\
\text { obligaciones financieras }\end{array}$} \\
\hline & D & $\begin{array}{l}\mathrm{DD} \\
\mathrm{D}\end{array}$ & \\
\hline
\end{tabular}

Fuente: Fabozzi y Modigliani (2013), p. 457

Las empresas que se encuentran inmersas en un proceso de emisión de bonos, realizan un primer acercamiento a las agencias de rating para que se les evalúe y se emita un rating preliminar, el cual puede ser específico de la estructura del valor a ser emitido o sobre la empresa emisora (rating corporativo). Este rating preliminar les permite a las empresas conocer la fortaleza de su propuesta e ir adecuando la estructura 
para poder obtener una clasificación que sea más atractiva al inversionista objetivo. Posteriormente, el emisor solicitará a la clasificadora de riesgos un rating final cuando se encuentre en la última etapa de salida al mercado. Estos ratings son revisados de manera periódica por las agencias gracias al monitoreo realizado sobre la calidad crediticia del emisor. Una baja crediticia inesperada aumenta el spread de crédito y trae consigo la disminución del precio del bono. Este riesgo se denomina riesgo de baja crediticia o downgrade y está muy relacionado con el riesgo de spread de crédito.

Según Fabozzi y Modigliani (2013), los factores considerados por las Agencias de Rating para asignar o reconsiderar una clasificación pueden ser resumidos en tres áreas (p. 455):

1. La protección otorgada a los inversionistas mediante el uso de covenants que limitan el accionar de la gerencia.

2. Las garantías disponibles para los inversores en el caso de default.

3. La capacidad de pago de un emisor para cumplir con el servicio de deuda programado.

Además de estas tres grandes áreas, las Agencias de Rating evalúan tres riesgos importantes del emisor:

- El riesgo del negocio que está ligado al flujo de caja generado por el emisor, el cual es incierto en la vida de este. La capacidad de generar flujo de caja dependerá de las condiciones del mercado en donde opera la compañía, su competencia, su eficiencia, condiciones políticas y de regulación y la capacidad operativa de la gerencia, entre otros afines.

- El riesgo de gobierno corporativo es aquel ligado a que la gerencia corporativa actúe bajo su propio beneficio en detrimento del desempeño de la compañía y, por ejemplo, elija no revelar información financiera relevante a los accionistas y al mercado. Se consideran dos tipos de mecanismos para mitigar este riesgo: (i) alinear los intereses de la gerencia con los de los accionistas, por ejemplo, dando un porcentaje de las acciones a la gerencia, y (ii) sistemas de control corporativo dentro de la compañía para monitorear el desempeño y el proceso de toma de decisiones de la gerencia. 
- Finalmente, el último riesgo a evaluar es el riesgo financiero el cual requiere un análisis cualitativo de los estados financieros del emisor mediante ratios y otros factores que afecten las finanzas del emisor. Las medidas más frecuentes para analizar este riesgo son el apalancamiento, el flujo de caja, cobertura del servicio de deuda, activos netos y el capital de trabajo. Estos ratios se comparan luego con empresas dentro de la misma industria y similares a la empresa en análisis.

\subsubsection{Emisiones Públicas y Privadas}

Los títulos valores, ya sean bonos o acciones, pueden ser emitidos en ofertas públicas u ofertas privadas.

\section{Emisiones Públicas}

En la oferta pública se lanza una invitación al público en general mediante distintos medios de difusión y se intercambian los valores en un mercado público (i.e. New York Stock Exchange, Bolsa de Valores de Lima, etc.). Las corporaciones que eligen este tipo de emisiones se ven obligadas a hacer públicos los documentos de información financiera y estructura corporativa ya que pasan a ser reguladas por las entidades reguladoras pertinentes.

\section{$\underline{\text { Emisiones Privadas }}$}

La emisión u oferta privada, por el contrario, no emplea medios masivos de difusión y está dirigida principalmente a inversionistas institucionales ${ }^{2}$. Por lo general, en distintos países a lo largo del mundo, las ofertas privadas no están reguladas o lo están en menor medida que en el caso de las públicas, por lo que la liberación de información financiera de la empresa emisora es bien baja. Un ejemplo son las emisiones privadas reguladas por la U.S. Securities and Exchange Commission (SEC).

Una empresa domiciliada en nuestro país, puede elegir realizar la emisión privada en el Perú o en el extranjero.

\footnotetext{
2 En el Perú y según el Artículo $8^{\mathbf{o}}$, literal j) de la Ley de Mercado de Valores, los Inversionistas Institucionales son “(...).- Los bancos, financieras y compañías de seguros regidos por la Ley General de Instituciones Bancarias Financieras y de Seguros, los agentes de intermediación, las administradoras privadas de fondos de pensiones, las sociedades administradoras de fondos de inversión, las sociedades administradoras de fondos mutuos, así como las entidades del exterior que desarrollen actividades similares y las demás personas a las que CONASEV califique como tales (...)”.
} 
En el caso de realizarla en el Perú, no tendrá que regirse bajo la Ley del Mercado de Valores, salvo en aquellos casos en que la ley lo mencione expresamente (Ley del Mercado de Valores, 2002). La inscripción en algún ente regulador estará a facultad del emisor, salvo en algunos casos excepcionales que se mencionan a continuación:

- Los valores de colocación privada producto de un proceso de titulización deberán estar inscritos en la Bolsa de Valores de Lima.

- $\quad$ En el caso de que la oferta privada se ofrezca a Administradoras Privadas de Fondos de Pensión, esta deberá estar inscrita en el Registro de Instrumentos de Inversión y de Operaciones de Cobertura de Riesgo Extranjeros de la Superintendencia Adjunta de Administradoras Privadas de Fondos de Pensiones.

- Por otro lado, se podrán inscribir en la Bolsa de Valores de Lima, a requerimiento del emisor, o en una Sociedad Agencia de Bolsa, aquellos valores ofrecidos por colocación privada que no se encuentren registrados o listados en ninguna Comisión de Valores o Mercados Organizados, y que se oferten o no mediante la Regla 144A de SEC o disposición similar (Reglamento de Inscripción y Exclusión de Valores Mobiliarios en la Rueda De Bolsa, 2012).

En el caso de que un emisor domiciliado en el Perú elija que la colocación privada se realice en el extranjero, existen diversos mercados a los que se puede acoger para realizar la emisión de deuda. Mundialmente, es de gran utilización la colocación privada acogida bajo la regulación de la SEC de los Estados Unidos de América. Las ofertas privadas no están obligadas a ser registradas en la SEC bajo la Securities Act de 1933 y la mayoría de ellas están regidas por la Sección 4(2) o bajo la Regulación D³ de dicha ley y presentan ciertas restricciones para su reventa ${ }^{4}$.

\footnotetext{
3 “La regulación D fue adoptada por la SEC en 1982 con el propósito de facilitar las necesidades de formación de capital de las empresas pequeñas. Ella puede ser utilizada por emisores y no por controladores en emisiones secundarias. Dentro de esta regulación se encuentra la regla 506 la que permite a los emisores, que cumplen con todos los requisitos normativos aplicables, que sus ofertas se consideren privadas y por lo tanto queden cubiertas por la exención de la sección 4(2) de la 33' Act.". (Jara, 2011, p 107).

4 "La entidad que compra los valores acogidos bajo estas normas con la intención de revenderlas al público, son underwriters y por lo tanto, no pueden realizar esta reventa por al menos un año, si es que no realizan el registro de los valores. Además, las emisiones privadas sólo pueden ser vendidas a "inversores
} 
Los títulos valores que sean restringidos (restricted securities), se regirán bajo la Regla 144 (o de ser aplicable, bajo la Regulación S) que solo permite la reventa pública, si un número de condiciones son cumplidas y luego de un período determinado de tenencia de los valores. Si bien las colocaciones privadas no son registradas, las restricciones a las ventas en los distintos tipos de formato buscan proteger de alguna manera a los inversionistas.

A continuación, se enfocará la descripción de las ofertas privadas acogidas bajo la Regla 144A para entender la razón de la elección de este formato para el caso en estudio.

Una excepción a la regla 144, es la Regla144A que entró en vigencia en 1990. Para los emisores no procedentes de los Estados Unidos, el uso de las colocaciones privadas para ingresar al mercado estadounidense siempre ha sido una opción atractiva para así evitar los requerimientos de registro de la SEC. Sin embargo, como las colocaciones privadas son menos líquidas que las ofertas públicas debido a que presentan restricciones en la reventa, la venta de este tipo de emisiones podría generar precios para nada competitivos.

Lo que se introdujo con esta regla 144A es que las personas naturales o jurídicas que quieran vender títulos valores, podrán hacerlo sin registrarse y solo a Inversionistas Institucionales Calificados (QIB por sus siglas en inglés) ${ }^{5}$ de los Estados Unidos. Además, no tendrán la restricción de no poder realizar reventas inmediatas de tales valores. Con ambas medidas, se trata de favorecer a los emisores al hacer que el mercado secundario de este tipo de valores se vuelva más líquido y por tanto, los valores sean más atractivos para los inversionistas.

Esta Regla ha tenido tan buena acogida, que actualmente las emisiones privadas tienen a clasificarse de acuerdo a si son Regla 144A o no. Las emisiones que no están bajo la Regla 144A son conocidas como emisiones privadas tradicionales (Fabozzi y Modigliani, 2013, p. 119).

Ya que la Regla 144A es aplicable para ventas de emisiones a Inversionistas Institucionales dentro de los Estados Unidos, comúnmente esta se combina con una

acreditados" (inversores institucionales o individuos con suficiente patrimonio) o a un máximo de 35 "inversores no acreditados". (Jara, 2011, p 107).

${ }^{5}$ La definición de un QIB es una institución que es propietaria de la menos USD 100 millones en tipos de valores específicos o un dealer que posee al menos USD 10 millones (Deutsche Bank Depositary Receipt Services, What is the difference between Reg S and 144A, párr. 4). 
colocación no restringida dirigida fuera de Estados Unidos bajo la Regulación S. En este caso, el emisor acogido bajo esta regulación, puede ser de Estados Unidos o un emisor extranjero.

En la Tabla 1.3, se presentan las principales diferencias entre las distintas reglas de colocaciones privadas.

Tabla 1.3

Diferencias entre Colocaciones Privadas bajo normativa de la SEC

\begin{tabular}{|c|c|c|c|c|}
\hline Descripción & $\begin{array}{l}\text { Sección 4(2)/Reg. } \\
\text { D }\end{array}$ & Regulación S & $\begin{array}{l}\text { Regulación } \\
\text { 144A }\end{array}$ & 144A/Reg. S \\
\hline $\begin{array}{l}\text { Base de } \\
\text { inversionistas }\end{array}$ & $\begin{array}{l}\text { Mayormente de } \\
\text { Estados Unidos y } \\
\text { compañías de } \\
\text { seguros de vida } \\
\text { canadienses }\end{array}$ & $\begin{array}{l}\text { No } \\
\text { estadounidenses e } \\
\text { inversores } \\
\text { institucionales } \\
\text { estadounidenses } \\
\text { offshore }\end{array}$ & $\begin{array}{l}\text { Inversionistas } \\
\text { Institucionales } \\
\text { de EUA }\end{array}$ & $\begin{array}{l}\text { Inversionistas } \\
\text { Institucionales de } \\
\text { EUA, Asia, } \\
\text { Europa, } \\
\text { Latinoamérica }\end{array}$ \\
\hline $\begin{array}{l}\text { Numero de } \\
\text { Ratings } \\
\text { Requeridos }\end{array}$ & Mínimo 1 rating & $\begin{array}{l}1 \text { rating, algunos } \\
\text { compradores } \\
\text { prefieren } 2\end{array}$ & 2 ratings & 2 ratings \\
\hline $\begin{array}{l}\text { Requerimiento } \\
\text { de documentos }\end{array}$ & $\begin{array}{l}\text { - Private } \\
\text { Placement } \\
\text { Memorandum } \\
\text { - Note Purchase } \\
\text { Agreement }\end{array}$ & $\begin{array}{l}\text { - Offering } \\
\text { Memorandum } \\
\text { - Bond Indenture }\end{array}$ & $\begin{array}{l}\text { - Offering } \\
\text { Memorandum } \\
\text { con opiniones } \\
\text { de asesores } \\
\text { legales. } \\
\text { - Bond } \\
\text { Indenture }\end{array}$ & $\begin{array}{l}\text { - Offering } \\
\text { Memorandu, } \\
\text { con opiniones } \\
\text { legales de } \\
\text { asesores } \\
\text { legales. } \\
\text { - Bond } \\
\text { Indenture. } \\
\text { - Purchase } \\
\text { Agreement }\end{array}$ \\
\hline $\begin{array}{l}\text { Nivel de } \\
\text { información }\end{array}$ & $\begin{array}{l}\text { Requisitos } \\
\text { flexibles de } \\
\text { divulgación }\end{array}$ & $\begin{array}{lr}\text { Requisitos } & \\
\text { limitados } & \text { de } \\
\text { divulgación } & \text { a } \\
\text { comparación } & \text { de } \\
\text { 144A/Reg } S & \end{array}$ & $\begin{array}{lr}\text { Nivel alto } & \text { de } \\
\text { divulgación } & y \\
\text { necesario } & \\
\text { realizar } & \text { due } \\
\text { diligence } & \end{array}$ & $\begin{array}{l}\text { Nivel alto de } \\
\text { divulgación y } \\
\text { necesario realizar } \\
\text { due diligence }\end{array}$ \\
\hline $\begin{array}{l}\text { Liquidez } \\
\text { precio }\end{array}$ & $\begin{array}{l}\text { Alta liquidez, } \\
\text { precios } \\
\text { competitivos }\end{array}$ & $\begin{array}{l}\text { Menos líquido } \\
\text { que 144A/Reg S, } \\
\text { mayores precios }\end{array}$ & $\begin{array}{l}\text { Mediana } \\
\text { liquidez }\end{array}$ & Mediana liquidez \\
\hline $\begin{array}{l}\text { Período de } \\
\text { restricción }\end{array}$ & & 40 días & 6 meses -1 año & \\
\hline
\end{tabular}

Es así, que la Regla 144A/Reg. S brinda los siguientes beneficios (Serfilippi, C., 1 de febrero de 2012, Bloomberg Law Reports, p. 1):

- Permite a los emisores no provenientes de Estados Unidos evitar los requerimientos de registro del Securities Act. Aunque la cantidad de revelación 
de información es parecida a la de una oferta pública, como las normas no son tan severas, el emisor tiene la potestad de elegir qué información revelar. Finalmente, no se está sujeto a obligaciones periódicas de reporte.

- Le otorga la posibilidad al emisor de controlar y mejorar los tiempos para salir a oferta. El "Offering Memorandum" bajo la 144A/Reg. S no tiene que ser revisado por la SEC por lo que puede cerrarse una versión final mucho más rápido.

- Los costos de estructuración de la emisión son generalmente más bajos que una oferta pública (no se tiene que inscribir en la SEC).

- Por otro lado, al tener un descuento por liquidez menor que las colocaciones privadas tradicionales, también presenta un costo de capital más bajo que estas.

\subsubsection{Oferta privada Regla 144A/Reg S}

A continuación, se describirá el proceso para llevar a cabo una emisión privada bajo esta modalidad. Se describen aquellos pasos que generalmente se realizan para diferentes tipo de emisores.

Primero, el emisor tendrá que determinar si realizará la venta directamente a los inversores o no y esto dependerá de si el emisor cuenta previamente con compradores potenciales. En el caso de que no se decida por la opción anterior, deberá elegir la institución que le ayudará a estructurar la oferta. Comúnmente el estructurador de la oferta, también ejerce el papel como undewriter o de Comprador Inicial ("Initial Purchaser") para garantizar la compra del bono al emisor (en caso no se ofrezca a comprar la emisión, el estructurador usará el método de mejores esfuerzos para vender la emisión a las inversionistas). Como se explicó anteriormente, la Regla 144A/Reg S tiene un período de restricción para vender, por lo que el emisor se acoge a las excepciones estipuladas en las Secciones 4(2) o Regulación D para poder vender los valores a los compradores iniciales. Inmediatamente, los compradores iniciales venden los bonos a los Inversionistas Institucionales. 
El segundo paso es escoger a los asesores legales. Los asesores legales del emisor, aparte de ayudar con el armado de los documentos de la emisión, son los que se encargarán de posteriormente emitir una opinión legal, requerida por los Compradores Iniciales para hacer la oferta más atractiva y segura a los futuros inversionistas. Por ello, es importante escoger a un estudio de abogados especializado en emisiones privadas y que se encuentre familiarizado con el emisor para que se revele la información adecuada a los Inversionistas.

Si bien ya se debería ir teniendo una idea desde el principio, el tercer paso es escoger que tipo de valor será ofrecido. La idea inicial de qué valor ofrecer será finiquitada con la asesoría del estructurador, analizando el estado del negocio del emisor y determinando el público inversionista al que se deberá dirigir el valor para poder recaudar los fondos requeridos por la empresa. Como se mencionó antes, hay distintos tipos de bonos, con características distintas. Esta etapa se apoya generalmente en el armado de un modelo financiero que ayudará a estimar el monto de la emisión considerando proyecciones viables para el emisor de acuerdo al tipo de valor que escoja emitir. Una vez elegido el tipo de bono que será emitido, con las proyecciones obtenidas en el modelo financiero, se realiza el primer acercamiento a las Agencias de Rating para que emitan un rating preliminar y así evaluar el potencial del valor. Con el rating preliminar, la empresa recibe feedback respecto a la fortaleza de la estructura del bono y como puede ser mejorada para atraer a los potenciales inversionistas.

El cuarto paso es preparar y recolectar la información necesaria para el due diligence que será solicitado tanto por los Compradores Iniciales como por los compradores posteriores. El objetivo del due diligence es verificar toda la información y documentación del emisor, sea esta financiera o legal, para asegurar que las declaraciones del emisor respecto al estado de su negocio son válidas.

Lo analizado y acordado en los pasos previos, se lleva en concreto en la documentación de la emisión. El documento que se debe armar para poder ir sondeando a los inversionistas es el Offering Memorandum. Una vez armado el resto de documentos, se actualiza el Offering Memorandum. En la sección posterior, se ahondará en mayor detalle respecto a la documentación para este tipo de ofertas. En paralelo, se presentan las últimas proyecciones (en base a la estructura cerrada de la emisión) a las Agencias de Rating para que emitan su clasificación final. Con esta clasificación, se inicia la promoción de los bonos. 
El quinto paso es realizar la promoción de la emisión a ofrecerse. Esto generalmente se hace mediante un proceso llamado "Road Show" en donde el emisor y el estructurador realizan presentaciones a inversionistas seleccionados para mostrarles las principales características del bono, realizar un resumen de la compañía y su negocio y presentar las principales fortalezas del esquema de la estructuración de la emisión. Este paso es uno de los más importantes, ya que la adecuada presentación de las fortalezas de la estructura de la emisión son las que asegurarán la compra de este por los inversores potenciales.

Finalmente, el sexto paso es que, una vez realizado el sondeo del mercado gracias al Road Show, el Estructurador procederá a realizar un "pricing" preliminar del bono para estimar cual será la demanda de este y por tanto el monto a poder emitirse. También se cerrará la versión final de los documentos de la oferta (los cuales se detallan en la sección inferior). En el "transaction day" del bono, se aceptan las ofertas de los inversionistas y se determina el precio y la tasa cupón final. Comúnmente, como explica la SEC (2003, Sección Settling Securities Transactions, T+3, párr. 3) la emisión o el "settlement day" de los valores se realiza 3 días después de recibidas las ofertas $(\mathrm{T}+3)$ y se recibe el dinero de los inversionistas que ofertaron por los valores. El pricing puede realizarse de dos maneras: mediante una transacción negociada o un proceso de subasta (Fabozzi, 2012, p, 71). En una transacción negociada, el underwriter ofrece comprar los bonos al emisor a una cierta tasa cupón y vencimiento, oferta que el emisor deberá aceptar o rechazar en un día como máximo; de ser aceptada, el undewriter comprará la emisión. Típicamente en este tipo de subasta, la decisión de compra del undewriter se toma si es que previamente ha realizado una pre-venta a sus clientes que son inversionistas institucionales, los cuales ofrecen comprar una parte de la emisión a una tasa cupón determinada ${ }^{6}$. Así, el underwriter minimiza el riesgo potencial de pérdida de capital generado por las diferencias entre el precio de compra al emisor y el precio de reventa a los inversionistas. Mientras tanto, en el proceso de subasta, más conocido como oferta competitiva, el emisor anuncia los términos de la emisión y los inversionistas interesados realizan ofertas para comprarla. Las ofertas con la tasa cupón más baja son los que ganan subasta.

\footnotetext{
${ }^{6}$ La tasa cupón se determina en base a los spreads de crédito generados por el riesgo país (sobre la base, comúnmente para este tipo de formatos, de un bono del Tesoro de EUA con vencimiento similar al bono que se está vendiendo, mediante la utilización de la curva cupón cero) y el riesgo crediticio inherente al emisor.
} 
Como se explicó en las secciones anteriores, debido a que la oferta es privada, no es necesario pasar ningún registro bajo la SEC. Lo que es necesario es registrar o "listar" el valor en una Bolsa para poder facilitar su comercialización mediante el uso de un sistema de intercambio confiable. La inscripción del listado a una Bolsa tendrá que ser determinada por el emisor dependiendo del mercado al que quiera dirigirse y de los requisitos que le exija cada plaza (existen diversas bolsas como la Bolsa de Lima, la Bolsa de Nueva York, Luxemburgo, Nasdaq, etc.). Para poder ser miembro de esas bolsas y poder realizar las operaciones debidas, se debe cumplir una serie de requerimientos definidos por cada bolsa y pagar una comisión ("listing fee"). La revisión de los requerimientos se realiza periódicamente por lo que un emisor listado en una bolsa puede ser retirado de ella de no cumplir los requisitos.

\section{$\underline{\text { Principales Documentos }}$}

Los principales documentos para llevar a cabo una oferta de este tipo son el Offering Memorandum y el Contrato de Compra Venta (Purchase Agreement):

- El Offering Memorandum incluye información básica del emisor y los términos del valor a ser ofrecido, entre otros. Si bien no se regula la información que debe contener este documento, comúnmente guarda un parecido a la información expuesta en una oferta registrada, sobre todo por temas de mercadeo y transparencia con los accionistas. Además, al tratarse de una combinación de la Regla 144A y Regulation S este documento debe contener expresa información sobre las limitaciones en las ventas y las restricciones en la transferencia. Una vez que este documento está preparado, no está sujeto a revisión de la SEC y cualquier cambio que se realice posteriormente es para detallar cambios en las condiciones financieras, de negocio u otros del emisor.

- En el caso de que el valor a ofrecerse sea de deuda, también se debe elaborar el Indenture que es aquel documento que regula el funcionamiento del pago de la deuda así como los términos y obligaciones respectivas del emisor y del fideicomisiario. El fideicomisario es el encargado de defender los intereses de los tenedores de los bonos, bajo los términos definidos en el Indenture y bajo los requerimientos del Trust Indenture Act de 1939. 
- El Contrato de Compra Venta regula el trato entre el emisor y los compradores iniciales en cuanto a precio, términos y otras condiciones relacionadas a la oferta, venta y compra de los valores. Comúnmente, su elaboración es liderada por el asesor legal de los compradores iniciales y es muy similar al Underwriting Agreement de las ofertas públicas, ya que el comprador inicial cumple un rol parecido a los underwriters de las ofertas públicas.

- Por último, será necesario que el auditor independiente del emisor, emita una Comfort Letter dirigida a los compradores iniciales en la que certifique su conformidad con la información financiera incluida en los documentos de la oferta. Asimismo, se necesitará una opinión legal del asesor legal del emisor en relación a los documentos de la oferta.

Existen muchos documentos más ligados a este tipo de oferta, como otros documentos de garantía y demás documentos que dependen del tipo de emisor, pero los mencionados arriba son los que comúnmente se encontrarán en las colocaciones de 144A/Reg S.

\subsection{SOBRE EL PROYECTO DE INVERSIÓN}

\subsubsection{Descripción del proyecto de inversión}

El 22 de julio de 2010, luego de un proceso de adjudicación organizado por Proinversión para fortalecer el tramo sur del Sistema Eléctrico Interconectado Nacional, se suscribió el contrato de concesión entre la sociedad concesionaria Abengoa Transmisión Sur S.A. (ATS) y el Ministerio de Energía y Minas (MINEM), en representación del Estado Peruano ${ }^{7}$. El objeto del contrato es el diseño, financiamiento, construcción, operación y mantenimiento de la Línea de Transmisión Chilca-MarconaMontalvo en $550 \mathrm{kV}$. Este contrato es del tipo Build, Own, Operate and Transfer (BOOT) puesto que obliga a la sociedad concesionaria a mantener la propiedad de la

\footnotetext{
7 Dicha concesión se da en el marco de lo dispuesto por la Ley $\mathrm{N}^{\circ}$ 28832, Ley para Asegurar el Desarrollo Eficiente de la Generación Eléctrica, el Reglamento de Transmisión (Decreto Supremo $\mathrm{N}^{\circ}$ 027-2007-EM), La Ley de Concesiones Eléctricas (Decreto Ley $\mathrm{N}^{\circ}$ 25844), el Decreto Legislativo $\mathrm{N}^{\circ}$ 1012 que aprueba la Ley Marco de Asociaciones Público - Privadas para la generación de empleo productivo y la agilización de los procesos de promoción de la inversión privada, su Reglamento (Decreto Supremo No 146-2008-EF) y demás Leyes aplicables.
} 
línea de transmisión hasta que termine el plazo de la concesión, luego de lo cual, se transferirá la propiedad al concedente o a la entidad que este indique.

La línea de transmisión recorre gran parte de la costa sur del país: comienza en Chilca, cruza todo Ica y Arequipa y termina en la mitad de Moquegua, abarcando un aproximado de 900 kilómetros en total. El proyecto comprendió la construcción de lo siguiente:

- Una línea de transmisión de 500 kilovoltios $(\mathrm{kV})$ de 872 kilómetros, 1766 torres metálicas entre las Subestaciones Chilca, Marcona, Ocoña y Montalvo. Además, incluye dos enlaces de 220kV en las Subestaciones (SE) existentes Marcona y Moquegua de $27 \mathrm{~km}$ y $5 \mathrm{~km}$ respectivamente.

- Tres nuevas subestaciones: SE Poroma, SE Ocoña y SE Montalvo.

- Tres ampliaciones de las subestaciones existentes: SE Chilca, SE Marcona Existente y SE Moquegua.

\section{Figura 1.2}

Extensión de la Línea Chilca-Marcona-Montalvo

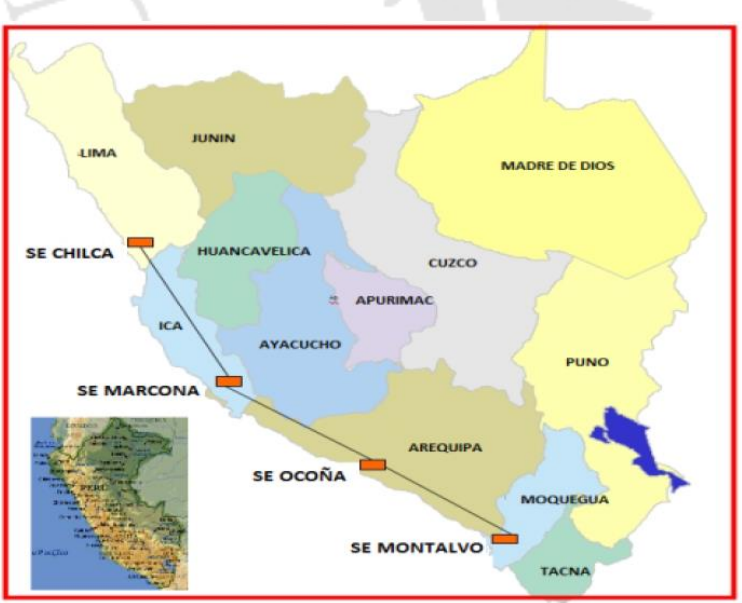

Fuente: Organismo Supervisor de la Inversión en Energía y Minería [Osinergmin] (2014). Centro Documental.

Este tipo de concesiones tiene dos etapas principales. La primera es la etapa constructiva o pre-operativa, donde se realiza el diseño e ingeniería, se obtienen los permisos legales necesarios (como licencias de construcción y presentación y 
aprobación del Estudio de Impacto Ambiental, obtención de las servidumbres necesarias, etc.) así como las tareas de procura y actividades de construcción y obras civiles. Luego de alcanzada esta etapa, que tiene un plazo definido por el contrato de concesión, se realiza un procedimiento estipulado por dicho contrato y las normas correspondientes, con el cual se declara la Puesta en Operación Comercial (POC) y se inicia el plazo de la concesión. Dicho plazo es por 30 años desde la operación comercial de la línea eléctrica. En el caso de ATS, la línea se puso en operación comercial el 17 de enero de 2014 por lo que el plazo concluirá el 17 de enero de 2034.

Esta línea de transmisión eléctrica por Resolución Ministerial No 024-2010MEM/DM, del Ministerio de Energía y Minas publicada el 17 de enero de 2010, forma parte del Sistema Garantizado de Transmisión, lo que le da otorga fortaleza legal y económica como se explicará en la siguiente sección.

\subsubsection{Composición del Sector Eléctrico Peruano}

Para entender el marco regulatorio de una compañía de transmisión, es necesario conocer la composición del sector eléctrico peruano. El mercado eléctrico peruano experimentó varias reformas en su estructura después de la década de los noventa para lograr mejorar la eficiencia del sector que dejaba mucho que desear antes de esa época. Es así que, mediante la participación de la inversión privada, la apertura del mercado a la competencia y la separación de la cadena productiva, se creó un mercado eléctrico compuesto por organismos reguladores, normativos y promotores, tres subsistemas (generación, transmisión y distribución) y los clientes o consumidores finales (libres o regulados). 
Figura 1.3

Composición del Sector Eléctrico Peruano

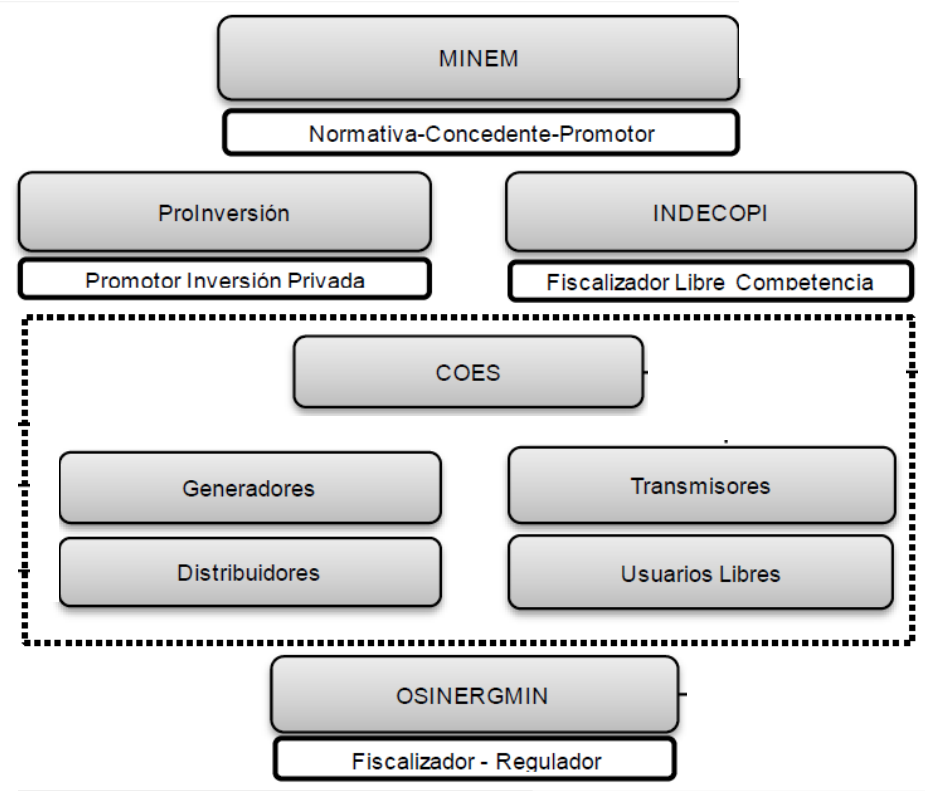

Fuente: Pacific Credit Rating. (2014). Informe Sectorial Perú: Sector Eléctrico. p. 4

Como se aprecia en la Figura 1.3, a la cabeza del Sector Eléctrico Peruano, se encuentra el MINEM. El MINEM vela por la promoción del desarrollo sostenible y competitivo para asegurar el suministro de energía de forma eficaz y eficiente, y por el cumplimiento del marco legal. Además, dirige las políticas energéticas de mediano y largo plazo orientadas al uso óptimo de los recursos sin perjudicar al medio ambiente. Por lo tanto, promueve la inversión privada en el sector para lograr estos objetivos.

Por otro lado, existen dos entidades de estado que apoyan al sector de energía. La agencia que dirige los procesos de promoción de la inversión privada en el Perú es Proinversión, por lo tanto, también tiene un papel importante en el sector al convocar las licitaciones de concesiones del sector eléctrico, liderado por el MINEM. El INDECOPI, por la función general que tiene en todos los sectores de la economía, es la entidad que actúa como fiscalizador de la libre competencia.

Otra entidad del Estado que tiene el papel de fiscalizador y/o regulador en el sector eléctrico es Organismo Supervisor de la Inversión en Energía y Minería (OSINERGMIN), el cual fiscaliza, supervisa y regula las actividades realizadas por el sector energía, mediante la regulación de las tarifas y la fijación los distintos precios regulados del servicio eléctrico. 
Los tres subsistemas que conforman el sector son los subsectores de generación, transmisión y distribución eléctrica (Pacific Credit Rating, 2014, p. 4):

- Generadores: Son aquellas empresas que se encargan de producir y planificar la capacidad de abastecimiento de la energía. En el Perú, actualmente existen dos formas predominantes de producir energía: mediante la producción hidráulica y la generación a base de combustible como diésel, petróleo o gas natural (las denominadas centrales termoeléctricas).

- Transmisores: Este sistema es el que permite la transferencia de energía desde las generadoras hacia los distribuidores, en líneas en niveles de alta y mediana tensión y así permitir las interconexiones. Presenta economías de alcance en el diseño de sus instalaciones por lo que tiene características de monopolio natural, razón por la cual está sujeta a regulación. Las distintas líneas de transmisión y sus interconexiones constituyen el Sistema Eléctrico Interconectado Nacional (“SEIN"), existente desde el año 2000, el cual absatece a una gran parte de la población. Un sistema de transmisión con mayor capacidad y eficiencia es necesario para poder satisfacer la mayor demanda de electricidad y oferta de generación, de forma tal que se podrán evitar congestiones, y brindar eficiencia, confiabilidad y seguridad a la operación del sistema.

- Distribuidores: Son aquellas compañías que reciben energía de las generadoras o transmisoras y las llevan hacia el usuario final. Sus líneas operan a un menor voltaje (media y baja tensión) que las líneas de transmisión. Al igual que la actividad de transmisión, la distribución está caracterizada por ser un monopolio natural debido a que presenta economías de alcance y de densidad. Cuando la energía eléctrica se transmite del generador al distribuidor, esta se reparte entre dos tipos de clientes, i) regulados, los cuales se caracterizan por una demanda máxima menor a $1 \mathrm{MW}$ por suministro, y ii) libres, cuya demanda se encuentra por encima de $1 \mathrm{MW}$, por lo que pueden optar libremente si por ser clientes regulados o libre (para estos últimos, los precios de carga y energía y otras condiciones de suministro de electricidad se negocian libremente). El sector eléctrico está compuesto casi en su totalidad por usuarios regulados. 
Finalmente, el Comité de Operación Económica del Sistema (COES-SINAC), una entidad privada con personería de Derecho Público y sin fines de lucro, es el organismo técnico encargado de coordinar la operación de corto, mediano y largo plazo del SEIN al mínimo costo, preservando la seguridad del sistema, el mejor uso eficiente de los recursos energéticos, así como planificar el desarrollo de la transmisión del SEIN y administrar el Mercado de Corto Plazo ${ }^{8}$. Está conformado por los titulares de las compañías de generación, transmisión y distribución, los cuales deben acatar las decisiones del COES de manera obligatoria.

\subsubsection{Funcionamiento del Sistema Garantizado de Transmisión}

El SEIN está integrado por instalaciones del Sistema Garantizado de Transmisión (SGT), del Sistema Complementario de Transmisión (SCT), del Sistema Principal de Transmisión (SPT) y del Sistema Secundario de Transmisión (SST). La Figura 1.4 contiene una breve descripción de los 4 tipos de sistemas.

Figura 1.4

Tipos de Sistemas de Transmisión

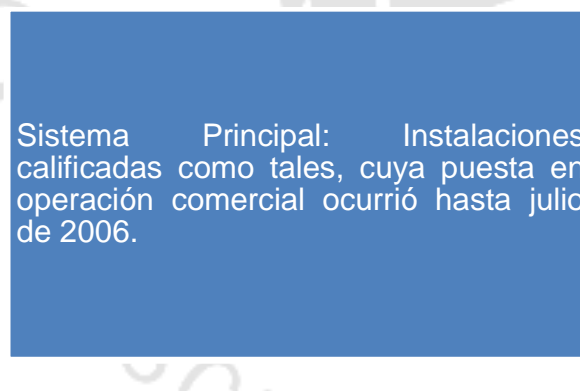

Sistema Secundario: Instalaciones

que permiten a los generadores

conectarse al sistema principal y al

distribuidor o consumidor obtener

electricidad del sistema. Se tratan

de instalaciones cuya puesta en

operación comercial ocurrió hasta julio de 2006.
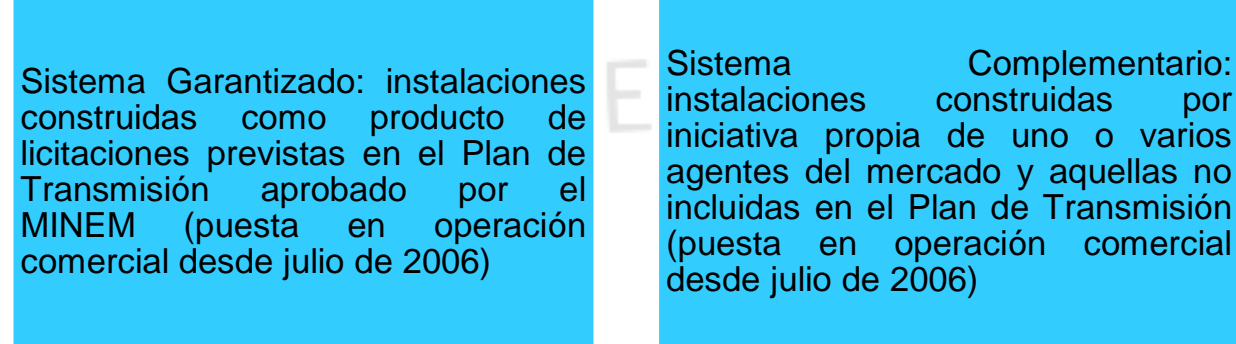

Fuente: Ley para asegurar el desarrollo eficiente de la generación eléctrica. Ley 28832 (2006). Artículo 20.- Sistema de Transmisión del SEIN.

\footnotetext{
${ }^{8}$ Página Web de COES-SINAC. http://portal.coes.org.pe/organizacion/webPages/qsomos.aspx
} 
Las instalaciones del SGT y del SCT son aquellas cuya puesta en operación comercial se produce con posterioridad al 10 de julio de 2006, fecha de promulgación de la Ley $\mathrm{N}^{\circ}$ 28832, Ley para Asegurar el Desarrollo Eficiente de la Generación Eléctrica.

Anterior a este tipo de instalaciones, el marco regulatorio de la transmisión definido originalmente por la Ley de Concesiones Eléctricas y su Reglamento utilizaba el concepto de "Sistema Económico Adaptado" introduciendo el riesgo de que el Valor Nuevo de Reemplazo (VNR) ${ }^{9}$ de la inversión difiera sustancialmente del valor real. Este VNR era usado para determinar el importe de contribución que debían recibir las transmisoras de los usuarios. El VNR estaba sometido a revisión del regulador cada cuatro años y se dejaba abierta la posibilidad de que la tasa de actualización del VNR sea modificada mediante decreto por el gobierno de turno por lo que resultó un instrumento obsoleto para atraer inversiones al generar tal nivel de incertidumbre que hacía poco viable la inversión en redes transmisión de uso público.

La modificación introducida mediante la Ley $\mathrm{N}^{\circ}$ 28832, Ley para Asegurar el Desarrollo Eficiente de la Generación Eléctrica, y las normas regulatorias posteriores constituyen un cambio sustancial en materia de remuneración de la inversión en transmisión, ya que se estableció que la Base Tarifaria a ser reconocida sería equivalente al producto de la propuesta ganadora en cada proceso de licitación para otorgar una concesión para instalaciones del SGT. De esta manera, la remuneración a recibir por parte del concesionario se define a través de la competencia de mercado entre los postores que participan del concurso público y no a través de un VNR fijado por OSINERGMIN considerando un Sistema Económicamente Adaptado que podría no reflejar necesariamente los costos efectivamente incurridos. Adicionalmente, se evita que la misma sea objeto de revisión por parte del regulador reduciendo la incertidumbre sobre los ingresos.

Es necesario mencionar el rol de OSINERGMIN como el órgano regulador que establece anualmente la Base Tarifaria aplicable al concesionario; mientras que, el Comité de Operación Económica del Sistema (COES) es la entidad que notifica a cada

\footnotetext{
${ }^{9}$ El Valor Nuevo de Reemplazo representa el costo de renovar las obras y bienes físicos destinados a prestar el mismo servicio con la tecnología y precios vigentes. Para su fijación, se toma en consideración la Guía de Elaboración del Valor Nuevo de Reemplazo de las Instalaciones de Distribución Eléctrica, aprobada por OSINERGMIN, o la que la sustituya (OSINERGMIN, Resolución de la Comisión de Tarifas Eléctricas No. 017-97 P/CTE, 1997).
} 
generador la liquidación mensual que le corresponde pagar a las empresas de transmisión. Posteriormente, los generadores trasladan el monto a sus usuarios y son los responsables de recaudar el dinero y pagar a las empresas de transmisión.

De esta forma, la regulación del SGT tiene como fundamentos (i) garantizar anualmente la remuneración de las instalaciones del SGT, (ii) lograr estabilidad y predictibilidad respecto de los ingresos de los concesionarios de transmisión y (iii) establecer las obligaciones de pago del sistema para pagar lo que corresponde a todos los participantes del SGT.

\subsubsection{La modalidad de Project Finance}

El concepto de Project Finance no es de mucha divulgación en Perú, pero su aplicación viene siendo usada desde los años 70 tanto por países desarrollados como economías emergentes. De manera simplificada, el Project Finance es una modalidad de financiamiento para proyectos de infraestructura de largo plazo cuyo repago de financiamiento es en base a la generación de flujos de caja futuros del proyecto y donde se pueden considerar los activos del mismo como garantía del financiamiento sin la necesidad de recurso pleno a los promotores o socios. Esta modalidad generalmente presenta un alto apalancamiento ya que los montos de inversión requeridos para desarrollar estos proyectos son tan altos que sobrepasan los recursos propios de los accionistas para llevarlos a cabo.

Las principales características del Project Finance consisten en:

- La creación de una sociedad de propósito especial (SPE o SPV por sus siglas en inglés) para desarrollar el proyecto de inversión, aislando de esta manera el proyecto del balance del Promotor. Para esto, se constituye una razón social aparte bajo el proceso común de constitución de empresas.

- Existe una empresa Promotora (Sponsor) que se encarga de gestionar el proyecto. Son las que aportan inicialmente la mayor cantidad de capital a la SPV.

- $\quad$ Los flujos del proyecto deben ser estables y predecibles. 
- La seguridad del proyecto se basa en la fortaleza del contrato de concesión, de construcción, permisos, licencias y derechos de explotación que tenga la SPV.

- Los prestamistas tienen limitada capacidad de reclamo al Estado o al Promotor en caso de default, ya que la SPV presenta un alto apalancamiento (ratios de endeudamiento entre 65\%-90\%).

- Se realiza un minucioso análisis de riesgo para luego trasladarlo a otras partes envueltas en el proyecto (Concedente, Constructor, Aseguradora, Usuario, etc.).

La Figura 1.5 explica la estructura del Project Finance. Como se puede apreciar, hay varios participantes detrás de este tipo de estructura. Cada uno de estos participantes se involucra en el Project Finance a través de un contrato que regula su función en el proceso de financiamiento, de esta manera transfiriendo los diversos riesgos de la SPV a la parte que mejor lo puede administrar.

Entre los contratos involucrados en la estructura de Project Finance tenemos los siguientes:

- Contrato de Concesión: Este contrato es para aquellos proyectos donde el Estado, sea el Gobierno Central, Regional o Municipal, otorga los derechos de construcción y explotación, por un tiempo determinado, a una empresa para proveer de servicios al sector público. En algunos proyectos, debido a la magnitud de la inversión necesaria para llevarlos a cabo, el Estado cofinancia una parte de la inversión, cuyo tratamiento también se regula en el Contrato de Concesión.

- Contrato de Construcción: También conocido como Contrato EPC (Engineering, Procurement, Construction): Con este contrato se determinan las condiciones mediante las cuales el constructor debe diseñar, construir y realizar la procura del proyecto.

- Contrato de Operación y Mantenimiento: Es el contrato mediante el cual un Operador se encargará de la explotación del proyecto una vez finalizada la etapa constructiva. 
- Contrato Off-Take: Son aquellos contratos de compra-venta en firme para asegurar la compra/venta de la producción futura de un proyecto. Generalmente se celebran estos contratos en la etapa de construcción, así se asegura un comprador y facilita la financiación del proyecto.

- Contratos de Garantías Gubernamentales: Las garantías gubernamentales se tratan de mejoradores que permitan reducir el riesgo del proyecto. Entre estas garantías se encuentran los incentivo tributarios, cartas fianzas, garantías de ingreso mínimo, garantías de riesgo de crédito parcial, entre otras.

- $\quad$ Contrato de Financiamiento: Es el contrato que se suscribe con los Acreedores Financieros para la financiación del proyecto. Tanto en el caso de la banca como el mercado de capitales, siempre existirá un contrato de financiamiento que regulará las condiciones precedentes para el desembolso del financiamiento, las obligaciones financieras del concesionario, la forma de pago y las garantías que darán soporte a la estructura.

- Contrato de Accionistas: En este tipo de estructura es común que el Promotor o Sponsor busque un socio para compartir el riesgo del proyecto y no tener que aportar todo el capital necesario. Mediante un contrato de accionistas se regula la venta de las acciones de la SPV y el papel que cada socio tendrá en el desarrollo del proyecto, ya sea mediante apoyo financiero o técnico.

- Otros Contratos: Existen otros participantes envueltos en el Project Finance como los asesores legales, asesores técnicos, asesores ambientales, ingenieros independientes, brokers y aseguradoras. 
Figura 1.5

Estructura y Participantes dentro del Project Finance

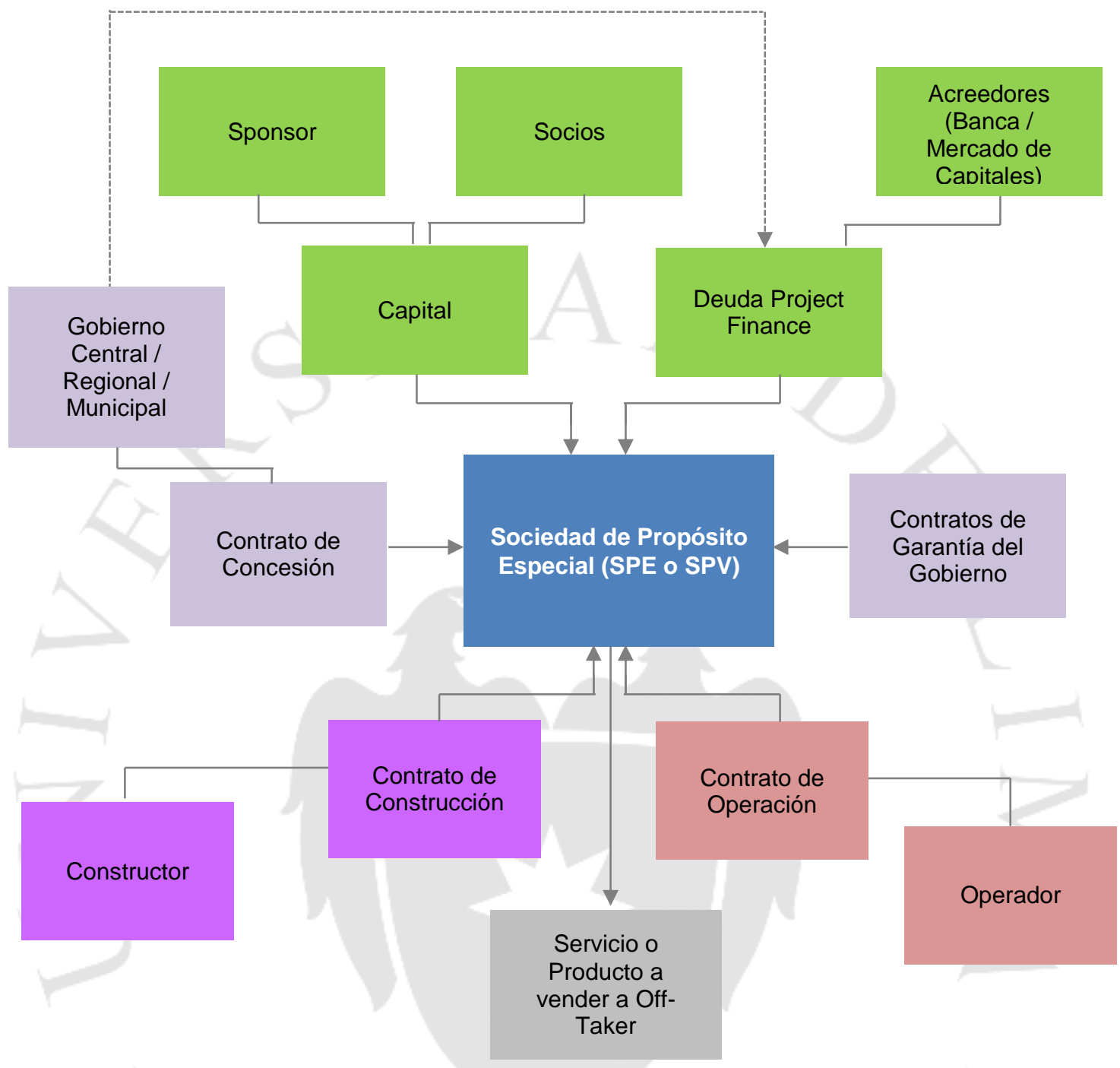

Fuente: Molina y Del Carpio (2004). Financiamiento de inversiones mediante el Project Finance. p. 79. 
En este esquema podemos apreciar cómo se traslada un tipo distinto de riesgo a la parte que puede administrarlo mejor que la SPV. Así pues, existen distintos tipos de riesgo relacionados a un proyecto de infraestructura (Molina y Del Carpio, 2004):

- Riesgo de Completion o de terminar el proyecto: Es aquel riesgo asociado a que el proyecto no se termine a tiempo, surjan sobrecostos para su realización o que no se construya de acuerdo a un estándar de calidad adecuado. Este es uno de los riesgos más relevantes para el desarrollo de un proyecto por lo que es muy importante elegir un contratista con experiencia y manejo de tecnología adecuados. Las causales que pueden impedir terminar un proyecto son diversas y pueden ir desde las razones técnicas, como falta de obtención de permisos (Estudio de Impacto Ambiental, derechos de uso y de paso, permisos, licencias municipales, etc.), hasta eventos de fuerza mayor fuera del control del Constructor o de la SPV. Sin embargo, para minimizar aquellos riesgos atribuibles al Constructor, es común en la práctica que se celebren contratos llave en mano, los cuales tienen un precio fijo que reduce el riesgo de sobrecostos. Otra forma de distribuirle el riesgo de construcción al Constructor es aplicarle penalidades en el caso de retraso del cronograma de construcción o bajos estándares de calidad de la construcción.

- Riesgo de Operación: Es aquel riesgo relacionado al mal funcionamiento del proyecto una vez realizada la puesta en marcha de este, lo que conlleva a pérdidas por falta de productividad. También está relacionado al aumento de costos operativos y de mantenimiento. Este riesgo es también uno de los más relevantes ya que muchos de estos proyectos son desarrollados para brindar un servicio público y la caída de este tipo de servicio tiene graves repercusiones en un Estado. Por ello, comúnmente los contratos de concesión regulan severas penalidades y sanciones administrativas en el caso de indisponibilidad de un servicio. Al igual que el contrato de construcción, se pueden trasladar las penalidades al Operador del proyecto.

- Riesgos del Contrato de Concesión: Si bien el contrato de concesión busca mitigar varios riesgos que podrían afectar al concesionario, estos muchas veces no son perfectos y dejan expuesto al concesionario a distintos riesgos 
contractuales. Un ejemplo de estos riesgos son aquellos contratos que no ajustan el precio o tarifa a pagarse a la SPV en el caso de retrasos de obtenciones de permisos por causas imputables al mismo gobierno, la ambigüedad en las cláusulas de Desequilibrio Económico, la posibilidad de una expropiación de la propiedad, las cláusulas de terminación del contrato, el extenso proceso de solución de controversias, entre otros. Muchas veces este tipo de riesgo no tiene una forma de mitigación, por lo que la SPV tendrá que identificarlo adecuadamente y cuantificar su posibilidad de ocurrencia.

- Riesgo de Demanda: Es aquel riesgo de que la demanda por el servicio final no exista al precio que le permita al proyecto generar flujos suficientes para superar sus costos y gastos de operacionales y con el servicio de deuda. Este riesgo se elimina en parte con los contratos Off-Take que se discutió previamente.

- Riesgos Financieros: Relacionado al riesgo de falta de capacidad de pago la deuda financiera. Las razones macroeconómicas pueden ser por fluctuaciones del tipo de cambio, tasa de interés, inflación, etc. Entre los factores relacionados a la SPV, pueden deberse a atrasos en el proyecto que no permitan la venta del servicio o el cobro de este, generando flujos insuficientes para el respectivo pago. Otra razón, y que resulta muy importante a pesar de la independencia de la SPV, es la solvencia del promotor del proyecto. Si bien el propósito de realizar un Project Finance es aislar la SPV del riesgo de la empresa promotora, de todas maneras, los inversores evalúan que esta sea solvente y en muchos casos, se establecen un gatillo de incumplimiento de obligaciones si el promotor disminuye su posesión en la concesionaria a partir de cierto porcentaje.

- Riesgos legales, macroeconómicos, medioambientales y de responsabilidad social.

Si bien armar un Project Finance es exigente, se ha probado a través de los años las ventajas de esta estructura al permitir a distintas empresas del sector infraestructura, dedicarse a la realización de centenares de estos proyectos, ya que al no comprometer sus recursos o comprometerlos de manera limitada, les permite no sólo enfocar la 
totalidad de sus fondos en un único proyecto con una inversión gigantesca, sino diversificarlos en un amplio abanico de proyectos.

La operación del Project Finance debe estar meticulosamente diseñada y por lo tanto, obliga la intervención de diversos especialistas jurídicos, técnicos y financieros para obtener buenos resultados. En muchos casos, el costo de contratar a todos estos especialistas puede equivaler al 1-2\% del volumen del costo del proyecto, lo que hace que sólo sea viable incurrir en estos, si el proyecto demanda un gran cantidad de inversión que permitirá diluir estos costos a lo largo de la vida del proyecto. Entre los costos relacionados a estos especialistas se encuentran los pagos realizados a los asesores tributarios, supervisores independientes de ingeniería, asesores ambientales, consultores de operación y mantenimiento, estructuradores financieros, asesores legales para la estructuración de los contratos de deuda, y muchas más aplicables de acuerdo al proyecto a desarrollar.

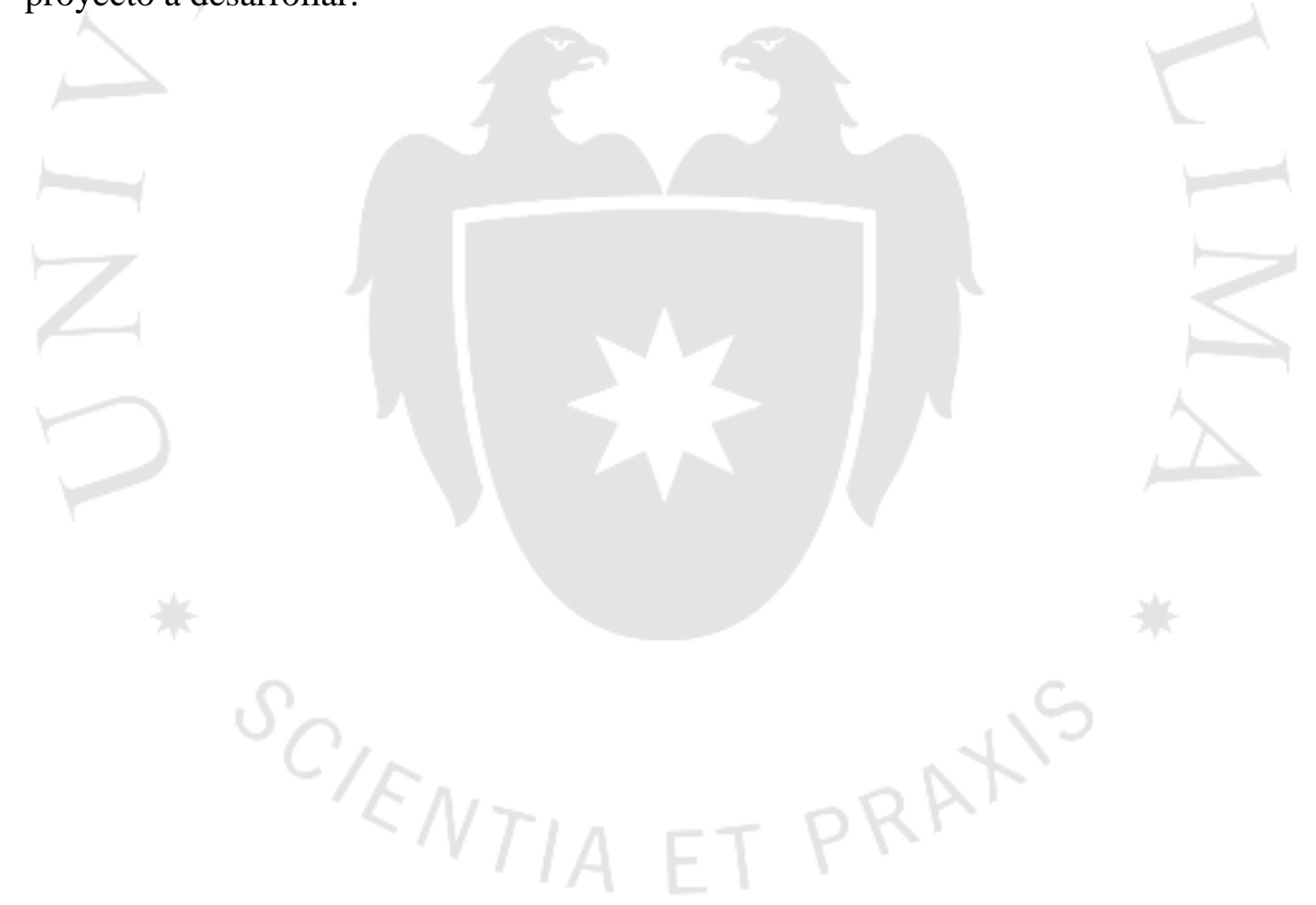




\section{CAPÍTULO II: DESCRIPCIÓN DE LA ESTRUCTURACIÓN DEL BONO Y SU IMPLEMENTACIÓN}

Como se ha explicado previamente, la fortaleza de un financiamiento bancario o en el mercado de capitales del tipo Project Finance subyace en la fortaleza de la concesión que lo sustenta. Por ello, en este capítulo se explicará la adecuación de la estructuración del bono al esquema contractual para el desarrollo del proyecto de concesión, así como aquellos mecanismos aplicados a la emisión para la gestión de riesgos del proyecto de inversión. Primero, es importante entender los participantes que forman parte del desarrollo del proyecto de inversión y los contratos que los vinculan a este. Luego, se describirá el motivo por el que se realizó la emisión y los principales términos financieros de esta. Finalmente, se describirá a detalle el proceso de estructuración de la deuda y su respectiva documentación, así como las herramientas utilizadas para el análisis financiero (modelo y evaluación de rating).

\subsection{PRINCIPALES PARTICIPANTES DEL PROYECTO ATS}

Tal cual como se explicó en el primer capítulo, hay varios participantes envueltos en el desarrollo de un Project Finance y en el caso del Proyecto ATS, no fue una excepción. En la Figura 2.6 se describen aquellos participantes involucrados (a la fecha de la emisión) en la estructura del proyecto y como se adecuó cada parte a la emisión del bono: 
Figura 2.6

Participantes del proyecto ATS

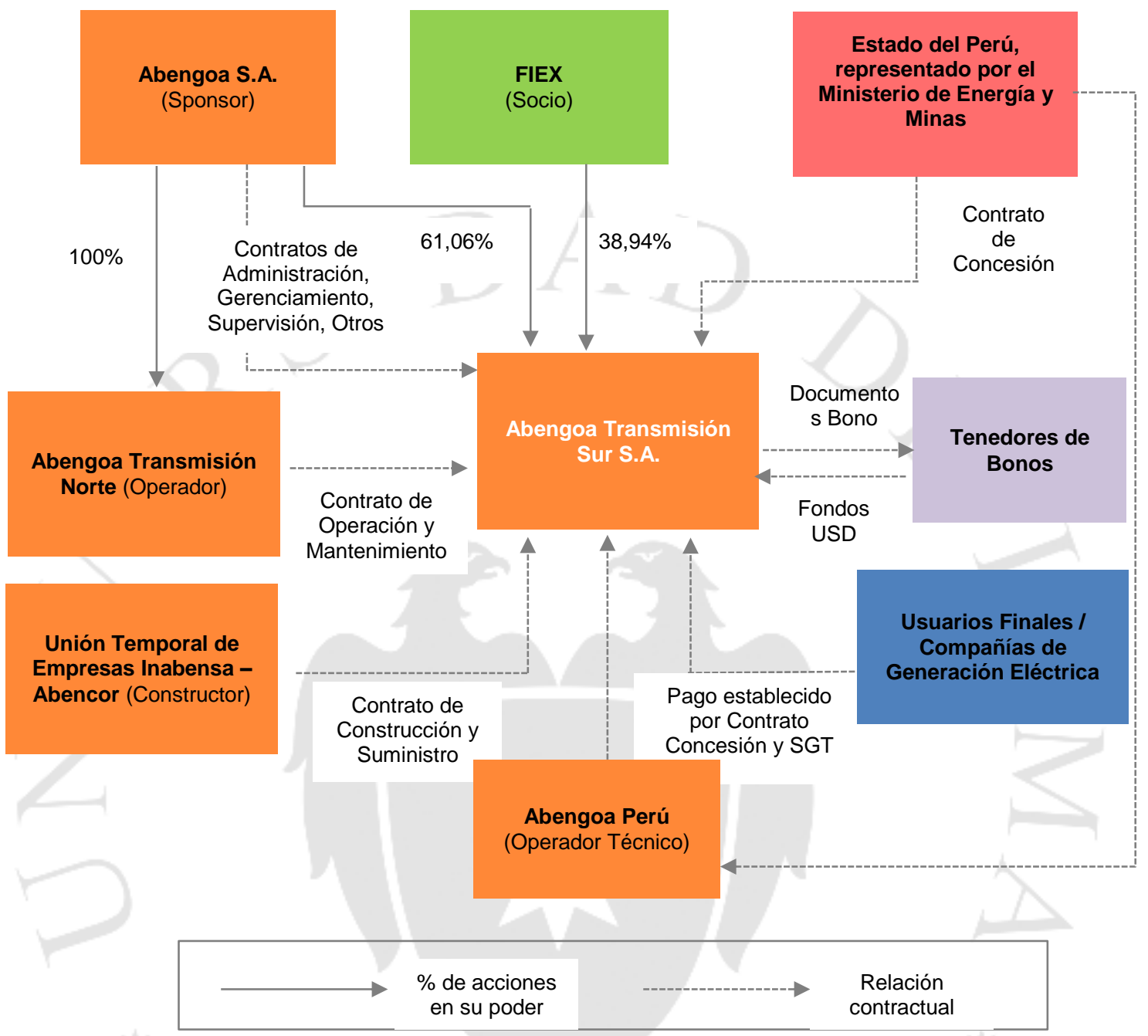

Fuente: Offering Memorandum (2014).

Elaboración propia.

- La Sociedad Concesionaria (SPV), llamada Abengoa Transmisión Sur S.A., que fue constituida para realizar la construcción, operación y mantenimiento de la línea de transmisión eléctrica de 500kV Chilca-MarconaMontalvo, la cual le fue entregada en concesión por el Estado Peruano a través del Ministerio de Energía y Minas bajo el Contrato de Concesión firmado el 22 de julio de 2010. La concesión consta de un período de 30 años, empezando desde el 17 de enero de 2014, fecha en la que se alcanzó la puesta en operación comercial de la línea. 
- $\quad$ El Sponsor o Promotor es Abengoa S.A. que a través de su subsidiaria ASA Iberoamerica S.A., ganó la concesión del proyecto en estudio. Abengoa S.A. fue fundada en 1941 en Sevilla, España cuyo rubro es la ingeniería y construcción de proyectos de infraestructura (principalmente de energía eléctrica y renovable). Abengoa S.A., por su larga experiencia y trayectoria, a través de sus diversas subsidiarias, es la que provee a ATS de servicios de administración, gerenciamiento y supervisión para la adecuada gestión del proyecto. Abengoa S.A. era poseedora de manera indirecta del 100\% de las acciones de ATS al momento de ganar la concesión, pero un año antes de realizarse la emisión del bono, Abengoa S.A. era dueña del $61 \%$ de las acciones de ATS debido a que vendió una parte de su participación al Fondo para Inversiones en el Exterior (“FIEX”), administrado por Compañía Española de Financiación del Desarrollo (“COFIDES”).

El Constructor o Contratista fue un joint venture de dos empresas subsidiarias de Abengoa S.A., las cuales se llamaron "Unión Temporal de Empresas Inabensa-Abencor Chilca-Montalvo". Con esta empresa se suscribieron dos contratos, llamados en conjunto Contratos EPC:

- Contrato de Procura: Firmado el 22 de julio de 2010 y bajo las leyes de Perú, define el suministro de los equipos y materiales (incluidos repuestos para mantenimiento) necesarios para la línea de transmisión. El monto del contrato es de USD 230,817, 214 (sin incluir IGV). Entre los suministros principales se tienen las torres metálicas, reactores, transformadores, conductores, aisladores, compensación serie, interruptores de potencia, entre otros.

- Contrato de Construcción: Firmado el 24 de agosto de 2010 y bajo las leyes de Perú, establece el esquema para el diseño, ingeniería y construcción de las líneas de transmisión. El trabajo del constructor incluye, entre otras tareas, la realización de los servicios de ingeniería, obras civiles, 
instalaciones electromecánicas y pruebas de desempeño. El monto del contrato es de USD 177,006, 786 (sin incluir IGV).

- El Operador del proyecto fue Abengoa Transmision Norte S.A. ("ATN"), que también es una subsidiaria del sponsor. Bajo el Contrato de Operación y Mantenimiento, con fecha 21 de junio de 2013, desde la fecha de Puesta en Operación Comercial, ATN estaba obligada a realizar los trabajos de operación y mantenimiento de la línea y subestaciones asociadas. Previo a la operación, también se encargó de supervisar la línea de transmisión y las subestaciones en el período de prueba y la creación de guías de operación y mantenimiento. El costo de este servicio está denominado en dólares y contabilizado como costos operativos (USD 2,000,000, ajustables anualmente al índice U.S. Finished Goods Less Food and Energy). Eventualmente, luego de una reestructuración corporativa, este cargo se trasladó a Omega Perú Operación y Mantenimiento S.A., otra subsidiaria de Abengoa S.A.

- El Operador Técnico es aquella entidad, definido bajo el Contrato de Concesión, que estará a cargo de la operación técnica del proyecto de inversión. Este está obligado a mantener directamente el $25 \%$ del capital social de la sociedad concesionaria y servir como Operador Técnico hasta 10 años después de la puesta en operación comercial. El Operador Técnico de este proyecto, fue ASA Iberoamérica S.L. Posteriormente a la emisión, se le transfirió este título a Abengoa Concessions Perú S.A.

- Los usuarios finales son las personas y empresas que consumen directamente la energía eléctrica. Como los distribuidores son los encargados de llevar la electricidad a las instalaciones del usuario final, ellos realizan el cobro por el consumo de energía. En el esquema del SGT, los distribuidores al tener contratos de compra de energía con las compañías de generación eléctrica, pagan a los generadores con el dinero recaudado de los usuarios finales y luego, los generadores son los encargados de pagar al transmisor la Base Tarifaria $^{10}$, que es

\footnotetext{
${ }^{10}$ En la siguiente sección se explica a fondo en que consiste la Base Tarifaria.
} 
la remuneración que recibe la empresa transmisora por sus servicios de transmisión.

- $\quad$ Finalmente, los Tenedores de Bonos o Bonitas, son aquellos inversionistas que adquirieron los bonos emitidos por ATS, bajo lo estipulado en los documentos de la emisión, por un monto de USD 432,000,000. En el caso de la emisión de ATS, la relación entre el emisor y los bonistas está regulada bajo varios contratos que forman parte del financiamiento. En el numeral 4 de este capítulo se detallarán los participantes en el financiamiento.

Todas estas entidades involucradas realizan una o varias tareas en el proyecto de infraestructura para que su desarrollo sea el más eficiente posible.

\subsection{FORTALEZAS DEL PROYECTO DE INVERSIÓN}

Luego de haber detallado las partes involucradas y los contratos que regulan su participación dentro del desarrollo de este proyecto de inversión, en esta sección se describirán aquellas características contractuales, del sector y de la empresa que suministran fortaleza a este Project Finance y por tanto, contribuyen a la fortaleza de la estructuración del bono.

\subsubsection{Contrato de Concesión}

Como se mencionó en el primer capítulo, el Contrato de Concesión de la línea de transmisión eléctrica Chilca-Marcona-Montalvo del tipo BOOT (Build, Operate, Own and Transfer) tiene como principal objeto el diseño, financiamiento, construcción, operación y mantenimiento de esta por parte de la sociedad concesionaria Abengoa Transmisión Sur S.A. La concesión se otorga por un plazo de 30 años luego de ser finalizado el periodo de construcción. En el caso de esta línea, el período operativo se inició el 17 de enero de 2014 (sin incluir la Compensación Serie) y el 02 de mayo de 2014 (incluyendo la Compensación Serie).

En los siguientes párrafos se expondrán una a una las fortalezas del Contrato de Concesión.

Base Tarifaria 
Uno de los principales temas de gran interés para los inversionistas en cualquier proyecto de concesión, es el método de pago que remunerará a la sociedad concesionaria la inversión realizada en la etapa constructiva y los costos de la etapa operativa. En el caso de las líneas de transmisión, como se explicó en el capítulo anterior, existen diferentes tipos de sistemas en el sector de la transmisión eléctrica. La línea eléctrica en estudio pertenece al Sistema Garantizado de Transmisión (SGT), lo que quiere decir que esta línea, una vez en operación comercial, recibirá su remuneración sin importar si esta efectivamente es utilizada o no por el SEIN. La Base Tarifaria es aquel monto que la sociedad concesionaria recibirá como remuneración y está conformada por los siguientes componentes:

(i) La remuneración por inversiones, que se calcula como la anualidad del valor de la inversión, considerando un periodo de recuperación de 30 años. Esta remuneración se actualiza anualmente con la tasa establecida en el artículo 79 de la Ley de Concesiones Eléctricas que a la fecha está establecida en 12\%.

(ii) Los costos eficientes de operación y mantenimiento de las instalaciones.

(iii) La liquidación que pueda corresponder al finalizar el año si se presenta un desajuste entre lo que fue autorizado como Base Tarifaria al inicio de la concesión y lo realmente recibido por la sociedad concesionaria, ya sea por un tema de tipo de cambio, tributario, etc ${ }^{11}$.

La remuneración de la inversión y los costos de operación y mantenimiento que forman parte de la Base Tarifaria son los que correspondan a la propuesta ganadora del proceso de licitación convocado para la construcción de las instalaciones del SGT. Ambos son actualizados anualmente por el Índice WPSSOP3500 (U.S. Finished Goods Less Food and Energy), publicado por el Departamento de Trabajo del Gobierno de los Estados Unidos de Norteamérica, brindándole otra fortaleza al proyecto, ya que el componente inflacionario es tomado en cuenta para la actualización de la Base Tarifaria.

En el caso de este proyecto, la Base Tarifaria ofrecida en la propuesta ganadora de la licitación fue la siguiente:

- Costo de Inversión: Usd 291,027,958. Dicho monto está expresado a la fecha de Puesta en Operación Comercial. Para obtener la Anualidad de la Inversión,

${ }^{11}$ La liquidación la efectúa OSINERGMIN de acuerdo a lo estipulado en el literal c) del Artículo $24^{0}$ de la Ley N ${ }^{0} 28832$ y el numeral 22.4 del Artículo $22^{0}$ del Reglamento de Transmisión. 
simplemente se usa la tasa de $12 \%$ y se obtiene un monto de Usd 36,129,275 anual.

- Costo de Operación y Mantenimiento: Usd 12,065,725. Monto expresado a la fecha de Operación Comercial.

Esta línea eléctrica al forma parte del Sistema Garantizado de Transmisión tiene garantizada el pago de la Base Tarifaria mediante un procedimiento que involucra a todos los usuarios del sistema eléctrico, a través de dos conceptos denominados Ingreso Tarifario y Peaje de Transmisión. El Comité Técnico de Evaluación y Estadística del COES efectúa la liquidación mensual del Peaje por Transmisión y del Ingreso Tarifario correspondiente a cada uno de los generadores integrante del COES. Acto seguido, el COES notifica a los generadores la mencionada liquidación. Los generadores deben hacer efectivos los pagos mensuales por Peaje por Transmisión e Ingreso Tarifario Esperado directamente a las empresas de transmisión dentro de los siete días calendario siguientes a la notificación de la liquidación mensual practicada por el COES.

Es así que este esquema del SGT reduce a prácticamente cero el riesgo de demanda en el proyecto de inversión y garantiza la estabilidad de los ingresos y el pago del financiamiento.

\section{Usufructo de Fibra Óptica}

Los transmisores están obligados a instalar cables de fibra óptica en los conductores de la línea de transmisión, con el propósito de dar soporte al sistema de telecomunicaciones peruano. El concesionario puede disponer libremente del $80 \%$ de la capacidad total de transmisión de telecomunicaciones (fibras ópticas iluminadas), mientras que se le otorgará al estado el derecho de usufructo gratuito sobre el $20 \%$ de la fibra óptica.

Los Contratos o acuerdos que suscriba la la sociedad concesionaria con terceros, relacionados a los servicios de telecomunicaciones, no podrán exceder el plazo del Contrato y culminarán simultáneamente con la terminación del este (Contrato de Concesión Línea de Transmisión SGT 500 kV Chilca-Marcona-Montalvo, 2010, p. 80). Esta actividad no debe perjudicar la continuidad ni seguridad del servicio de transmisión eléctrica y por tanto, tampoco deberá afectar la Base Tarifaria. 


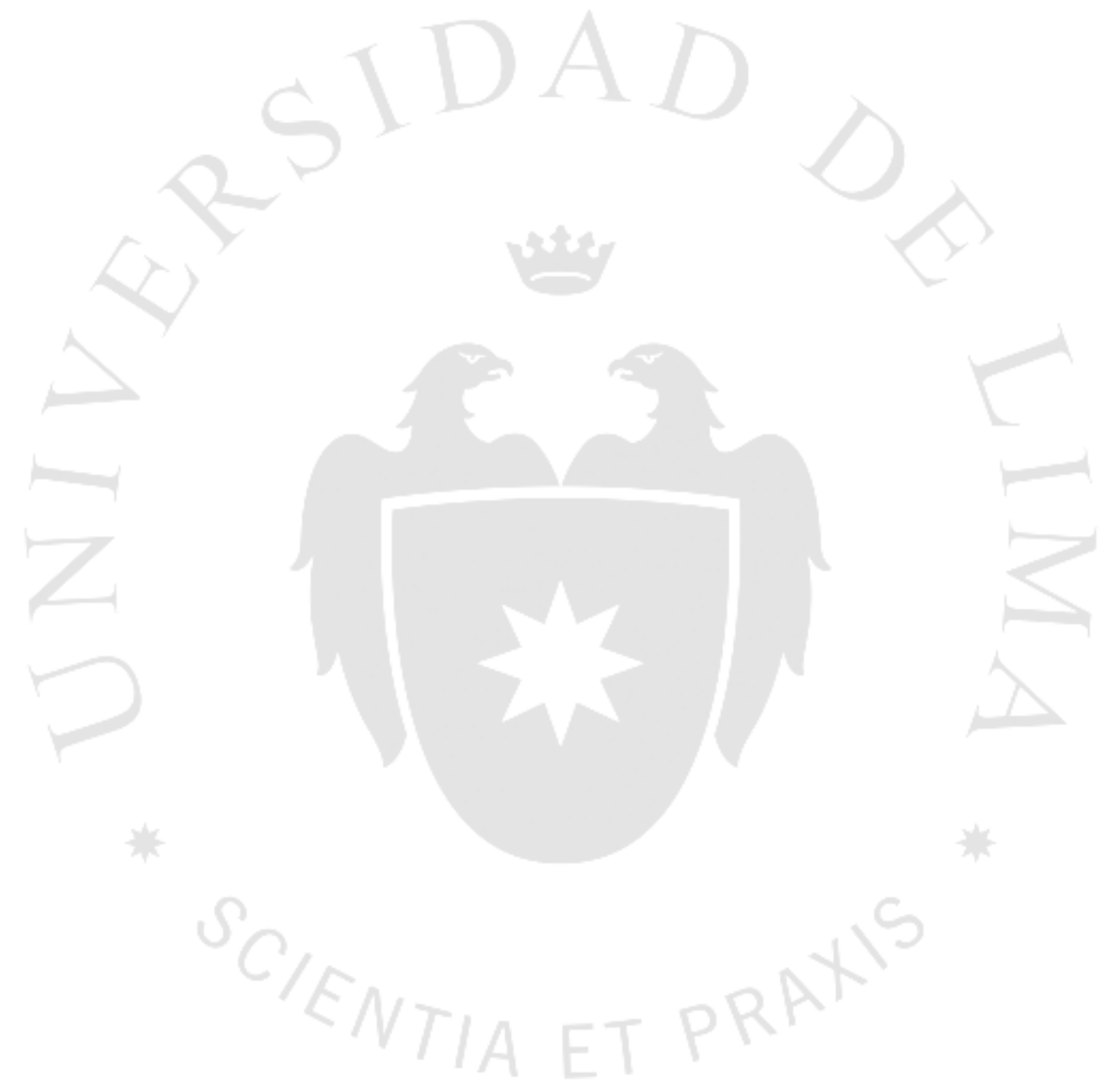




\section{Financiamiento de la Concesión}

En el numeral 9 del Contrato de Concesión, se estipulan aquellos derechos y obligaciones que la Sociedad Concesionaria posee respecto al financiamiento propio o de mano de terceros que podrá adquirir para desarrollar el proyecto.

Uno de los puntos fuertes del Contrato de Concesión frente al financiamiento, es que se puede transferir en dominio fiduciario la concesión a un fideicomiso, claro está, con permiso previo del Concedente. También está permitida la entrega en garantía de los bienes de la concesión, la concesión misma y los flujos de dinero generados de la prestación del servicio, siempre que se las estipulaciones en los contratos de deuda no vayan contra la naturaleza del mismo contrato de concesión (Contrato de Concesión Línea de Transmisión SGT 500 kV Chilca-Marcona-Montalvo, 2010, p. 14). Asimismo, para hacer evidente el apoyo del Concedente a los potenciales financistas del proyecto, el contrato de concesión permite que los contratos de deuda tengan las siguientes disposiciones (Contrato de Concesión Línea de Transmisión SGT 500 Kv ChilcaMarcona-Montalvo, 2010, p. 14):

a) A pedido de la sociedad concesionaria o los Acreedores Permitidos ${ }^{12}$, el Concedente enviará a los Acreedores Permitidos, copia de las comunicaciones entre del Concedente a la sociedad concesionaria, y les informará de cualquier hecho que pudiera ocasionar la terminación del Contrato.

b) Los Acreedores Permitidos podrán solicitar al Concedente la sustitución de la sociedad concesionaria sin que haga falta el consentimiento de ésta, si por consideraciones financieras o de otra índole, perciben que tal sociedad no podrá cumplir con las obligaciones del Contrato o con el pago de la deuda garantizada, proponiendo una terna de empresas a sustituir a la sociedad concesionaria. El Concedente no negará la sustitución sin causa razonable y responderá la solicitud en 30 días hábiles.

c) Los Acreedores Permitidos tendrán el derecho de recibir las sumas de dinero derivadas de la licitación de la Concesión, en el caso de terminación del Contrato.

\footnotetext{
${ }^{12}$ La definición de Acreedores Permitidos se encuentra en el Anexo N`3 del Contrato de Concesión y se refiere a entidades que institución financiera o inversionista que cumpla ciertos criterios. Más detalle se encuentra en el Anexo 1.
} 


\section{Responsabilidad Contractual}

En el caso de un evento de Fuerza Mayor $^{13}$ y durante su duración, tanto el concesionario como el Concedente no son imputables por la inejecución de una obligación o por su cumplimiento parcial, tardío o defectuoso, siempre que se acredite que tal causa impidió el debido cumplimiento de alguna de las partes.

La Sociedad Concesionaria podrá solicitar por causal de Fuerza Mayor, si las circunstancias así lo requieran, la suspensión del plazo de la concesión. La suspensión del plazo deberá ser acordada entre las partes. En dicho caso, se extenderá el plazo de la concesión por un plazo igual al plazo estipulado para la suspensión.

En el supuesto de que una de las partes no estuviera de acuerdo con la calificación del evento como de Fuerza Mayor o sus consecuencias, puede recurrir al procedimiento de solución de controversias determinado en el Contrato de Concesión.

\section{Equilibrio Económico}

El Contrato de Concesión (2010) contempla un mecanismo para restablecer el equilibrio económico-financiero, “al cual tendrán derecho el concesionario y el Concedente, en caso que el equilibrio económico de la concesión sea significativamente afectado exclusiva y explícitamente por cambios en las leyes aplicables” (p.29), siempre que afecte aspectos económicos financieros tales como la variación de ingresos o costos de operación y mantenimiento relacionados con la prestación del Servicio.

Se entenderá que el equilibrio económico financiero ha sido afectado, cuando se afectan los ingresos o los costos de operación y mantenimiento del servicio de manera tal que la diferencia entre los ingresos menos los costos de operación y mantenimiento de la sociedad concesionaria por un período de doce meses consecutivos o más, varíe en más $10 \%$ de la diferencia entre los ingresos y costos de los mismos 12 meses sin la afectación del cambio de la ley vigente.

La parte afectada podrá invocar ruptura del equilibrio económico-financiero dentro del plazo de cuatro meses después de vencidos los doce meses anteriormente

13 "Fuerza Mayor significará un evento, condición o circunstancia más allá del control razonable y previsible de la Parte que la invoca, la cual a pesar de los esfuerzos razonables de la Parte que invoca Fuerza Mayor para prevenirla o mitigar sus efectos, causa el incumplimiento de una obligación o su cumplimiento parcial, tardío o defectuoso." (Contrato de Concesión Línea de Transmisión SGT 500 KV Chilca-Marcona-Montalvo, 2010, p. 15) 
mencionados, pero sólo después de transcurridos dos años luego de la Puesta en Operación Comercial.

La parte respectiva podrá proponer por escrito a la otra parte y con la necesaria sustentación, las soluciones y procedimientos a seguir para restablecer el equilibrio económico afectado. El restablecimiento del equilibrio económico se efectuará sobre la base de los Estados Financieros Auditados de la sociedad concesionaria del periodo en el que se verifiquen las variaciones de ingresos o costos que sustentan el desequilibrio económico-financiero. No obstante lo indicado, el Concedente podrá solicitar documentación distinta de los estados financieros auditados para determinar el restablecimiento del equilibrio económico.

La existencia de un desequilibrio sólo podrá dar lugar a la modificación de las disposiciones contenidas en el Contrato de Concesión, pero no a la suspensión ni resolución de este.

Por último, el Contrato de Concesión (2010) añade: "De existir discrepancias entre las partes sobre si existe ruptura del equilibrio económico financiero, la cuantía del mismo o la forma de restablecerlo, serán resueltas de conformidad con los mecanismos estipulados en el Contrato de Concesión para las Controversias No Técnicas" (p. 30).

\section{Terminación del contrato}

Las causales de terminación del contrato son las siguientes:

a) Acuerdo de las Partes.

b) Terminación del Contrato de Concesión Definitiva de Transmisión Eléctrica.

c) Vencimiento del plazo del Contrato, o

d) Resolución del Contrato por alguna de las partes.

Así, "la sociedad concesionaria podrá resolver el Contrato, si el Concedente incumpliera, de manera injustificada, grave y reiterada, cualquiera de las obligaciones que le corresponden conforme al Contrato o las leyes aplicables" (Contrato de Concesión Línea de Transmisión SGT 500 Kv Chilca-Marcona-Montalvo, 2010, p. 19). Asimismo, cualquiera de las partes podrá resolver el Contrato si un evento de fuerza mayor transcurre por más de 12 meses sin ser resuelto. 
Las causales de terminación del contrato que son imputables al concesionario o a un incumplimiento del Operador Técnico, obligan al concedente a realizar una licitación pública para transferir la concesión y sus bienes a un nuevo concesionario. El monto base de la primera convocatoria de la licitación no será menor al Valor Contable $^{14}$ de los bienes de la concesión. De ser necesaria una segunda convocatoria por falta de postores, el Concedente podrá reducir hasta en $25 \%$ el monto base de la convocatoria inmediata anterior (Contrato de Concesión Línea de Transmisión SGT 500 Kv Chilca-Marcona-Montalvo, 2010, p. 21). En ambos casos, luego de realizada la licitación, y recibido el pago correspondiente por el postor ganador, se descontarán los gastos directos asociados al proceso de licitación, las remuneraciones y derechos laborales de los trabajadores del concesionario, el principal e intereses adeudados a los Acreedores Permitidos, tributos, multas, penalidades, pasivos adeudados al Estado y otros pasivos. El saldo remanente luego de estos descuentos, será entregado al Concesionario hasta por un monto límite equivalente al Valor Contable. Si hubiese un saldo luego del pago al concesionario, este corresponderá el Estado.

Si el concesionario decidiera terminar el contrato por incumplimiento reiterado e injustificado del Concedente, o si es que el Concedente decidiera terminarlo de facto o por las vías de hecho, el Concedente debe pagar a la sociedad concesionaria el mayor valor entre (i) el valor presente de los ingresos por base tarifaria que se hubiera generado durante el saldo del plazo del contrato de concesión, descontados a una tasa de $12 \%$ y (ii) el Valor Contable de los bienes de la concesión. De este monto también serán descontados los gastos descritos en el párrafo anterior, excepto aquellos asociados al proceso de licitación.

Por último, "si el Contrato termina por resolución debido a causa distinta a Destrucción Total, y el Plan de Transmisión vigente o el Concedente determinase que la Línea Eléctrica no debe mantenerse en uso, el Concedente quedará obligado a pagar el Valor Contable de los Bienes de la Concesión" (Contrato de Concesión Línea de Transmisión SGT 500 Kv Chilca-Marcona-Montalvo, 2010, p. 22).

\footnotetext{
${ }^{14}$ Es el valor en libros de los Bienes de la Concesión expresado en dólares (de acuerdo a Estados Financieros), neto de depreciaciones y amortizaciones acumuladas al momento de realizar el cálculo (la depreciación se calcula bajo el método de línea recta, para un período de treinta (30) años). Si la depreciación para efectos tributarios es mayor que la definida en este párrafo, se descontará del valor en libros resultante la diferencia entre (1) el impuesto a la renta que se hubiera pagado bajo el método de depreciación de línea recta y (2) el impuesto a la renta resultante del método de depreciación utilizado por la sociedad concesionaria. (Contrato de Concesión Línea de Transmisión SGT 500 Kv Chilca-MarconaMontalvo, 2010, p. 77)
} 
Es así, que en todas las situaciones (salvo el de terminación del contrato por vencimiento del plazo), la sociedad concesionaria se asegura la devolución de la inversión realizada al menos por un monto equivalente al $75 \%$ del valor en libros de los bienes de la concesión. Además, de cara a los bonistas, se tiene estipulado claramente que antes de cualquier pago del remanente de la licitación al concesionario, se deberá pagar primero los saldos adeudados de principal e intereses que el concesionario tenga bajo concepto de deudas comprometidas para el financiamiento del proyecto.

\subsubsection{Contratos EPC}

En esta sección se analizarán las estipulaciones en beneficio de la sociedad concesionaria descritas en los Contrato EPC.

El diseño, ingeniería, suministro y construcción de la línea Chilca-MarconaMontalvo y subestaciones asociadas fue determinado mediante la suscripción de dos contratos EPC con la Unión Temporal de Empresas Inabensa-Abencor, subsidiaria de la matriz Abengoa S.A. El Contrato de Construcción establece el marco en que la ingeniería, el diseño y la construcción deben llevarse a cabo y el Contrato de Procura estipula la entrega de suministros, equipos y materiales complementarios para el proceso de construcción.

Si bien a la fecha de la emisión, la línea se encontraba en operación, el Concedente solicitó la construcción de una segunda barra en la Subestación Montalvo. Esta segunda barra no es requerida para la operación comercial del proyecto y el presupuesto para su construcción era de un costo aproximado de USD 681,995. Por ello, se considera adecuado mencionar los contratos EPC y sus ventajas a beneficio del concesionario, a pesar de que el proyecto de inversión ya tenía completado la etapa de construcción a un $99 \%$.

- Contrato de Procura: Las siguientes características del contrato fueron determinadas para resguardar los intereses de la sociedad concesionaria (Offering Memorandum, 2014):

i. Precio del contrato y pago: Se determinó un precio fijo de US\$230 millones (sin incluir IGV), los cuales se realizaban en pagos progresivos de acuerdo a un 
cronograma que establecía la fecha de llegada de cada suministro, asegurando de esta manera la efectiva entrega de los equipos y materiales.

ii. Garantías: El contratista asegura que los equipos y servicios entregados bajo este contrato cumplen con estándares de calidad y fueron entregados en buen estado. Por ello, este extiende una garantía de hasta 12 meses después de la Puesta en Operación Comercial para los equipos y materiales entregados. En el caso de las garantías otorgadas por los fabricantes, en el caso de conductores, estas se extienden hasta 30 años y para los aisladores hasta 3 años.

iii. Daños y perjuicios: Se le hace responsable al contratista por cualquier retraso de suministros o equipo defectuoso, por lo que podría pagar hasta $10 \%$ del monto del Contrato de Procura (se excluye lucro cesante o daños indirectos).

iv. Fuerza Mayor: Las disposiciones sobre fuerza mayor del Contrato de Concesión también son aplicables a este contrato.

v. Terminación del contrato por causas imputables al contratista:

a. Quiebra de alguna de las empresas que conforman la Unión Temporal de Empresas.

b. Demora de 180 días después de la fecha prevista bajo cronograma para la entrega de materiales y equipos en buenas condiciones, atribuible al contratista.

c. Un evento de fuerza mayor que no se haya resuelto luego de 3 meses.

vi. Riesgos asumidos por el contratista: Financieros, políticos, regulatorios, legales, de mercado, tecnológicos y los relacionados a la solvencia de los fabricantes.

- Contrato de Construcción: En el caso de ese contrato, se estipuló lo siguiente para proteger los intereses del concesionario (Offering Memorandum, 2014):

i. Precio del contrato y pago: Se determinó un precio fijo, pagable de forma mensual sujeto al cumplimiento en fecha de los hitos.

ii. Garantías: El Constructor garantiza que el diseño, la ingeniería y construcción y los materiales usados son de alta calidad y libres de defectos. Se extiende la garantía hasta 12 meses después de entregada la línea de transmisión y las subestaciones. Es así, que será responsable por los costos de subsanar cualquier 
trabajo defectuoso o incompleto durante este período de garantía, y en el caso de que no lo logre en 5 días, el concesionario podrá atender el problema a cuenta del Constructor.

iii. Daños y perjuicios: Se le hace responsable al Constructor por los retrasos en el cumplimiento de hitos o el mal desempeño de las líneas de transmisión y subestaciones hasta por penalidades de $10 \%$ del monto del Contrato de Construcción (se excluye lucro cesante o daños indirectos).

iv. Pruebas de desempeño: El Constructor realizará pruebas de desempeño de acuerdo a los requerimientos del Contrato de Concesión.

v. Fuerza Mayor: Las disposiciones sobre fuerza mayor del Contrato de Concesión también son aplicables a este contrato.

vi. Seguros: El Constructor debe contratar a su propio costo, seguros contra accidentes laborales y seguros para protección de vehículos, maquinaria y equipos usados en las tareas de construcción.

vii. Terminación del contrato por causas imputables al contratista:

a. Quiebra de alguna de las empresas que conforman la Unión Temporal de Empresas.

b. Demora de 75 días después de la fecha prevista bajo cronograma para la entrega de la línea de transmisión y subestaciones, al menos que se declare un evento de fuerza mayor.

c. Un evento de fuerza mayor que no se haya resuelto luego de 12 meses.

Como se puede apreciar de estas descripciones, en la etapa de construcción el concesionario contaba con cláusulas en los Contratos EPC que le brindaban salidas en situaciones donde el Contratista podría estar en incumplimiento de sus obligaciones, ya sea de manera deliberada o por eventos fuera de su control. Además, los períodos de garantía otorgados para el buen funcionamiento de las instalaciones y equipos, y que son aplicables en el período de operación comercial, se consideran adecuados y de acuerdo al estándar comercial para estos tipos de estructuras ${ }^{15}$.

${ }^{15}$ Esta opinión es de acuerdo al informe del Ingeniero Inpedendiente, publicado en el Offering Memorandum de la emisión. 


\subsubsection{Contrato de Operación}

Se suscribió un Contrato de Operación y Mantenimiento con ATN (posteriormente a la emisión, se cambió por Omega Perú) para garantizar el buen manejo de los servicios operativos a través del personal y las facilidades con las que cuenta ATN. Las principales fortalezas de este contrato son (Offering Memorandum, 2014):

i. Experiencia de ATN: ATN cuenta con experiencia en operación y mantenimiento de líneas de transmisión, en la gestión de personal calificado para estar tareas, familiaridad con las regulaciones medioambientales, laborales y de salubridad.

ii. Precio del contrato y pago: Si bien se ha determinado un monto anual que se ajusta cada año, la variación no afectará significativamente a ATS ya que el índice de ajuste utilizado es el mismo que se utiliza para ajustar la Base Tarifaria determinada en el Contrato de Concesión (U.S. Finished Goods Less Food and Energy). Los pagos se realizan de manera mensual.

iii. Renovación del contrato: ATN puede elegir no renovar el contrato pero sujeto a un número de condiciones, incluyendo la elección de un operador que cumpla los requisitos estipulados en algún documento relacionado al proyecto (ya sea el contrato de concesión, de financiamiento, etc.). En el caso de elegirse otro operador, ATN deberá seguir cumpliendo a cabalidad sus obligaciones relacionadas al contrato hasta que ocurra dicho cambio (pero no por más de 6 meses luego de terminado el contrato).

iv. Terminación del contrato por causas imputables al operador:

a. ATN entra en un proceso de insolvencia.

b. La ocurrencia de un evento de fuerza mayor que no es resuelto luego de 12 meses.

c. Ocurre la terminación del Contrato de Concesión.

d. Daños causados por ATN a la sociedad concesionaria en un monto que supere el pago anual bajo el Contrato de O\&M, y que dicho pago no sea realizado luego de 30 días de la ocurrencia.

e. Si ATN otorga un gravamen o hipoteca sobre la línea de transmisión o subestaciones. 
f. Si se incumple alguna guía establecida por el Estudio de Impacto Ambiental del proyecto (daños materiales al medioambiente, o patrimonio cultural o natural de Perú).

g. Si ATN transfiere algún derecho derivado de este contrato sin previa autorización de ATS.

h. Incumplimiento por más de 30 días de alguna obligación del contrato.

i. Si ATN deja de ser una afiliada de ATS (cambio de control), al menos que se cumplan ciertas condiciones descritas en el contrato.

v. Fuerza Mayor: Si bien la fuerza mayor liberará a las partes del incumplimiento de obligaciones afectadas por este evento, el resto de obligaciones que no han sido afectadas deberán seguir siendo cumplidas y ATN deberá hacer sus mejores esfuerzos para reanudar el servicio luego de esta ocurrencia. La Fuerza Mayor no será excusa para el desempeño de una obligación cuando está haya ocurrido por más de 12 meses.

vi. Responsabilidad: ATN asumirá la entera responsabilidad frente a la sociedad concesionaria y terceros por la adecuada operación de las líneas de transmisión y el proyecto. Dentro de su responsabilidad, se hará cargo de cualquier multa administrativa y daños directos por el incumplimiento de sus obligaciones bajo este contrato, hasta por un monto equivalente al pago anual bajo este contrato.

De esta manera, la exposición del proyecto de inversión a costos de operación y mantenimiento crecientes se ve mitigado parcialmente mediante la fijación de un precio, que si bien se actualiza anualmente, utiliza el mismo índice al cual se actualiza la Base Tarifaria, por lo que no debería haber mayores incidencias que afecten el flujo operativo del proyecto.

Adicionalmente se puede apreciar que el contrato de operación trata de mantener vigente la obligación del operador de preservar el adecuado funcionamiento de la línea de transmisión y subestaciones, sea cual fuese la situación del momento (a pesar de si se encuentra en un evento fuera de su control o realizando un cambio de operador). Esto es importante notar, puesto que la razón de ser del proyecto es brindar el servicio de transmisión de energía, por lo que la sociedad concesionaria no puede permitirse fallas en el servicio tanto por un tema de sanciones, como de riesgo reputacional. 
Posteriormente, se realizó la cesión contractual a favor de Omega Perú como Operador del proyecto de inversión. Omega Perú es una compañía subsidiaria de Omega, una empresa de Abengoa en Brasil que también cuenta con amplia experiencia en operaciones de líneas de transmisión. En principio, el personal de Omega Perú sería el mismo empleado por ATN, por lo que se iba asegurar la transferencia de conocimientos y experiencia hacia los servicios brindados a ATS.

\subsubsection{Sector Transmisión}

Actualmente, Perú está experimentando una expansión importante de su sistema de transmisión. Durante el año 2015, se incorporaron al SEIN 1,018 km de líneas de transmisión en 220, 138 y menos de 69 kV (Comité de Operación Económica del Sistema Interconectado Nacional [COES-SINAC], 2016, p.17). Este sector se caracteriza por su naturaleza monopólica, por lo que se realizan concesiones para la transmisión según el Plan de Transmisión definido por el COES.

El Sistema Garantizado de Transmisión, al que pertenece la línea de ATS, tiene como ventaja que tiene garantizado el pago de la Base Tarifaria al distribuir el riesgo de impago a través de todo el sistema eléctrico. Esto se logra ya que ATS recibe mensualmente los pagos por las generadoras (cálculo que es definido por el COES), que provienen del pago realizado por los distribuidores, los cuales les cobran a los consumidores finales de la electricidad. Si alguna compañía generadora incumple su obligación de pago a la transmisora, este incumplimiento implicaría una sustancial multa mediante el Anexo 7 de la Escala de Multas y Sanciones de la Gerencia de Fiscalización Eléctrica de OSINERGMIN, aparte de las multas que puede imponer OSINERGMIN si es que la compañía generadora decidiera no pagar las multas anteriores. Por último, la compañía transmisora afectada puede iniciar un proceso judicial a la generadora por este incumplimiento.

Sin embargo, la posibilidad de que un generador incumpla esta obligación es muy improbable. Los ratings crediticios en Perú de casi el $90 \%$ de las generadoras actuales en el sistema eléctrico peruano son de AAA, lo cual indica la alta capacidad de pago y record de buenos pagadores de estas compañías generadoras.

\subsubsection{Experiencia del Promotor y compañías afiliadas}


Como se mencionó anteriormente, Abengoa S.A., como Promotor del proyecto de inversión, cuenta con más de 70 años de experiencia en ingeniería y construcción en proyectos relacionados con energía, agua y tecnología de la información. A la fecha de emisión, contaba con presencia en más de 70 países alrededor del mundo. En cuanto a experiencia en el sector transmisión, tiene en su haber la construcción de más de 31,000 kilómetros de líneas de transmisión y 400 subestaciones a nivel global y 2,500 kilómetros de líneas que se encuentran en operación.

En el Perú, sus subsidiarias se han adjudicado tres proyectos de línea de transmisión otorgadas por el Estado. Estas son las siguientes:

Tabla 2.4

Concesiones de transmisión de Abengoa en Perú otorgadas por el Estado

\begin{tabular}{|c|c|c|c|}
\hline $\begin{array}{c}\text { Empresa } \\
\text { Concesionaria }\end{array}$ & Nombre de la línea & $\begin{array}{l}\text { Extensión } \\
\text { aproximada }\end{array}$ & $\begin{array}{c}\text { Fecha } \\
\text { Operación } \\
\text { Comercial }\end{array}$ \\
\hline ATN & $\begin{array}{l}\text { Lt. Carhuamayo- Paragsha-Conococha- } \\
\text { Huallanca- Cajamarca- Cerro Corona- } \\
\text { Carhuaquero }\end{array}$ & $583 \mathrm{~km}$ & Enero 2011 \\
\hline ATS & Lt. Chilca-Marcona-Montalvo & $915 \mathrm{~km}$ & Enero 2014 \\
\hline ATN 3 & $\begin{array}{l}\text { Lt. Machupicchu-Quencoro-Onocora- } \\
\text { Tintaya }\end{array}$ & $356 \mathrm{~km}$ & $\begin{array}{l}\text { Diciembre } \\
2016 \\
\text { (Estimada) }\end{array}$ \\
\hline
\end{tabular}

Fuente: COES-SINAC (2016). Memoria COES SINAC 2015.

La experiencia de la matriz se transmite a ATS en forma de diversos contratos entre empresas afiliadas:

- $\quad$ Como se sabe, ATN fue la empresa asignada como Operador del proyecto de inversión de ATS (posteriormente Omega Perú) bajo el Contrato de Operación y Mantenimiento. Esta empresa cuenta con la experiencia de llevar la operación de su propia línea desde el 2011 y la de otras líneas de transmisión privadas desarrolladas por Abengoa. 
- Mediante el Contrato de Servicios Administrativos, Abengoa Perú provee a ATS de servicios administrativos, legales y tecnológicos, mediante el uso de su propio personal e instalaciones para proveer dichos servicios. Abengoa Perú tiene más de 20 años establecido en el Perú y cuenta con experiencia en administración de proyectos de construcción de líneas de transmisión.

- $\quad$ El Contrato de Gerenciamiento también firmado con Abengoa Perú, provee a ATS de servicios de gerencia y asesoría financiera. Entre los servicios estipulados en este contrato están (i) actuar en beneficio de ATS en sus asuntos administrativos y financieros, (ii) establecer procedimientos de estándares operativos, (iii) manejar la caja de la empresa y (iv) analizar la planificación de largo plazo del proyecto de inversión.

- Por último, el Contrato de Supervisión Corporativa suscrito con ASA Iberoamérica S.L. tiene como objeto el proveer a ATS con servicios de asesoría y supervisión.

De esta manera, con estas vinculaciones se busca transmitir el know how de las afiliadas de ATS que cuentan con experiencia previa en el manejo de proyectos de inversión de este tipo.

\subsection{MATRIZ DE RIESGOS DEL PROYECTO DE INVERSIÓN}

Aparte de las fortalezas, también es necesario mencionar aquellos riesgos que pueden afectar la viabilidad del proyecto de inversión. A continuación, se presentará un resumen de aquellos riesgos que afectan directamente el desarrollo del proyecto de inversión de ATS. En el Anexo 2 se encuentra un detalle más elaborado de estos riesgos.

En la estructuración de la emisión, se trata de mitigar algunos de estos riesgos mediante la implementación de mecanismos en los distintos contratos de financiamiento. Sin embargo, no todos podrán ser mitigados, y por ello es importante que estos riesgos sean transmitidos al inversionista de manera clara mediante el Offering Memorandum para que los tome en cuenta al momento de tomar su decisión de inversión. 


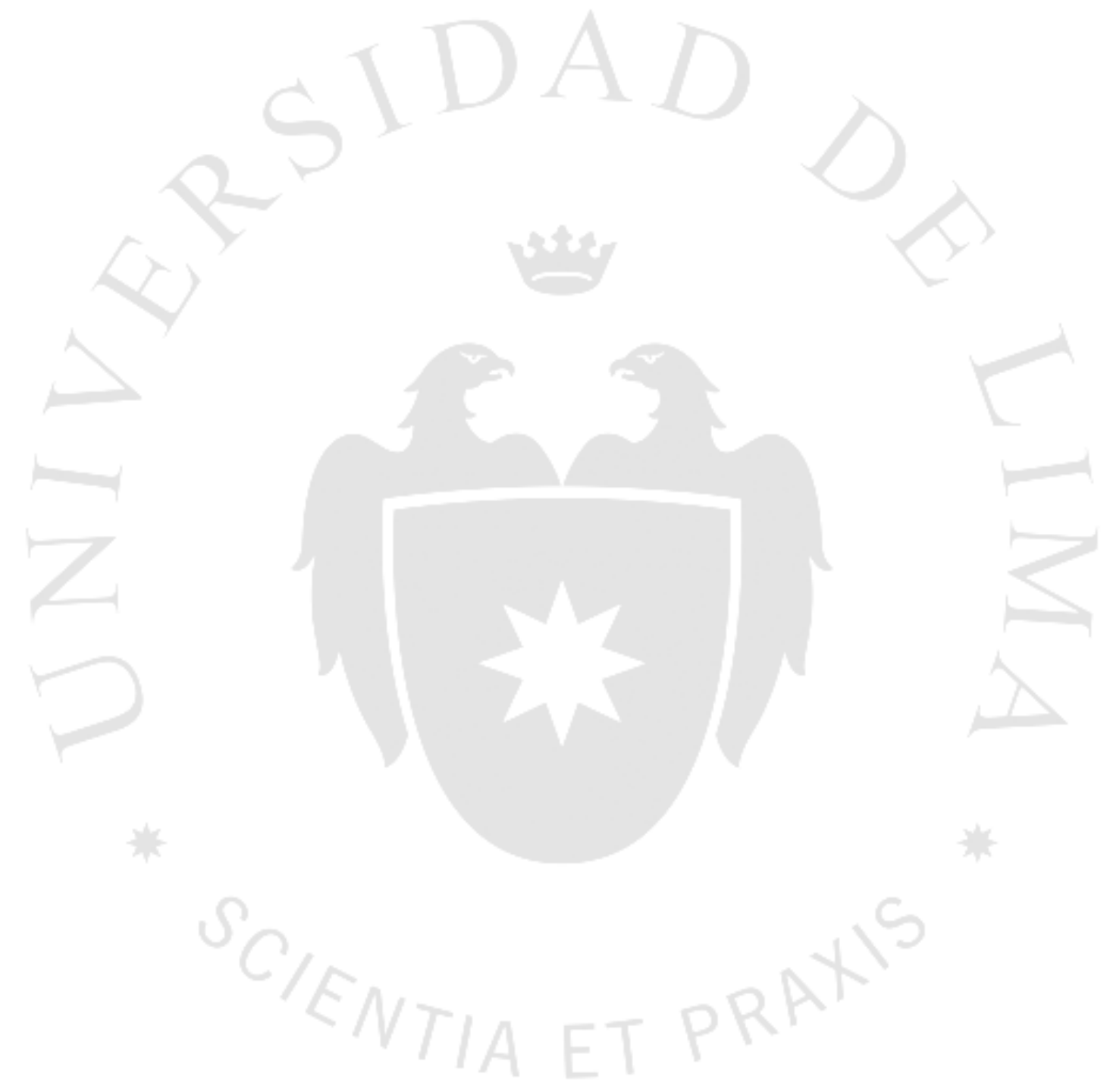


Tabla 2.5

\section{Matriz resumen de riesgos del proyecto de inversión}

\begin{tabular}{|c|c|}
\hline Riesgo & Consecuencia \\
\hline A. Riesgos de la Base Tarifaria & $\begin{array}{l}\text { - Riesgo de variaciones en la tasa de actualización del artículo } 79^{\circ} \text { de la LCE. Si la tas a fijada a la } \\
\text { fecha de cierre de } 12 \% \text {, sube, genera un costo de oportunidad para la empresa ya que tiene una } \\
\text { Base Tarifaria menor a la que tendría si la tasa fuese actualizable. } \\
\text { - Riesgo de inflación para la actualización del Costo de inversión y los Costos de OyM, ya que el } \\
\text { primer ajuste se realiza en la Puesta en Operación Comercial y no desde la Fecha de Cierre del } \\
\text { Contrato. }\end{array}$ \\
\hline \multicolumn{2}{|l|}{$\begin{array}{l}\text { B. Riesgos del Contrato de } \\
\text { Concesión }\end{array}$} \\
\hline Desequilibrio Económico & $\begin{array}{l}\text { - La redacción ambigua de la cláusula de Desequilibrio Económico podría impedir el derecho a } \\
\text { obtener el restablecimiento en aquellos supuestos que no se consideren cambios "explícitos" o } \\
\text { "exclusivos" a las Leyes Aplicables. } \\
\text { - Podría verse afectado los costos e ingresos dentro del período de } 2 \text { años luego de la POC sin } \\
\text { posibilidad de invocar el equilibrio económico-financiero. }\end{array}$ \\
\hline $\begin{array}{l}\text { Terminación del Contrato por } \\
\text { Expropiación de la línea de } \\
\text { transmisión y por } \\
\text { incumplimiento del Concedente }\end{array}$ & $\begin{array}{l}\text { - Monto de indemnización insuficiente para recuperar la inversión debido a los descuentos } \\
\text { realizados. }\end{array}$ \\
\hline $\begin{array}{l}\text { Resolución del Contrato por } \\
\text { culpa de la Sociedad } \\
\text { Concesionaria o el Operador } \\
\text { Técnico }\end{array}$ & $\begin{array}{l}\text { - La Sociedad Concesionaria tiene derecho al resultado de la licitación menos sus pasivos, hasta } \\
\text { por un monto equivalente al Valor Contable, el cual puede no ser suficiente. } \\
\text { - Prohibición para participar en proceso de promoción de la inversión privada a que se refiere el } \\
\text { Decreto Legis lativo } \mathrm{N}^{\circ} 674 \text {, el TUO o la Ley } \mathrm{N}^{\circ} 28059 \text {, Ley Marco de Promoción de la Inversión } \\
\text { Descentralizada. } \\
\text { - Riesgo de pago de indemnización al Estado por daño ulterior sin ninguna limitación. }\end{array}$ \\
\hline Destrucción Total & $\begin{array}{l}\text { - La definición de "Destrucción Total" de acuerdo con el Contrato es una situación producida por } \\
\text { cualquier causa que provoque daños a la Línea Eléctrica, estimados en cincuenta por ciento (50\%) o } \\
\text { más de su Valor Contable. } \\
\text { - En algunos caso la Destrucción Total imposibilita la reconstrucción y reanudación del servicio, se } \\
\text { recibirá el remanente del monto as egurado luego de pagar los pasivos de la Sociedad } \\
\text { Concesionaria, dicho monto puede ser insuficiente para recuperar la inversión. }\end{array}$ \\
\hline C. Riesgos de los Contratos EPC & $\begin{array}{l}\text { - El Contratista podría deicdir unilateralmente no mantener las garantías ofrecidas posteriores a la } \\
\text { entrega de las instalaciones. } \\
\text { - Los daños y perjuicios mayores al } 10 \% \text { del monto de los Contratos EPC no son asumidos por el } \\
\text { Contratista. }\end{array}$ \\
\hline $\begin{array}{l}\text { D. Riesgos de Operación y } \\
\text { Mantenimiento }\end{array}$ & $\begin{array}{l}\text { - En caso de indisponibilidad de la Línea de transmisión, la Sociedad Concesionaria será penalizada, } \\
\text { según se indica en las Directivas y Procedimientos de Osinergmin } \\
\text { - Se aplica una penalidad de USD 3M cuando exista: } \\
\text { Incumplimiento total o parcial, tardío o defectuoso de un Mandato de conexión por } \\
\text { Osinergmin o Autoridad Competente. } \\
\text { Actos de abuso de posición de dominio en el mercado eléctrico o que limitan, restrinjan o } \\
\text { distorsionen la libre competencia declarada por la Autoridad competente } \\
\text { - Se aplica la resolución del contrato en estos casos: } \\
\text { Dejar de operar la línea eléctrica, sin causa justificada, por } 180 \text { horas, continua o no, en un año } \\
\text { Persistencia en el incumplimiento de prestación del servicio en los plazos y según las normas } \\
\text { técnicas y de seguridad y estándares de calidad, tras la sanción administrativa de Osinergmin } \\
\text { - Incrementos en el Costo de Operación y Mantenimiento respecto del considerado en el modelo } \\
\text { financiero pueden causar un menor retorno. }\end{array}$ \\
\hline $\begin{array}{l}\text { E. Riesgos Macroeconómicos, } \\
\text { legales y ambientales de Perú }\end{array}$ & $\begin{array}{l}\text { - Cambios en la política macroeconómica del Gobierno de Péru (en cuanto a política monetaria, } \\
\text { fiscales, tributaria, etc) pueden afectar la Base Tarifaria y costos del proyecto. } \\
\text { - La pérdida de los permisos ambientales y arqueológicos (Estudio de Impacto Ambiental, } \\
\text { Certificado de Inexistencia de Restos Arqueológicos) puede provocar la pérdida de la concesión. } \\
\text { - El incumplimiento en las regulaciones medioambientales pueden generar multas y descontento } \\
\text { social. }\end{array}$ \\
\hline
\end{tabular}

Fuente: Offering Memorandum (2014); Contrato de Concesión (2010). Elaboración propia. 


\subsection{ESTRUCTURACIÓN DE LA EMISIÓN}

El Bono 144A/Reg S de ATS fue emitido principalmente para refinanciar un préstamo bancario sindicado por 341 millones de dólares aproximadamente. El refinanciamiento era necesario debido a que el préstamo sindicado tenía una vida de 7 años lo que aceleraba el plazo de repago y amenazaba seriamente con afectar la caja de la empresa que recién se encontraba en la fase de operación cuando el préstamo ya iba en la mitad de su plazo. Es así que se decide realizar la emisión, puesto que la empresa necesitaba de manera urgente extender su plazo de financiamiento. Además, alentó a la empresa saber que existía apetito del mercado respecto a estructuras Project Finance cuando en el año 2013, una empresa competidora directa emitió bonos en el mercado internacional por USD 450,000,000 a un plazo de 10 años y a una tasa de 4,38\%. Por otro lado, en el año 2012 se dio el mayor monto de emisión de bonos hasta esa fecha por la concesionaria Línea Amarilla por USD 439,000,000 con un plazo de 25 años. De esta manera, el mercado lucía propicio para realizar una emisión del proyecto ATS, cuyo riesgo de construcción ya estaba reducido al mínimo al tener más del 99\% de la línea eléctrica y subestaciones en operación.

La decisión de realizar una emisión privada para este bono fue por la leve necesidad de revelación de información exigida, lo cual era muy importante para la empresa por un tema de confidencialidad requerido por la matriz. A pesar de que Abengoa en Perú no contaba con experiencia previa en la estructuración de bonos 144A/Reg. S, fue en base al consejo del estructurador que se decidió emitir bajo este formato de emisión privada debido a la necesidad de fondeo de la empresa, que era bastante alto para lo que se suele recaudar en otros formatos de emisiones privadas. Si bien los costos de estructuración bajo este formato pueden ser más altos que otros tipos de emisiones privadas, la combinación de un bono 144A con la Regulación S, permite ampliar la base de inversionistas y recibir mayores ofertas y por tanto, mejores precios para un bono de esta magnitud. La obtención de una tasa cupón menor gracias a la liquidez del 144A/Reg S, al fin y al cabo, compensa los costos de estructuración adicionales incurridos.

Por estas principales razones, se decidió realizar la emisión del bono del proyecto de inversión ATS. Se adentrará en mayor de detalle de las condiciones de la emisión en las secciones siguientes. 
En las siguientes secciones entraremos a describir la estructuración de la emisión del Bono 144A/Reg. S de Abengoa Transmisión Sur. Primero se describirán las entidades involucradas en este proceso de financiamiento para tener un panorama completo de la estructuración.

\subsubsection{Participantes del Bono 144A/Reg. S de ATS}

Dentro de la estructuración de un financiamiento tipo Project Finance también existen varios participantes involucrados que desempeñan una función especial para asegurar el funcionamiento óptimo del bono. En la Figura 2.7 se puede apreciar aquellas entidades que, a la fecha de la emisión, desempeñaron algún rol bajo los diversos contratos de financiamiento implicados en la emisión del bono.

A continuación, se explicará el rol de cada participante y se explicará brevemente los contratos bajo los que se regula su desempeño:

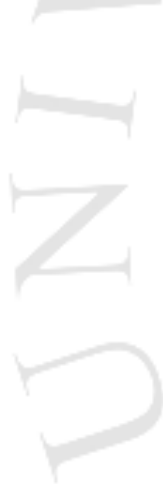


Figura 2.7

Participantes del Bono 144A/Reg S de ATS

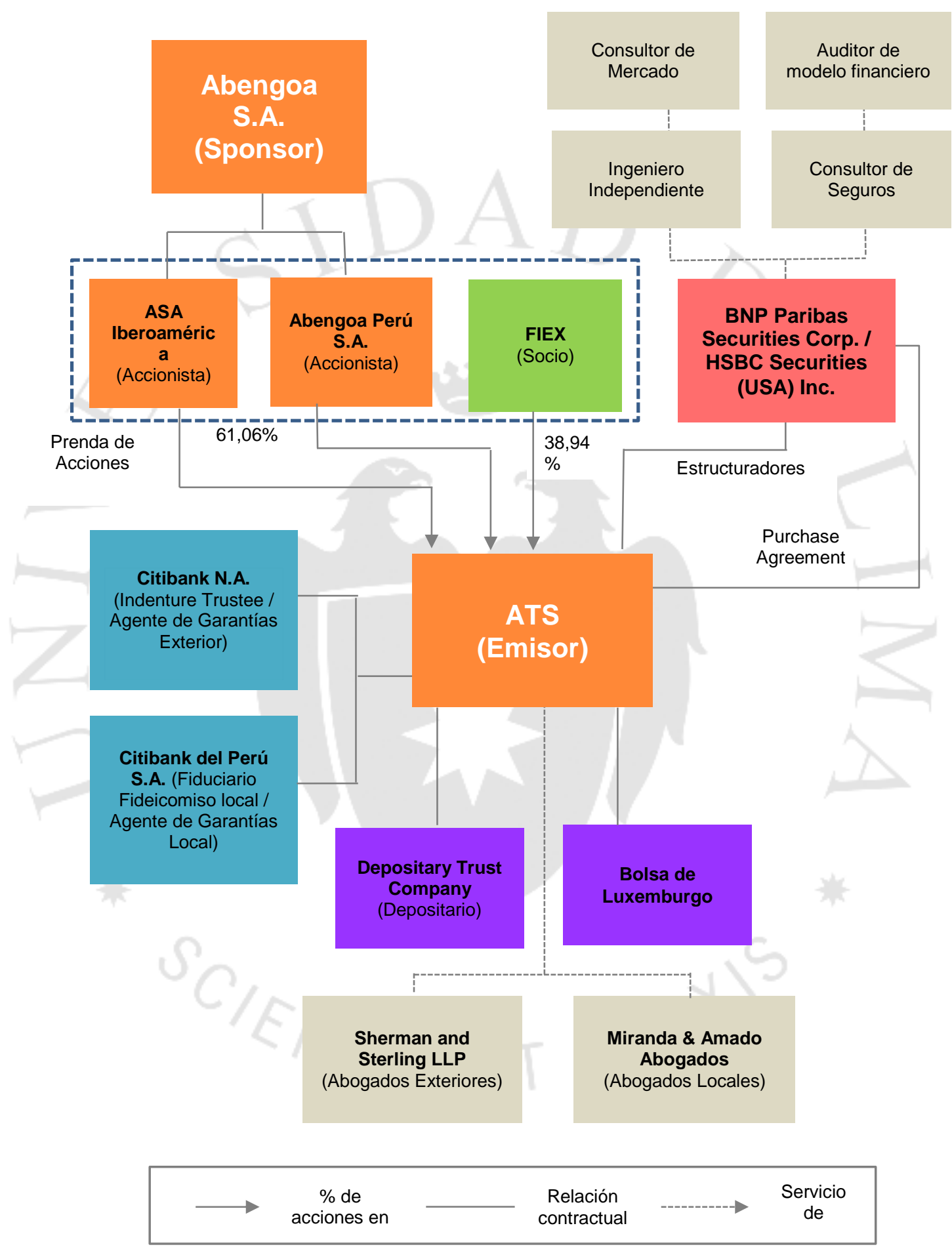

Fuente: Offering Memorandum (2014). Elaboración propia. 
- Emisor: Abengoa Transmisión Sur S.A. es la empresa emisora de los bonos y responsable frente a los bonistas de las obligaciones que debe cumplir según los distintos contratos firmados en el esquema de este financiamiento.

- Estructuradores: BNP Paribas Securities Corp. y HSBC Securities (USA) Inc. fueron los bancos de inversión encargados de la estructuración del Bono 144A/Reg. S de ATS. Dentro de sus funciones están: (i) su participación en la negociación de los contratos, (ii) la elaboración del Offering Memorandum, (iii) la preparación y asesoría para cumplir los requerimientos necesarios del formato de la Regla 144A/Reg. S y del listado en la Bolsa de Luxemburgo, (iv) publicidad y promoción del bono al mercado objetivo, (v) sondeo del mercado para el pricing del bono, (vi) entre otras funciones afines.

- Compradores Iniciales (Initial Purchasers): Mediante el Contrato de Purchase Agreement, los estructuradores se comprometen a comprar la emisión de los bonos emitidos por USD 432,000,000. Asimismo, se le permite a los Compradores Iniciales revender los bonos en el mercado secundario en cualquier momento luego de la firma de este contrato, siempre tomando en cuenta que este bono no está registrado bajo la SEC por lo que la reventa se rige bajo las excepciones otorgadas por la Regla 144A y la Regulación S.

- Fiduciarios y Agentes de Garantías: El Indenture Trustee es el fiduciario encargado de administrar la operatividad de la emisión y velar que las obligaciones que tiene el emisor frente a los bonistas bajo el Indenture y los contratos de garantías relacionados a este, sean cumplidas. En este caso, el Indenture Trustee es Citibank N.A; asimismo, bajo esta emisión, se le otorgaron a Citibank N.A. otros cargos como Agente de Garantías Exterior. El Agente de Garantías Exterior (Offshore Collateral Agent) es aquella entidad que mantiene y administra las garantías constituidas fuera del Perú y que toma todas las acciones sobre el colateral en beneficio de los bonistas. Entre los contratos que administra Citibank N.A. como Agente de Garantías Exterior, están el Senior Offshore Security Agreement, el Contrato de Garantías y Cuentas (Collateral 
and Accounts Agreement) y el Contrato de Apoyo de los Promotores (Sponsor Support and Cash Contribution Agreement).

Por otro lado, Citibank del Perú S.A., actúa como Fiduciario del Fideicomiso de Flujos local y Agente de Garantías Local (Onshore Collateral Agent), por lo que se encarga de administrar las garantías constituidas en Perú, de acuerdo a los contratos de garantías exteriores y bajo las instrucciones de Citibank N.A. como Indenture Trustee. Entre los contratos que Citibank del Perú se desempeña como Agente de Garantías local están la Prenda de Acciones de Abengoa (Senior Onshore Abengoa Share Pledge), Prenda de Acciones de FIEX (the Onshore FIEX Share Pledge), el Contrato de Fideicomiso de Flujos local (Peruvian Cash Flow Trust Agreement) y el Contrato de Hipoteca de la Concesión (Senior Concession Mortgage Agreement).

- Accionistas: Los accionistas directos de ATS, a la fecha de emisión, eran ASA Iberoamérica, Abengoa Perú y FIEX. Las acciones de los tres accionistas fueron entregadas en prenda bajo los contratos mencionados en el punto anterior. Por otro lado, Abengoa S.A. como promotor del proyecto de inversión, es partícipe, junto con los accionistas directos, en el Contrato de Apoyo de los Promotores (Sponsor Support and Cash Contribution Agreement). Bajo este contrato, el Sponsor asume la obligación de fondear potenciales sobrecostos del proyecto de inversión, cubrir falta de fondos para el primer servicio de deuda, cubrir aumentos de costos por adendas a los Contratos EPC, asegurar que se mantengan las garantías de los Contratos EPC, y por último, causar la culminación de los trabajos sobre la segunda barra en la Subestación Montalvo.

- El Depositary Trust Company o DTC es una organización que actúa como depositario de los bonos en forma física y que irá realizando las actividades de compensación y liquidación de las transferencias de los bonos mediante registros electrónicos. En este bono, DTC actúa también a través de otros sistemas de liquidación llamados Euroclear y Clearstream.

- Auditor Independiente: Es el encargado de la auditoría de los estados financieros de la empresa y la emisión del Comfort Letter requerido por los 
Compradores iniciales. En este caso es la empresa Beltrán, Gris y Asociados S. Civil de R.L., una firma miembro de Deloitte Touche Tohmatsu Limited.

- La Bolsa de Luxemburgo es el mercado escogido para el intercambio de los valores de ATS. Dentro de esta plaza, existen dos mercados: El Euro MTF y el Mercado Regulado. El bono de ATS se encuentra inscrito en el Euro MTF y la razón es que este mercado está dirigido a aquellos emisores que no desean tener muchas obligaciones de reporte o realizar una amplia revelación de información. Este mercado por tanto, es perfecto para ofertas privadas.

- Asesores o Consultores: Como el desarrollo del proyecto de inversión es complejo y se necesita la ayuda de diversos especialistas para poder llevarlo a cabo, el Estructurador para la estructuración de la emisión necesita el apoyo de asesores o consultores que le ayuden a evaluar la viabilidad y buen funcionamiento del proyecto en sus distintos aspectos. Posteriormente a la fecha de emisión, algunos de estos consultores brindarán sus servicios al Indenture Trustee. Es así que se contrataron a cuatro empresas para apoyar en dichas tareas:

1. Sargent \& Lundy L.L.C como Ingeniero Independiente. Fue la empresa encargada de preparar el Reporte de Evaluación Técnica de las instalaciones del proyecto, evaluando de esta manera que la línea eléctrica haya sido construida con los debidos estándares de calidad, con diseños de ingeniería viables y que los costos de la construcción se encuentren dentro de los parámetros del mercado.

Por otro lado, su función como Ingeniero Independiente se mantiene durante la vida del bono bajo el Indenture y la eventual necesidad de su asesoría en temas técnicos definidos bajo dicho contrato.

2. Estudios Energéticos Consultores S.A. como Consultor de Mercado. Realizó el Reporte sobre el Mercado Eléctrico Peruano y la viabilidad del proyecto considerando la evolución de dicho mercado y el esquema del SGT.

3. Weiser Mazars LLP como el Auditor del Modelo Financiero, el cual se encargó de certificar que el modelo financiero funciona adecuadamente, 
cumple lo especificado en los documentos del financiamiento y del proyecto, asume supuestos tributarios correctos y que los resultados y proyecciones de este sean fiables.

4. El Consultor de Seguros de los Estructuradores fue Marsh S.A. Sus servicios consistían en analizar los riesgos que pudieran afectar a ATS, así como la posibilidad de asegurar dichos riesgos, identificando algunas de las restricciones del mercado de seguros que limitan la cobertura de las pólizas.

En el numeral 4) de esta sección, se realizará una explicación más meticulosa sobre los principales contratos de este financiamiento.

\subsubsection{Principales Términos Financieros del Bono 144A/Reg. S}

A continuación se presentan los principales términos financieros de la emisión en la Tabla 2.6. Esta sección tratará de resumir aquellas características financieras más relevantes del bono para realizar un primer acercamiento.

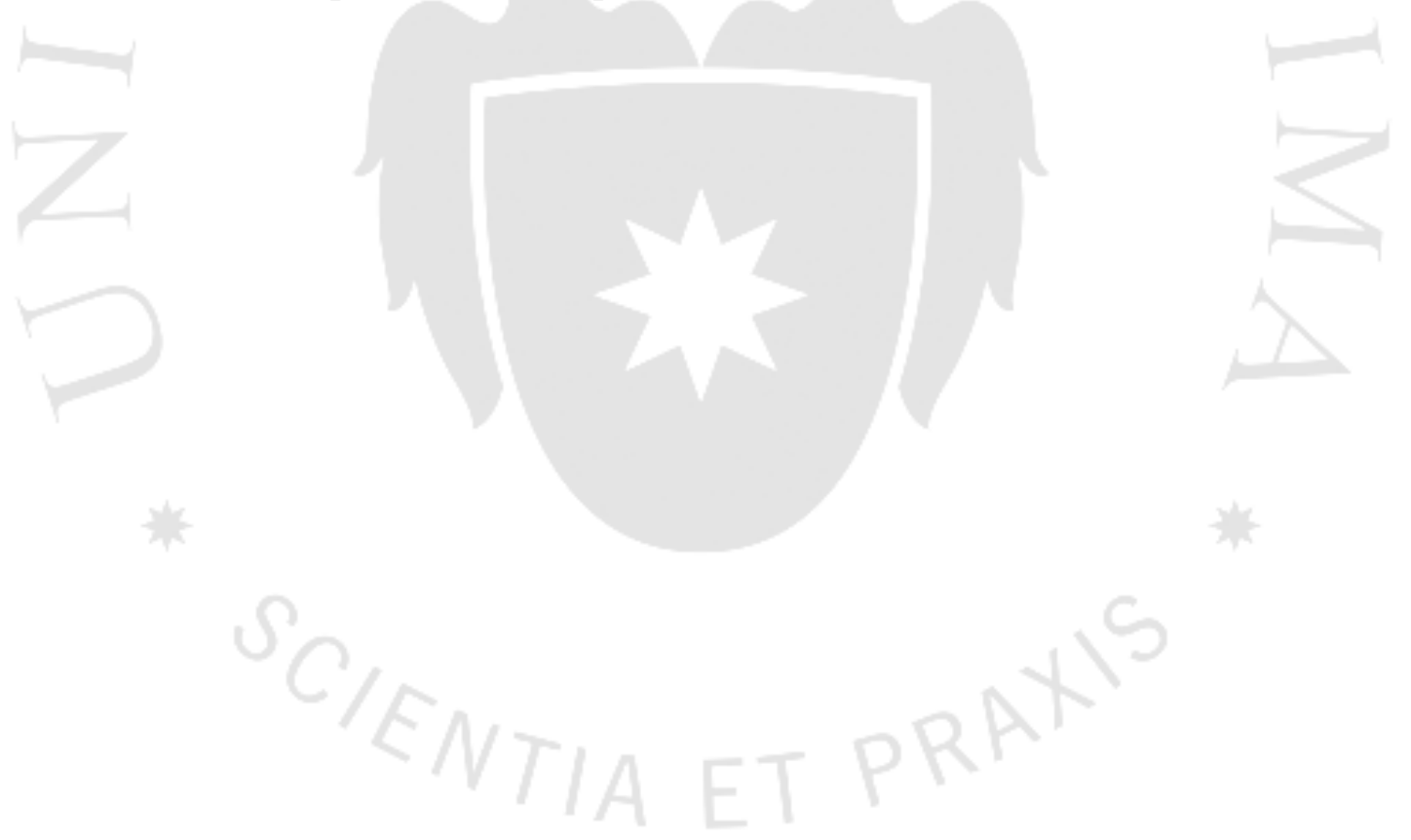


Principales términos financieros de la emisión

\begin{tabular}{|l|}
\hline Emisor \\
\hline Emisión \\
\hline Vencimiento \\
\hline Formato, Listado \\
\hline Denominación Mínima \\
\hline Ley Aplicable \\
\hline Amortización \\
\hline Ratings de emisión \\
\hline Garantías \\
\hline Uso de fondos \\
\hline Cuentas de Reserva \\
\hline Conjucturador \\
\hline
\end{tabular}

Abengoa Transmision Sur S.A. (“ATS”)

USD 432,000,000 Senior Secured Notes due 2043

Abril 2043 (29 años)

144A / Reg S, Euro MTF Market de la Bolsa de Luxemburgo USD 200,000

Leyes de Nueva York

Amortización a la medida (comienza en Octubre 2016 y se paga semestralmente, con retención de exceso de flujo de caja en los últimos 5 años).

BBB- (Estable) por S\&P / BBB- (Estable) por Fitch

Garantía de primer rango sobre los bienes de la concesión, derechos de cobro y flujos bajo contrato y Garantía Mobiliaria sobre acciones del emisor y cuentas bancarias.

1. Prepagar el préstamo bancario sindicado por USD 344.6M y los swaps de tasa de interés relacionados.

2. Fondear la Cuenta de Reserva del Servicio de Deuda (USD 15.6 millones) y la Cuenta de Reserva de O\&M (USD 2.4 millones).

3. Pagar comisiones y gastos generados por la emisión y el prepago del préstamo sindicado (USD 8.2 millones).

4. Prepagar una porción de deuda subordinada de empresas relacionadas (USD 59.8 millones)

Sujeto a una Prima Make Whole (Tasa Bono comparable del Tesoro EUA + 50bps)

El Sponsor debe mantener (i) durante los 2 primero años más del $50 \%$ de las acciones con derecho a voto, y luego de ese período, más del 35\% de las acciones con derecho a voto y (ii) el control operacional diario del proyecto ATS.

Cuenta de Reserva de Servicio de Deuda equivalente a 6 meses. Cuenta de Reserva de O\&M equivalente a 6 meses.

BNP Paribas, HSBC Securities

Fuente: Offering Memorandum (2014). Elaboración Propia.

En el día de la emisión, que fue el 16 de abril de 2014, el Emisor y el Fiduciario de los Bonos, celebraron el Indenture bajo el cual ATS emitió los bonos. Estos bonos constituyen deuda no subordinada, con rango senior en prioridad de pago frente a otras deudas actuales del emisor, frente a garantías ofrecidas, y frente a cualquier deuda subordinada futura o presente del emisor. Sin embargo, tendrá prelación pari passu ${ }^{16}$ frente a otras deudas (no subordinadas) con las que se vea obligada ATS en el futuro. El Indenture y los demás documentos relacionados a este financiamiento (salvo los que constituyen garantías en Perú), estarán gobernados bajo las leyes de Nueva York.

\footnotetext{
${ }^{16}$ Es una frase en latín utilizada para establecer en un contrato financiero que las obligaciones de un emisor conservarán los mismos derechos y obligaciones en relación con otras deudas similares del mismo emisor.
} 
El pago de principal e intereses está establecido en un cronograma de pagos semestral. El pago de intereses comienza desde el 31 de octubre de 2014, mientras que la amortización de capital comienza desde el 31 de octubre de 2016, por lo que este bono goza de 2 años de gracia al pago de principal. El cronograma termina el 30 de abril de 2043, con el vencimiento del bono. La amortización de este bono fue hecha a la medida (tailor-made) de tal manera que la predictibilidad de los flujos disponibles para el pago de servicio de deuda se estabilice durante los 2 primeros años de entrada en operación comercial del proyecto.

Usualmente, en los bonos del formato 144A/Reg. S, se exige la clasificación de rating por dos agencias clasificadoras. En el caso de ATS, las agencias elegidas para la realización de la evaluación de rating fueron Fitch Ratings y Standard and Poor's. Ambas le asignaron a este bono la calificación de BBB-, rating que se mantiene hasta la actualidad $^{17}$.

Las garantías del presente bono son diversas y de distinta naturaleza para poder cubrir cada aspecto de los riesgos previamente discutidos del proyecto de inversión. Estas se especificarán en la siguiente sección.

Otra forma de garantizar el pago del servicio de deuda establecido bajo el cronograma de pagos, es mediante la constitución de cuentas de reserva. Generalmente, las cuentas de reserva son aquellas cuentas abiertas en un banco designado o en una cuenta bajo domino fiduciario, fondeadas con un monto de dinero, las cuales, en el caso de falta de pago del emisor, serán utilizadas para cubrir el servicio de deuda comprometido. En el caso del bono de ATS, las cuentas de reserva constituidas son dos: Cuenta de Reserva de Servicio de Deuda y Cuenta de Reserva de Operación \& Mantenimiento. Al tratarse el bono en estudio de un Project Finance, las cuentas de reservas no sólo se constituyen para resguardar a los bonistas en el caso de un déficit de flujos que impida el cumplimiento del pago de la deuda, sino también en el caso de que los flujos no sean suficientes para poder continuar con la operación del proyecto, lo que causaría en última instancia, el cese de cualquier flujo para cubrir costos y gastos de toda naturaleza. El monto que se debe mantener en la cuenta de Reserva de Servicio de Deuda es equivalente al próximo pago de intereses y principal aplicables, según el

\footnotetext{
${ }^{17}$ En el caso de Fitch, la última revisión de rating es a 21 de junio de 2015, mientras que de S\&P es al 9 de setiembre 2015
} 
cronograma de pagos. El monto a mantener en la Cuenta de Reserva de O\&M debe ser equivalente a los costos operativos presupuestados semestrales.

Este bono le brinda la opción al emisor de realizar una redención parcial o total pagando un precio de redención igual a (a) $100 \%$ del monto de principal de los bonos a ser redimidos, más (b) el interés devengado y no pagado, más (c) montos adicionales a ser pagados a los bonistas por temas de impuestos, más (d) una prima Make-Whole. La Prima Make-Whole es el monto equivalente a la resta de (a) la suma del valor presente del interés y principal pendiente de pago a la tasa de un bono de tesoro de EUA comparable al presente bono más 50 pbs, sobre el (b) el monto del principal de los bonos a ser redimidos. Hay otras situaciones donde se permite la redención de los bonos que serán comentadas más adelante.

Por último, el cambio de control, regulado en el Contrato de Apoyo de los Promotores regula las disposiciones que los accionistas de la sociedad concesionaria deben cumplir en cuanto a su posesión accionarial.

En el numeral 4 de esta sección se detallarán los términos financieros del bono.

\subsubsection{Análisis financiero de la sociedad concesionaria ATS}

De manera previa a la descripción detallada de los documentos involucrados en este financiamiento, es importante realizar un análisis financiero de las cifras usadas para la estructuración del bono.

A continuación se presenta el Estado de Resultados y el Balance General de la empresa para los años 2013 y 2012, en base a los estados financieros auditados preparados de acuerdo a las normas del International Financial Reporting Standard (IFRS).

El Estado de Resultados del emisor a los años 2013 y 2012, refleja la nulidad de ingresos operativos debido a que la línea inició su operación en enero de 2014. Por lo mismo, tampoco presenta costos operativos. Como se puede apreciar, la única fuente de ingresos de la sociedad concesionaria es de origen especulativo y proviene de la cobertura de swap para la tasa de interés del préstamo sindicado que mantenía la empresa hasta el 2013. 
En el plazo posterior al año 2013, la fuente de ingresos de la sociedad concesionaria provendrá de la operación del proyecto de inversión. Desde la Puesta en Operación Comercial se comenzó a devengar la Base Tarifaria, la cual se paga al mes siguiente del mes del servicio efectivo. Además, como se explicó anteriormente, la sociedad concesionaria también puede generar ingresos del usufructo de la fibra óptica instalada en la línea eléctrica. Los costos operativos provendrán principalmente del Contrato de O\&M, la comisión de 1\% anual pagable a OSINERGMIN y al MINEM y una pequeña porción del Contrato de Servicios Administrativos (1\% Base Tarifaria), por lo que se espera sean relativamente bajos durante la vida del proyecto. Los gastos administrativos provendrán principalmente del Contrato de Gerenciamiento y otros gastos relacionados a alquileres, servicios, entre otros.

Tabla 2.7

Estado de Resultados

\begin{tabular}{lrr} 
Al31 de Diciembre de & 2013 & 2012 \\
& En miles de dólares \\
Gastos pre-operativos, administrativos y generales & -563 & -840 \\
Gastos/Ingresos Financieros Netos & 39 & 3 \\
Diferencia por Cambio Neta & -414 & 139 \\
\hline Pérdidas antes de impuestos & -938 & -698 \\
Impuesto a la Renta & 266 & 288 \\
\hline Pérdida del período & -672 & -410 \\
\hline Variaciones por derivados financieros & 18,380 & $-13,805$ \\
Impuesto a la Renta reclasificado & $-5,514$ & 4,142 \\
\hline Otros Ingresos/Egresos & 12,866 & $-9,663$ \\
\hline Pérdida/Ganancia del Período & 12,194 & $-10,073$ \\
\hline
\end{tabular}

Fuente: Offering Memorandum (2014). p. 53 
Tabla 2.8

Balance General

\begin{tabular}{|c|c|c|c|c|c|}
\hline & 2013 & 2012 & & 2013 & 2012 \\
\hline & \multicolumn{2}{|c|}{ En miles de dólares } & & \multicolumn{2}{|c|}{ En miles de dólares } \\
\hline Activos Corrientes & & & Pasivos Corrientes & & \\
\hline Efectivo y equivalentes de efectivo & 70,224 & 49,946 & Obligaciones garantizadas & 9,721 & - \\
\hline Anticipos otorgados a terceros & 443 & 1,815 & Cuentas por Pagar & 67,810 & 31,166 \\
\hline Anticipos otorgados a relacionadas & 473 & 31,356 & Cuentas por Pagar a relacionadas & 1,529 & 1,341 \\
\hline Crédito Fiscal parte corriente & 8,230 & 20,583 & Impuestos por pagar & - & 48 \\
\hline Cuentas por cobrar a relacionadas & 10 & 21 & Otras cuentas por pagar & 60 & 242 \\
\hline Otras cuentas por cobrar & 391 & 2 & Total Pasivos Corrientes & 79,120 & 32,797 \\
\hline Gastos prepagados & 699 & 738 & & & \\
\hline \multirow[t]{3}{*}{ Total Activos Corrientes } & 80,470 & 104,461 & Pasivos No Corrientes & & \\
\hline & & & Obligaciones garantizadas & 305,930 & 271,527 \\
\hline & & & Intrumentos financieros derivados & 962 & 17,015 \\
\hline Activos No Corrientes & & & Deuda subordinada de largo plazo & 146,715 & 84,053 \\
\hline Activos Intangibles & 510,700 & 344,802 & Total Pasivos No Corrientes & 453,607 & 372,595 \\
\hline Crédito Fiscal & 9,744 & 6,870 & & & \\
\hline Muebles y Equipos & 9 & 13 & $\underline{\text { Total Pasivos }}$ & $\mathbf{5 3 2 , 7 2 7}$ & 405,392 \\
\hline Impuesto Diferido & 4,581 & 9,829 & & & \\
\hline \multirow[t]{5}{*}{ Total Activos No Corrientes } & 525,034 & 361,514 & Patrimonio & & \\
\hline & & & Capital Social & 82,989 & 82,989 \\
\hline & & & Otras reservas & $(8,817)$ & $(21,683)$ \\
\hline & & & Resultado Acumulados & $(1,395)$ & (723) \\
\hline & & & Total Patrimonio & $\mathbf{7 2 , 7 7 7}$ & 60,583 \\
\hline Total Activos & 605,504 & 465,975 & Total Pasivos y Patrimonio & 605,504 & 465,975 \\
\hline
\end{tabular}

Fuente: Offering Memorandum (2014). p. 54

En cuanto al balance general, podemos apreciar la inexistencia de cuentas por cobrar comerciales debido a que al cierre del año 2013, la sociedad concesionaria no se encontraba en operación. A pesar de lo anterior, se puede apreciar que la empresa contaba con efectivo y equivalentes de efectivo de montos importantes, pero tiene que ser tomado en cuenta que este monto se explica casi en su totalidad por cuentas en garantía que debía mantener como obligaciones bajo el préstamo sindicado y por una línea de confirming para pago a proveedores. Por lo tanto, el efectivo en esas cuentas era prácticamente inmobilizable para otros propósitos diferentes a los de garantizar obligaciones.

El crédito fiscal tanto corriente como no corriente es explicado por el IGV de compras relacionadas a los bienes y servicios para la construcción y operación de la línea de transmisión que se devuelve anticipadamente a la sociedad concesionaria al gozar del régimen de recuperación anticipada de $\mathrm{IGV}^{18}$.

${ }^{18}$ Consiste en la devolución del IGV que gravó las importaciones y/o adquisiciones locales de bienes de
capital nuevos, bienes intermedios nuevos, servicios y contratos de construcción; realizados en la etapa
preproductiva de un proyecto (por un monto de ejecución mayor a $\$ 5 \mathrm{MM}$ ), a ser empleados por los
beneficiarios del régimen directamente para la ejecución del proyecto previsto en el Contrato de 
Por otro lado, podemos apreciar que la cuenta más significativa del rubro Activos es la de Activos Intangibles. Esta cuenta es la que registra los contratos de concesión con el gobierno peruano, bajo la adopción de la CINIIF 12 - Contratos de Concesión. Para aplicar esta norma, el contrato de concesión debe cumplir algunos criterios como:

- El Concedente controla o regula qué servicios debe proporcionar la sociedad con la infraestructura, a quién debe suministrarlos y a qué precio (la Base Tarifaria en este caso ya está predefinida).

- No hay garantías incondicionales brindadas por el Concedente para asegurar el pago de la Base Tarifaria por lo que riesgo comercial es asumido por ATS y su capacidad de mantener operativa la línea.

Por lo tanto, el activo intangible representa el derecho otorgado por el Estado para efectuar cargos a los usuarios del servicio de transmisión de energía eléctrica. Mientras progresa la construcción del proyecto, se realizan adiciones al activo intangible debido a que se espera que generen beneficios económicos futuros para el concesionario. El Activo Intangible se comenzará a amortizar (método de línea recta) desde la fecha de la puesta en operación comercial hasta el fin de la concesión, lo cual se verá reflejado también en el Estado de Resultados.

En cuanto a los Pasivos, una de las cuentas más representativas del balance es la de Cuentas por Pagar, que incluyen los montos adeudados a los proveedores de bienes y servicios para la construcción del proyecto. Dicha cuenta irá disminuyendo a un monto mucho menor conforme se sanee el pago a proveedores y se entre en la etapa de operación. La otra cuenta importante del pasivo son las Obligaciones Garantizadas corriente y no corriente. Ambas partes están explicadas por el saldo desembolsado a dicha fecha del préstamo sindicado (posteriormente en enero de 2014, se desembolsó la totalidad de los USD 341MM del préstamo). Finalmente, la cuenta de Deuda Subordinada de Largo Plazo refleja la deuda subordinada que mantenía ATS con Abengoa Perú por USD 146MM la cual, según contrato, no contaba con una fecha de madurez.

Inversión correspondiente y que se destinen a la realización de operaciones gravadas con el IGV o a exportaciones. (Proinversión, Régimen de Recuperación Anticipada del IGV) 
Por otro lado, el capital social suscrito a la fecha en evaluación era de S/. 217,058,975, equivalente en dólares a USD 82,989 (en miles). La cuenta Otras Reservas recoge los cambios en el valor razonable de los contratos de swap vigentes a esa fecha. Por último, la cuenta de Resultados Acumulados refleja las pérdidas arrastradas por la empresa a través de toda su etapa pre-operativa. Esta servirá para compensar el impuesto a la renta de tercera categoría que estará obligada a pagar por los resultados positivos que genere en su etapa de operación.

Dada esta imagen de los estados financieros de ATS antes de la puesta en operación comercial, se observa que no arroja historial operativo alguno del proyecto de inversión, ni el efecto de la emisión de bonos (usado para la cancelación del préstamo sindicado y una porción de la deuda subordinada con Abengoa Perú). Por ello, fue bastante importante transmitir a los potenciales bonistas las fortalezas de la estructura subyacente al bono (descritos en el numeral 1) de este capítulo) y también las fortalezas financieras de la estructuración de la deuda. Asimismo, también fueron de gran relevancia las proyecciones de ingresos y costos operativos para determinar el flujo de caja disponible para el pago del servicio de deuda, las cuales fueron obtenidas gracias al modelo financiero aplicado desarrollado por los Estructuradores.

\subsubsection{Principales documentos y garantías}

El preámbulo del primer capítulo y las secciones anteriores del capítulo actual, han servido para que el lector se familiarice con el proyecto de inversión y entienda su funcionamiento en cada nivel, ya sea contractual, operativo o financiero; asimismo, ha introducido brevemente el esquema de financiamiento del bono en estudio. Sin embargo, en la presente sección se explicará minuciosamente los contratos principales en los que se sustenta la emisión del bono 144A/Reg. S de ATS.

Describir la naturaleza de los documentos del financiamiento y sus garantías, definirá de manera clara la estructuración de este bono y los ejes que sustentan el financiamiento. Para esto, es también necesario conocer el rol de modelo financiero aplicado a la emisión y el de las agencias de rating.

Antes de entrar al detalle de los principales contrato, en la Tabla 2.9 se presentan la totalidad de los contratos celebrados según el Offering Memorandum (2014) para perfeccionar la estructuración del bono y una breve descripción de la naturaleza de cada uno. 


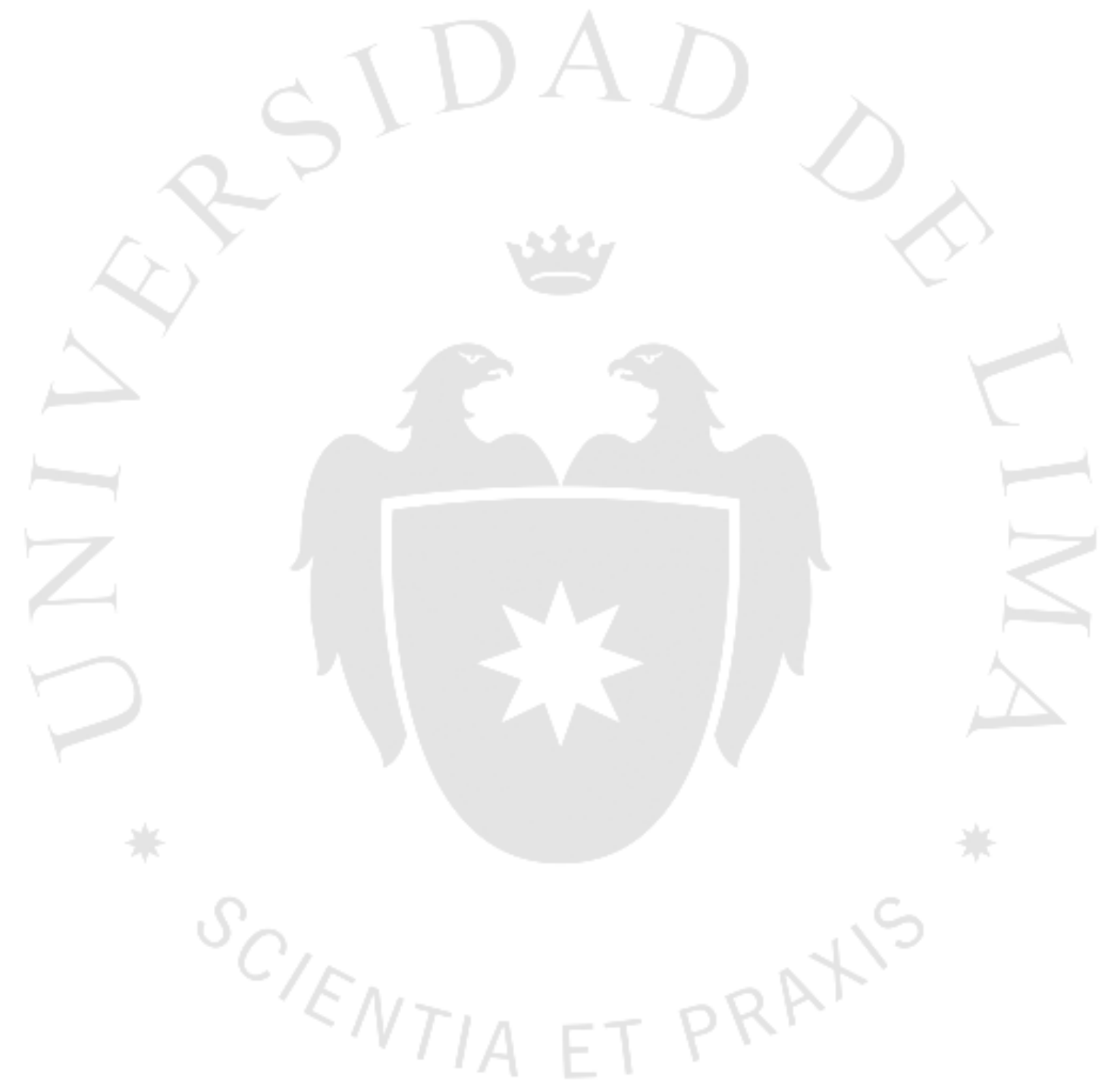


Tabla 2.9

\section{Listado de los documentos del bono de ATS}

\begin{tabular}{|c|c|c|}
\hline \multicolumn{3}{|c|}{ Contrato y Documentos del Bono 144A/Reg. S de Abengoa Transmisión Sur } \\
\hline Documento & Partes involucradas & Breve descripción \\
\hline \multicolumn{3}{|c|}{ Contratos del Financiamiento } \\
\hline Indenture & $\begin{array}{l}\text { - Emisor: ATS } \\
\text { - Indenture Trustee, Registrador, } \\
\text { Agente de Pago y Transferencia: } \\
\text { Citibank N.A. }\end{array}$ & $\begin{array}{l}\text { Contrato bajo el cual se realiza la } \\
\text { emisión y regula el funcionamiento } \\
\text { del pago de la deuda así como los } \\
\text { términos y obligaciones de las } \\
\text { partes. }\end{array}$ \\
\hline $\begin{array}{l}\text { Contrato de Apoyo } \\
\text { del Promotor }\end{array}$ & $\begin{array}{l}\text { - Sponsor: Abengoa S.A. } \\
\text { - Accionistas Abengoa: ASA } \\
\text { Iberoamérica S.L. y Abengoa Perú } \\
\text { - Accionista: FIEX } \\
\text { - Emisor: ATS } \\
\text { - Indenture Trustee, Agente Facilador } \\
\text { de Deuda Subordinada y Agente de } \\
\text { Garantías Exterior: Citibank N.A. } \\
\text { - Prestamistas de deuda subordinada } \\
\text { de afiliadas }\end{array}$ & $\begin{array}{l}\text { Contrato que establece la } \\
\text { responsabilidad del Sponsor y } \\
\text { Accionistas Abengoa de fondear } \\
\text { potenciales sobrecostos, cubrir falta } \\
\text { de fondos para el primer servicio de } \\
\text { deuda y asegurar que se mantengan } \\
\text { las garantías de los Contratos EPC }\end{array}$ \\
\hline $\begin{array}{l}\text { Abengoa Perú } \\
\text { Subordination } \\
\text { Agreement }\end{array}$ & $\begin{array}{l}\text { - Prestamista: Abengoa Perú } \\
\text { - Emisor: ATS } \\
\text { - Indenture Trustee, Agente Facilador } \\
\text { de Deuda Subordinada y Agente de } \\
\text { Garantías Exterior: Citibank N.A. }\end{array}$ & $\begin{array}{l}\text { Contrato de deuda subordinada } \\
\text { otorgada por Abengoa Perú. }\end{array}$ \\
\hline $\begin{array}{l}\text { Secured } \\
\text { Subordination and } \\
\text { Intercreditor } \\
\text { Agreement }\end{array}$ & $\begin{array}{l}\text { - Emisor: ATS } \\
\text { - Indenture Trustee, Agente de } \\
\text { Facilador de Deuda Subordinada y } \\
\text { Agente de Garantías Exterior: } \\
\text { Citibank N.A. }\end{array}$ & $\begin{array}{l}\text { Contrato que regula que toda deuda } \\
\text { subordinada futura será junior en } \\
\text { prelación de pagos frente a la deuda } \\
\text { del Bono. }\end{array}$ \\
\hline \multicolumn{3}{|c|}{ Contratos de Garantías } \\
\hline $\begin{array}{l}\text { Collateral and } \\
\text { Accounts Agreement }\end{array}$ & $\begin{array}{l}\text { - Emisor: ATS } \\
\text { - Indenture Trustee, Agente de } \\
\text { Facilador de Deuda Subordinada, } \\
\text { Agente de Garantías Exterior y } \\
\text { Depositario: Citibank N.A. } \\
\text { - Agente de Garantías Local y } \\
\text { Fiduciario Local: Citibank del Perú } \\
\text { S.A. }\end{array}$ & $\begin{array}{l}\text { Contrato que establece las cuentas } \\
\text { en garantía y la cascada de los } \\
\text { flujos para asegurar el pago de la } \\
\text { deuda. }\end{array}$ \\
\hline $\begin{array}{l}\text { Senior Offshore } \\
\text { Security Agreement }\end{array}$ & $\begin{array}{l}\text { - Emisor: ATS } \\
\text { - Agente de Garantías Exterior del } \\
\text { Préstamo Sindicado: BNP Paribas } \\
\text { Securities Services, London Branch } \\
\text { - Agente de Garantías Exterior: } \\
\text { Citibank N.A. }\end{array}$ & $\begin{array}{l}\text { Contrato que establece las garantías } \\
\text { a otorgarse a los bonistas bajo las } \\
\text { leyes de Nueva York. }\end{array}$ \\
\hline $\begin{array}{l}\text { Contrato de Garantía } \\
\text { Mobiliaria sobre } \\
\text { cuenta bancaria y } \\
\text { saldos en cuenta en } \\
\text { Banco de Crédito del } \\
\text { Perú }\end{array}$ & $\begin{array}{l}\text { - Emisor: ATS } \\
\text { - Agente de Garantías Local: Citibank } \\
\text { del Perú S.A. } \\
\text { - Representante Común: Servicios } \\
\text { Conexos NOTREG E.I.R.L. } \\
\text { - Banco: Banco de Crédito del Perú }\end{array}$ & $\begin{array}{l}\text { Contrato que otorga en garantías } \\
\text { los saldos de las cuentas del emisor } \\
\text { en el banco en referencia (estas } \\
\text { cuentas no están dentro del } \\
\text { fideicomiso). }\end{array}$ \\
\hline $\begin{array}{l}\text { Contrato de Garantía } \\
\text { Mobiliaria sobre } \\
\text { cuenta bancaria y } \\
\text { saldos en cuenta en } \\
\text { Citibank del Perú }\end{array}$ & $\begin{array}{l}\text { - Emisor: ATS } \\
\text { - Agente de Garantías Local: Citibank } \\
\text { del Perú S.A. } \\
\text { - Representante Común: Servicios } \\
\text { Conexos NOTREG E.I.R.L. } \\
\text { - Banco: Citibank del Perú }\end{array}$ & $\begin{array}{l}\text { Contrato que otorga en garantías } \\
\text { los saldos de las cuentas del emisor } \\
\text { en el banco en referencia (estas } \\
\text { cuentas no están dentro del } \\
\text { fideicomiso). }\end{array}$ \\
\hline $\begin{array}{l}\text { Contrato de Garantía } \\
\text { Mobiliaria sobre } \\
\text { cuenta bancaria y } \\
\text { saldos en cuenta en } \\
\text { Banco Internacional } \\
\text { del Perú - Interbank }\end{array}$ & $\begin{array}{l}\text { - Emisor: ATS } \\
\text { - Agente de Garantías Local: Citibank } \\
\text { del Perú S.A. } \\
\text { - Representante Común: Servicios } \\
\text { Conexos NOTREG E.I.R.L. } \\
\text { - Banco: Banco Internacional del Perú }\end{array}$ & $\begin{array}{l}\text { Contrato que otorga en garantías } \\
\text { los saldos de las cuentas del emisor } \\
\text { en el banco en referencia (estas } \\
\text { cuentas no están dentro del } \\
\text { fideicomiso). }\end{array}$ \\
\hline
\end{tabular}




\begin{tabular}{|c|c|c|}
\hline & - Interbank & \\
\hline $\begin{array}{l}\text { Contrato de Garantía } \\
\text { Mobiliaria sobre } \\
\text { Acciones de Abengoa } \\
\text { y FIEX }\end{array}$ & $\begin{array}{l}\text { - Constituyentes: ASA Iberoamérica } \\
\text { S.L. y Abengoa Perú S.A. } \\
\text { - Agente de Garantías Local: Citibank } \\
\text { del Perú S.A. } \\
\text { - Emisor: ATS } \\
\text { - Representante Común: Servicios } \\
\text { Conexos NOTREG E.I.R.L. }\end{array}$ & $\begin{array}{l}\text { Contrato que otorga en prenda las } \\
\text { acciones de los accionistas } \\
\text { Abengoa y FIEX. }\end{array}$ \\
\hline $\begin{array}{l}\text { Contrato de Hipoteca } \\
\text { de primer rango sobre } \\
\text { la Concesión y los } \\
\text { Bienes de la } \\
\text { Concesión }\end{array}$ & $\begin{array}{l}\text { - Emisor: ATS } \\
\text { - Agente de Garantías Local: Citibank } \\
\text { del Perú S.A. }\end{array}$ & $\begin{array}{l}\text { Contrato que otorga la hipoteca en } \\
\text { primer rango sobre los derechos de } \\
\text { la Concesión y los Bienes de la } \\
\text { Concesión. }\end{array}$ \\
\hline $\begin{array}{l}\text { Contrato de } \\
\text { Fideicomiso de Flujos } \\
\text { local }\end{array}$ & $\begin{array}{l}\text { - Fideicomitentes: ATS, ASA, } \\
\text { Abengoa Perú } \\
\text { - Fiduciario: Citibank del Perú S.A. } \\
\text { - Depositario: ATS }\end{array}$ & $\begin{array}{l}\text { Contrato que constituye las cuentas } \\
\text { locales del Fideicomiso en Perú y la } \\
\text { regulación del respectivo flujo. }\end{array}$ \\
\hline \multicolumn{3}{|c|}{ Consentimientos de Terceros } \\
\hline $\begin{array}{l}\text { Autorización del } \\
\text { Ministerio de Energía } \\
\text { y Minas }\end{array}$ & & $\begin{array}{l}\text { Autorización del MINEM para } \\
\text { conformar la hipoteca de primer } \\
\text { rango y ceder los derechos de cobro } \\
\text { derivados de la Concesión. }\end{array}$ \\
\hline $\begin{array}{l}\text { Consentimiento del } \\
\text { Contratista }\end{array}$ & $\begin{array}{l}\text { - Contratista: EP de la UTE Inabensa } \\
\text { Abencor Chilca-Montalvo } \\
\text { - Emisor: ATS } \\
\text { - Fiduciario local: Citibank del Perú } \\
\text { S.A. }\end{array}$ & $\begin{array}{l}\text { Consentimiento de la contraparte } \\
\text { para que se cedan todos los } \\
\text { derechos en beneficio de ATS bajo } \\
\text { el contrato en referencia, al } \\
\text { fideicomiso local. }\end{array}$ \\
\hline $\begin{array}{l}\text { Consentimiento del } \\
\text { Proveedor }\end{array}$ & $\begin{array}{l}\text { - Proveedor: UTE Inabensa Abencor } \\
\text { Chilca-Montalvo } \\
\text { - Emisor: ATS } \\
\text { - Fiduciario local: Citibank del Perú } \\
\text { S.A. }\end{array}$ & $\begin{array}{l}\text { Consentimiento de la contraparte } \\
\text { para que se cedan todos los } \\
\text { derechos en beneficio de ATS bajo } \\
\text { el contrato en referencia, al } \\
\text { fideicomiso local. }\end{array}$ \\
\hline $\begin{array}{l}\text { Consentimiento del } \\
\text { Operador }\end{array}$ & $\begin{array}{l}\text { - Operador: ATN } \\
\text { - Emisor: ATS } \\
\text { - Fiduciario local: Citibank del Perú } \\
\text { S.A. }\end{array}$ & $\begin{array}{l}\text { Consentimiento de la contraparte } \\
\text { para que se cedan todos los } \\
\text { derechos en beneficio de ATS bajo } \\
\text { el contrato en referencia, al } \\
\text { fideicomiso local. }\end{array}$ \\
\hline \multicolumn{3}{|c|}{ Documentos del Proyecto } \\
\hline $\begin{array}{l}\text { Contrato de } \\
\text { Concesión }\end{array}$ & $\begin{array}{l}\text { - Concedente } \\
\text { - ATS }\end{array}$ & - \\
\hline $\begin{array}{l}\text { Contrato de } \\
\text { Construcción }\end{array}$ & $\begin{array}{l}\text { - Contratista: EP de la UTE Inabensa } \\
\text { Abencor Chilca-Montalvo } \\
\text { - ATS }\end{array}$ & - \\
\hline Contrato de Procura & $\begin{array}{l}\text { - Proveedor: UTE Inabensa Abencor } \\
\text { Chilca-Montalvo } \\
\text { - ATS }\end{array}$ & \\
\hline Contrato de O\&M & $\begin{array}{l}\text { - Operador: ATN } \\
\text { - ATS }\end{array}$ & - \\
\hline $\begin{array}{l}\text { Resolución } \\
\text { ministerial } \\
\text { reconociendo las } \\
\text { servidumbres del } \\
\text { proyecto } \\
\end{array}$ & & - \\
\hline \multicolumn{3}{|c|}{ Purchase Agreement y Offering Memorandum } \\
\hline Purchase Agreement & $\begin{array}{l}\text { - Compradores Iniciales: BNP Paribas } \\
\text { Securities Corp. y HSBC Securities } \\
\text { (USA) Inc. } \\
\text { - Emisor: ATS } \\
\text { - Indenture Trustee: Citibank N.A. } \\
\text { - The Depositary Trust Company }\end{array}$ & $\begin{array}{l}\text { Regula el trato entre el emisor y } \\
\text { los compradores iniciales en } \\
\text { cuanto a precio, términos y otras } \\
\text { condiciones relacionadas a la } \\
\text { oferta, venta y compra de los } \\
\text { valores. }\end{array}$ \\
\hline
\end{tabular}




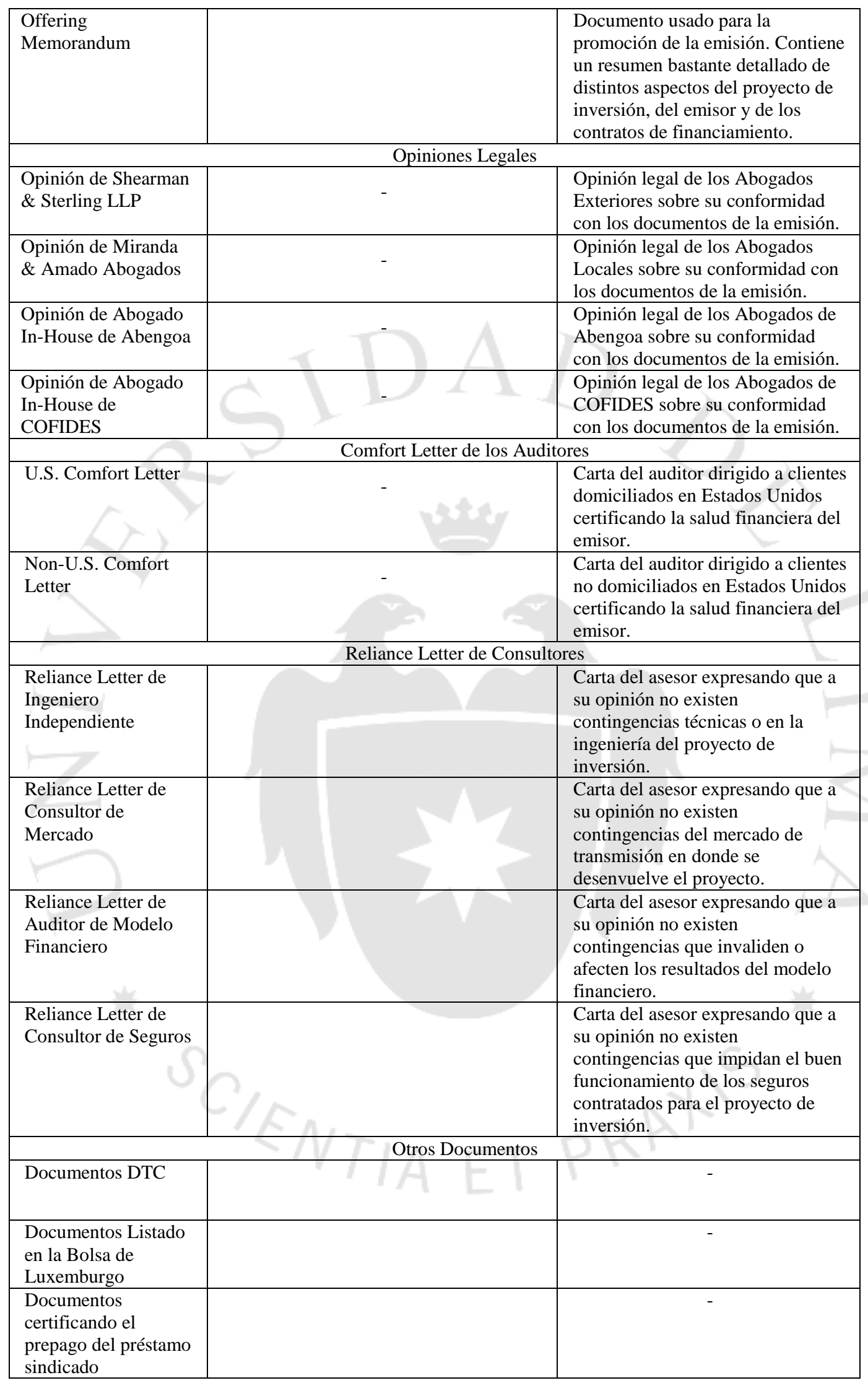

Elaboración Propia

A continuación, se procederá a describir en detalle los documentos más importantes que definen la estructura del bono. 


\section{Offering Memorandum}

Este documento no se trata de un contrato, sin embargo, se le considera también un documento legal dentro del paquete de documentos de la emisión. Su principal función es declarar información del emisor sobre su negocio, riesgos y los principales términos relacionados con la emisión del bono. Es por ello, que incluye información diversa como estados financieros, riesgo de tipo de cambio, información sobre el sector de electricidad y el esquema SGT, permisos y regulaciones, descripción sobre el equipo de la gerencia de ATS, información sobre los accionistas, las transacciones entre afiliadas, resumen de los contratos del proyecto (EPC, Concesión, Operación) y principalmente, una resumida pero eficaz descripción del bono y las garantías ofrecidas, así como las opiniones emitidas por cada el Ingeniero Independiente y el Consultor del Mercado Eléctrico Peruano. Asimismo, también detalla información sobre temas tributarios o legales que deben considerar los distintos inversores a través del mundo.

Así, con este documento se provee al potencial comprador con información completa del emisor y su respectiva emisión. Si bien bajo las ofertas privadas, el emisor no está obligado a presentar este documento para revisión de la SEC, es de buena práctica presentarlo con los demás documentos, de tal manera que se libra al vendedor de la responsabilidad de revelación de información. Comúnmente un inversionista tendrá más precauciones de realizar la inversión en algún bono si no se presentase el Offering Memorandum con los documentos de la emisión (U.S. Securities and Exchange Comission, 2014, sección What should you do before investing?, párr. 3).

En el caso en estudio, el Offering Memorandum si era necesario como requisito para poder listar en la Bolsa de Luxemburgo. Este documento fue evaluado por la Bolsa de Luxemburgo para permitir su ingreso al mercado Euro MTF. Es así que, el prospecto del bono de ATS fue aprobado por la bolsa el 17 de abril del 2014.

Actualmente, en la página web de la Bolsa de Luxemburgo se puede encontrar este documento y otros reportes publicados eventualmente relacionados al bono de ATS. 


\section{Indenture}

Este documento es el más importante del presente financiamiento, puesto que en base a este se declara que ha sido realizada la emisión y se definen las obligaciones del emisor y del Indenture Trustee frente a los bonistas. Este contrato fue celebrado entre ATS como emisor y Citibank N.A. en su papel de Indenture Trustee, Registrador, Agente de pagos y transferencias, bajo las Leyes de Nueva York.

Este contrato declara que las obligaciones de deuda generadas por el bono, son de ranking senior y de pago preferente frente a cualquier deuda subordinada, presente y futura y pari passu frente a deudas senior permitidas que el emisor adquiera en el futuro, salvo por aquellas obligaciones exigibles por las Leyes Peruanas. Además, se expresa claramente que el Indenture al no calificar bajo el Trust Indenture Act, no otorgará a los bonistas la protección al amparo de dicha norma.

A continuación, se describirán las cláusulas más relevantes del Indenture que buscan regular el accionar del emisor y del Indenture Trustee frente a determinadas situaciones.

\section{Pago de Principal e Intereses de los Bonos}

El pago de los intereses y principal de los bonos será pagado a cada bonista de manera prorrata al porcentaje de bonos en su poder.

El pago del principal será pagado de acuerdo a un cronograma semestral establecido en los anexos del Indenture. Como se comentó antes, la amortización del principal fue hecha a la medida para permitir a la empresa la estabilización de su flujo de caja durante los 2 primeros años de vida del bono por lo que presenta un período de gracia del principal para las fechas de pago programadas del 31 de octubre de 2014 al 30 de abril del 2016. Asimismo, en la Tabla 2.10, se aprecia que la amortización de principal es creciente conforme transcurren los años hasta la madurez del bono en la fecha del 30 de abril del 2043, donde se terminará de pagar el saldo del principal equivalente al 5.08\% del USD 432 millones de la emisión. De esta manera, se le permitirá a ATS no tener problemas de liquidez para el pago del servicio de deuda a través de la vida del bono. 
Tabla 2. 10

Cronograma de amortización de la emisión

\begin{tabular}{|c|c|c|c|}
\hline $\begin{array}{c}\text { Fecha de } \\
\text { Pago }\end{array}$ & $\begin{array}{c}\text { \% de Principal } \\
\text { Amortizable }\end{array}$ & $\begin{array}{c}\text { Fecha de } \\
\text { Pago }\end{array}$ & $\begin{array}{c}\% \text { de Principal } \\
\text { Amortizable }\end{array}$ \\
\hline 31 -oct-14 & $0.00 \%$ & $30-a b r-29$ & $1.50 \%$ \\
\hline 30 -abr-15 & $0.00 \%$ & 31 -oct-29 & $1.63 \%$ \\
\hline 31 -oct-15 & $0.00 \%$ & 30 -abr-30 & $1.68 \%$ \\
\hline $30-a b r-16$ & $0.00 \%$ & $31-$ oct-30 & $1.82 \%$ \\
\hline 31 -oct-16 & $0.21 \%$ & 30 -abr-31 & $1.88 \%$ \\
\hline $30-a b r-17$ & $0.17 \%$ & 31 -oct-31 & $2.02 \%$ \\
\hline 31 -oct-17 & $0.25 \%$ & 30-abr-32 & $2.08 \%$ \\
\hline $30-a b r-18$ & $0.26 \%$ & $31-$ oct-32 & $2.24 \%$ \\
\hline 31 -oct-18 & $0.35 \%$ & 30 -abr-33 & $2.14 \%$ \\
\hline 30-abr-19 & $0.36 \%$ & 31 -oct-33 & $2.29 \%$ \\
\hline 31 -oct-19 & $0.45 \%$ & $30-a b r-34$ & $2.36 \%$ \\
\hline $30-a b r-20$ & $0.47 \%$ & $31-$ oct-34 & $2.53 \%$ \\
\hline 31 -oct-20 & $0.57 \%$ & $30-a b r-35$ & $2.61 \%$ \\
\hline $30-a b r-21$ & $0.58 \%$ & 31 -oct-35 & $2.78 \%$ \\
\hline 31 -oct-21 & $0.69 \%$ & $30-a b r-36$ & $2.84 \%$ \\
\hline $30-a b r-22$ & $0.71 \%$ & 31 -oct-36 & $2.63 \%$ \\
\hline 31 -oct-22 & $0.83 \%$ & $30-a b r-37$ & $2.71 \%$ \\
\hline $30-a b r-23$ & $0.85 \%$ & $31-$ oct-37 & $2.86 \%$ \\
\hline 31 -oct-23 & $0.97 \%$ & $30-a b r-38$ & $2.94 \%$ \\
\hline $30-a b r-24$ & $0.84 \%$ & $31-$ oct-38 & $3.10 \%$ \\
\hline $31-$ oct-24 & $0.88 \%$ & $30-a b r-39$ & $3.18 \%$ \\
\hline $30-a b r-25$ & $0.90 \%$ & 31-oct-39 & $3.35 \%$ \\
\hline $31-$ oct-25 & $1.01 \%$ & $30-a b r-40$ & $3.44 \%$ \\
\hline $30-a b r-26$ & $1.04 \%$ & 31 -oct-40 & $3.62 \%$ \\
\hline $31-$ oct-26 & $1.15 \%$ & $30-a b r-41$ & $3.72 \%$ \\
\hline 30 -abr-27 & $1.18 \%$ & 31-oct-41 & $3.91 \%$ \\
\hline 31 -oct-27 & $1.30 \%$ & $30-a b r-42$ & $4.02 \%$ \\
\hline 30 -abr-28 & $1.34 \%$ & $31-$ oct-42 & $4.22 \%$ \\
\hline 31 -oct-28 & $1.46 \%$ & $30-a b r-43$ & $5.08 \%$ \\
\hline
\end{tabular}

Fuente: Offering Memorandum (2014), p. 93

En cuanto a los intereses, la tasa aplicable para su cálculo es de $6.875 \%$ anual y estos se computan sobre la base de un año de 360 días y un mes de 30 días, desde la fecha de emisión (16 de abril de 2016). Los pagos de intereses se realizarán desde el 30 de octubre de 2014 y de manera semestral desde esa fecha cada 30 de abril y 31 de octubre. 
La forma operativa del pago de principal e intereses (llamado conjuntamente Servicio de Deuda), está definida en el Contrato de Garantías y Cuentas que se detallará más adelante.

\section{$\underline{\text { Montos Adicionales (Additional Amounts) }}$}

El Indenture establece que cualquier pago realizado, en relación a los bonos, por el emisor en beneficio de los bonistas, será realizado sin ninguna deducción o retención de impuestos exigidos por la Superintendencia Nacional de Administración Tributaria (SUNAT) y/u otra autoridad tributaria, al menos que dichos impuestos sean requeridos que sean efectivamente deducidos o retenidos por una ley aplicable. En dicho caso, el Emisor tendrá que realizar lo siguiente:

- Pagar al Indenture Trustee, en beneficio de los bonistas, la cantidad necesaria de dinero para que el bonista reciba en sus manos el dinero que hubiese recibido sin la retención o deducción exigida por dichos impuestos (denominados "Montos Adicionales").

- Deducir o retener dichos impuestos.

- Remitir a la autoridad tributaria aplicable los impuestos retenidos o deducidos.

Los pagos por Montos Adicionales no se realizarán en los siguientes casos:

- Impuestos exigidos a los bonistas que no estén relacionados a transacciones efectuadas por los Documentos del Financiamiento y los pagos relacionados a estos.

- Impuestos por herencia o donaciones.

- Si el emisor notifica, en un plazo de 30 días previos al próximo pago programado, que el bonista podía ser eximido o ver reducida su tasa de retención si cumple con un proceso determinado frente a la autoridad tributaria, pero este falla en realizar dicho trámite. 
- Impuestos exigidos por la Directiva 2003/48/EC del Concejo Europeo.

- Cualquier impuesto que sea exigido que no sea por deducción o retención de pagos de principal y de intereses de los bonos.

- Cualquier combinación de las situaciones anteriores.

Al pedido escrito de algún bonista, el emisor tendrá que proveer al Indenture Trustee de la evidencia del pago realizado de los impuestos por los que han sido pagados los Monto Adicionales.

De cara al bonista, esta cláusula presenta una ventaja ya que la obligación del emisor de pagar estos Montos Adicionales sobrevivirá a pesar de haber realizado el pago total de interés y principal de los bonos o si se hubiesen realizado la transferencia y ventas de algún bono por parte de un bonista a otra persona.

\section{$\underline{\text { Redención de los Bonos }}$}

Los bonos de ATS pueden estar sujetos a redención total o parcial, ya sea de forma voluntaria u obligatoria, de acuerdo a los términos del Indenture.

- Redención Obligatoria

En el caso de que ocurran las siguientes situaciones, el emisor deberá notificar al Indenture Trustee de dicha ocurrencia y usar los pagos recibidos para realizar la redención obligatoria de los bonos:

a) Cuando el emisor, el Sponsor o los accionistas hayan recibido montos por encima de USD 10,000,000, provenientes de pagos por seguros debido a eventos donde hayan sido dañadas las instalaciones del proyecto de inversión o por compensaciones de expropiación por departe del Estado, y dichos montos no hayan sido usados para reparar o reemplazar las instalaciones afectadas (después de aplicado lo establecido en el Contrato de Garantías y Cuentas).

b) Cuando el emisor, el Sponsor o los accionistas hayan recibido pagos por parte del MINEM relacionados con una terminación de facto o por las vías de hecho del acuerdo al numeral 12.14 del Contrato de Concesión. 
c) Montos depositados en la Cuenta de Retención de Caja según lo estipulado en el Contrato de Garantías y Cuentas.

El precio por la Redención Obligatoria será equivalente al:

(i) $100 \%$ del saldo de principal de los bonos que serán redimidos +

(ii) Montos Adicionales e intereses devengados y no pagados de los bonos a ser redimidos hasta la Fecha de Redención (sin incluir esa fecha).

La elección de aquellos bonos que deberán ser redimidos en el caso de una redención parcial, será realizada por el Indenture Trustee de acuerdo al procedimiento regulado por la Bolsa de Luxemburgo. La redención parcial se aplicará de forma prorrata y de manera inversa en orden de vencimiento para la reducción de los pagos de principal bajo el cronograma establecido.

Mediante este tipo de redención obligatoria, se busca que el riesgo de los bonistas por impago para los casos de eventos que perjudiquen la operatividad de la línea o expropiación de parte del Concedente de las instalaciones (como mencionado antes en el resumen del Contrato de Concesión), sea reducido significativamente.

\section{- Redención Opcional}

El emisor podrá redimir los bonos de forma parcial (si es parcial, sólo hasta el $45 \%$ del saldo de principal de los bonos) o total con una notificación al Indenture Trustee al menos 30 días antes de la fecha seleccionada para aplicar la redención. El precio de redención será:

i) $\quad 100 \%$ del saldo de principal de los bonos que serán redimidos +

ii) Montos Adicionales e intereses devengados y no pagados de los bonos a ser redimidos hasta la Fecha de Redención ( $\sin$ incluir esa fecha) +

iii) Una Prima Make-Whole (Make-Whole Premium).

La Prima Make-Whole está definida como el exceso que hubiese de restar (i) la suma de los valores presentes de los pagos programados de intereses y principal, descontados a la Fecha de Redención en una base semestral a una tasa del bono del Tesoro de Estados Unidos que sea equivalente al vencimiento del bono de ATS más 50 puntos básicos, sobre (ii) el monto de principal de dichos bonos. 
Esta alternativa de redención opcional es atractiva para el emisor debido a que en un posible escenario donde el mercado experimente una baja de las tasas de interés, permitiría a ATS pagar la presente emisión y vender una nueva emisión con una tasa cupón más baja. Sin embargo, esta opción a redención puede estar en detrimento de los bonistas. Si las tasas de interés en el mercado suben, ATS no ejecutará la redención, dejando al bonista con una tasa de cupón menor que las del mercado. Sin embargo, si las tasas de interés caen, ATS realizará la redención y pagará a los bonistas, los cuales tendrán que realizar inversiones en valores que pagan tasas menores a la que ganaban con el bono de ATS. Para poder atraer al inversor a tomar este tipo de bono con opción de redención, se le debe compensar con una tasa cupón superior a emisiones similares sin dicha opción de redención (Ehrhardt y Brigham, 2011, p. 178). Por tanto, podemos deducir que la tasa cupón de $6,875 \%$ presenta el costo de oportunidad generado al bonista por constar con esta opción de redención.

- Redención Opcional por Cambios en Impuestos

El emisor podrá elegir redimir la totalidad de los bonos, en el caso de cambios en las leyes aplicables del Perú en cuanto a materia tributaria, que obliguen al emisor a (a) pagar Montos Adicionales en exceso a los que debe pagar por el impuesto de retención de $4.99 \%$ o (b) realizar pagos por indemnización a un bonista afectado por el IGV aplicable al interés, principal o la prima MakeWhole, y que dichos pagos de IGV no puedan ser usados como crédito fiscal debido a razones ajenas al emisor. La notificación tendrá que ser realizada con 30 días de anticipación al Indenture Trustee.

El precio por la redención será el mismo estipulado para la Redención Obligatoria.

\section{$\underline{\text { Bonos Adicionales (Additional Notes) }}$}

Se le denomina de esta manera a los bonos adicionales a los USD 432,000,000 emitidos de acuerdo al Indenture. El emisor podrá emitir sin el consentimiento de los bonistas, sujeto al cumplimiento de la sección 5.1(a) del Indenture ${ }^{19}$, Bonos Adicionales bajo el presente Indenture (con las mismas condiciones que los bonos iniciales)

\footnotetext{
${ }^{19}$ Cláusula de Covenants Negativos sobre Deuda Permitida.
} 
garantizados por los Documentos del Financiamiento. Al menos que esos Bonos Adicionales sean emitidos bajo diferentes CUSIP, ISIN, y Código Común, formarán parte de la emisión original. Cualquier Bono Adicional emitido, tendrá la misma prelación de derecho de pago y acceso a las garantías que los bonos originales, y tendrá derecho a voto en todos los asuntos como una sola clase junto a los bonos originales. 


\section{Covenants}

Los covenants son aquellas obligaciones asumidas por el emisor que estarán vigentes hasta que no quede saldo de deuda pendiente. Estos covenants están divididos en covenants afirmativos (Affirmative Covenants), Covenants de Reporte (Reporting Covenants) y convenants negativos (Negative Covenants). Los covenants afirmativos son aquellas obligaciones que establecen los actos que el emisor debe cumplir; los negativos, aquellos actos en los cuales el emisor no debe incurrir; y finalmente, los de reporte son para cumplir el envío de información periódica al Indenture Trustee.

Los covenants afirmativos definidos en el Indenture son los siguientes:

a) Existencia corporativa: El emisor tiene que mantener su existencia corporativa como sociedad anónima bajo las leyes de Perú.

b) Contabilidad y Registros:

a. El emisor tendrá que mantener el registro contable de todas sus operaciones y costos.

b. Permitir al Auditor realizar auditorías anuales sobre sus estados financieros.

c. Mantener sus libros contables en su oficina principal.

d. Una vez por año, y cuando ocurra un Evento de Incumplimiento, el emisor permitirá que representantes del Indenture Trustee revisen los registros contables y documentos que el Indenture Trustee considere necesarios.

c) Cumplimiento con la ley: El emisor cumplirá con las leyes aplicables, incluidas las medioambientales, de la Superintendencia de Banca, Seguros y AFP y la Superintendencia de Mercado de Valores.

d) Aprobaciones gubernamentales: El emisor está obligado a mantener y obtener las aprobaciones gubernamentales relacionadas con la posesión, uso, desarrollo, construcción, diseño, ingeniería, energización, pruebas, operación y mantenimiento del proyecto de inversión.

e) Desarrollo del proyecto:

a. El emisor ejecutará el proyecto de inversión de acuerdo al presupuesto anual $^{20}$, los estándares industriales, los términos de los Documentos del Proyecto (incluyendo las garantías bajo los Contratos EPC) y bajo los

\footnotetext{
${ }^{20}$ Aprobado por el Indenture Trustee y el Ingeniero Independiente de manera anual.
} 
términos de los pólizas de seguros que el emisor debe mantener respecto al proyecto.

b. El emisor deberá causar la finalización de la construcción de la segunda barra en la Subestación Montalvo y permitir al Ingeniero Independiente que realice una inspección cuando se haya finalizado dicha construcción.

c. Cuando se haya realizado el pago completo de los costos del proyecto (a ese momento sólo faltaba pagar los costos de la construcción de la segunda barra de la SE Montalvo), el emisor deberá instruir al Ingeniero Independiente para que emita un certificado respecto a este tema.

f) Impuestos: Se obliga el emisor a realizar los pagos y las declaraciones de impuestos requeridos.

g) Uso de fondos: El emisor está obligado a:

a. Usar los fondos recibidos de la emisión del bono para:

i. Pagar el saldo de principal del préstamo sindicado y los montos de terminación de los swaps relacionados.

ii. Realizar el fondeo de la Cuenta de Reserva del Servicio de Deuda y la Cuenta de Reserva de O\&M por el monto requerido. El monto que se debe mantener en la cuenta de Reserva de Servicio de Deuda es equivalente al próximo pago de intereses y principal aplicables, según el cronograma de pagos. El monto a mantener en la Cuenta de Reserva de O\&M debe ser equivalente a los costos operativos presupuestados semestrales.

iii. Pagar las comisiones y gastos ligados a la emisión del bono, la cancelación del préstamo sindicado y la terminación de los swaps.

iv. Pagar deuda subordinada a relacionadas por US\$ 62,500,000.

v. Pagar comisiones y gastos derivados de la estructuración de deuda subordinada garantizada.

b. Que se usen las Contribuciones de Caja Contigentes ${ }^{21}$ sólo para pagar costos del proyecto y las Contribuciones de Caja por Déficit ${ }^{22}$ para pagar servicio de deuda.

21 Contingent Cash Constributions, según el Contrato de Apoyo del Promotor, son aquellas contribuciones de caja hechas por los accionistas (excepto FIEX) o las que el Sponsor debe obligar a los accionistas o afiliadas realizar a favor del emisor para cubrir aquellos costos del proyecto que no se encuentren fondeados en la cuenta del fideicomiso específica para inversiones en capex. 
c. Las emisiones futuras de este bono deberán ser usadas sólo para pagar costos asociados a refuerzos bajo el contrato de concesión.

h) Seguros: El emisor deberá:

a. Mantener pólizas de seguros en los montos y coberturas requeridos por el Contrato de Concesión, con empresas aseguradoras de buena reputación. Dichas pólizas no podrán ser terminadas por el asegurador aún en el caso de falta de pago de la prima respectiva por parte del emisor, al menos que el asegurador lo notifique con antelación.

b. Si el asegurador no tiene un rating de al menos BBB- por Fitch o S\&P o de Baa3 por Moody's, este deberá tener un reaseguro con una entidad que si cumpla con dichos ratings.

c. Se debe nombrar al Indenture Trustee como asegurado adicional.

d. Realizar el endoso de los seguros a favor de:

i. El MINEM como beneficiario de cualquier cobertura por accidente que cause una pérdida total.

ii. El Fiduciario local como beneficiario de todos los demás seguros que sean pagados en Perú.

iii. El Agente de Garantías Exterior como beneficiario de todos los demás seguros que sean pagados fuera de Perú.

i) Mantenimiento de Propiedad: El emisor deberá mantener la propiedad de las instalaciones de acuerdo a las aprobaciones obtenidas y los documentos del proyecto, así como mantener la integridad y buen funcionamiento de dichas instalaciones.

j) Documentos del Proyecto: El emisor deberá:

i. Cumplir con todas sus obligaciones bajo el Contrato de Concesión, los Contratos EPC, el Contrato de Operación y cualquier otro contrato necesario para el desarrollo del proyecto.

ii. Renovar el Contrato de O\&M cada 5 años.

k) Documentos de Garantías Senior: El emisor realizará todos los registros ante la autoridad correspondiente, de las garantías que garantizan la deuda del bono y enviar al Indeture Trustee una copia certificada de la constancia de registro.

\footnotetext{
${ }^{22}$ Shortfall Cash Constributions, según el Contrato de Apoyo del Promotor, son aquellas contribuciones que están obligados a realizar los accionistas (excepto FIEX) o las que el Sponsor debe obligar a los accionistas o afiliadas realizar a favor del emisor, para cubrir, si existiese, el déficit existente en la fecha de pago establecida en octubre de 2014.
} 
1) Derechos de propiedad: El emisor deberá mantener los derechos de propiedad sobre servidumbres e inscribirlas en el Registro Público de Concesiones.

m) Información: El emisor proveerá al Indenture Trustee y a los Agentes de Garantías aquella información que requieran de acuerdo al Indenture.

n) Agencias de Rating: El emisor deberá mantener clasificaciones de rating de al menos 2 agencias.

o) Lugar de arbitraje: El emisor deberá elegir Washingotn D.C. como lugar del arbitraje para el proceso de solución de controversias detallado en el numeral 13.5(b) del Contrato de Concesión.

Por otro lado, los covenants de reporte son los que siguen a continuación:

a) Estados Financieros, requisitos de reporte: El emisor deberá entregar al Indenture Trustee, y cuando lo pidan los bonistas, la siguiente información:

a. Los estados financieros no auditados trimestrales a los 90 días del cierre de cada trimestre fiscal, y los estados financieros auditados anuales a los 150 días de cerrado el año fiscal del emisor, adjuntos con un certificado de un representante legal de ATS, certificando la validez y autenticidad de los estados y acreditando que no ha ocurrido o está ocurriendo un evento de incumplimiento.

b. Los estados financieros trimestrales no auditados y auditados anuales del Sponsor.

c. Dentro de los 7 días hábiles luego de una fecha de pago, un certificado del emisor con el cálculo detallado del Ratio de Cobertura de Servicio de Deuda $(\mathrm{RCSD})^{23}$.

b) Presupuesto Anual: El emisor deberá entregar al Indenture Trustee un Presupuesto Anual adjunto a un certificado de un representante de la empresa y del Ingeniero Independiente, 60 días antes del término del año fiscal. Este presupuesto detallará las estimaciones de ingresos, costos operativos, capex, y necesidades de capital de trabajo, las cuales deberán estar hechas de buena fe y ser consistentes con las obligaciones de ATS frente al Contrato de Concesión.

${ }^{23}$ Definido en el Contrato de Garantías y Cuentas, el Ratio de Cobertura del Servicio de Deuda es el resultado de la división del (a) flujo operativo entre (b) el servicio de deuda programado y Montos Adicionales en el período de los 12 meses anteriores a la fecha de pago aplicable. Más adelante se discutirá en detalle las implicancias de este ratio. 
c) Notificaciones: Cuando el emisor tome conocimiento de los siguientes eventos, deberá notificar al Indenture Trustee dentro de 5 días:

a. La ocurrencia de un evento de incumplimiento.

b. Un cambio de control.

c. Cualquier litigación material o administrativa o procedimiento gubernamental que pueda afectar la propiedad material de ATS, los accionistas o el Sponsor y que pueda resultar en un evento de incumplimiento bajo los contratos de financiamiento.

d. Un accidente que provoque el pago por parte del seguro de montos superiores a USD 5,000,000.

e. Cualquier incumplimiento bajo algún Documento del Proyecto que pudiera resultar en un Efecto Materialmente Adverso ${ }^{24}$.

f. La ocurrencia de abandono de la línea de transmisión, evento de Fuerza Mayor o una acción de expropiación por parte del Concedente.

d) Enviar la información requerida según la Regla 144A(d)(4).

Por último, los covenants negativos estipulados son los siguientes:

a) Endeudamiento: El emisor no podrá incurrir en deuda que no sea Deuda Permitida $^{25}$.

b) Gravámenes: El emisor no podrá ofrecer en gravamen su propiedad salvo aquellos Gravámenes Permitidos ${ }^{26}$.

c) Existencia y giro del negocio: El emisor no podrá adquirir acciones de otra empresa, fusionarse, extinguirse, cambiar sus documentos societarios, si es que estas acciones afectan a los bonistas o su capacidad de cumplir sus obligaciones bajos los documentos de la transacción. Tampoco podrá cambiar el objeto de su negocio.

\footnotetext{
${ }^{24}$ Según el Contrato de Garantías y Cuentas, un Efecto Materialmente Adverso es un evento o condición que resultará o podrá resultar en un cambio material adverso en el negocio del emisor, la capacidad de las partes de poder cumplir sus obligaciones bajo los Documentos del Proyecto o los Documentos del Financiamiento o que afecte la validez de las garantías y el accionar del Indenture Trustee y los Agentes de Garantías.

${ }^{25}$ La Deuda Permitida son los Bonos Adicionales, deuda subordinada de afiliadas y terceros (no mayor a USD 50MM), deuda usada para pagos del curso normal del negocio, deuda para pagar los contratos EPC (no mayor a USD 5MM), para la realización de refuerzos (no mayores a USD 5MM), entre otros estipulados en el Indenture.

${ }^{26}$ Los Gravámenes Permitidos son: (i) garantías creadas a favor de los documentos de la deuda del bono, (ii) garantías creadas a favor de los documentos de la deuda subordinada, (iii) garantías necesarias para el curso normal del negocio, (iv) garantías creadas para un litigio o proceso legal, (v) garantías ofrecidas para la línea de confirming de pago a proveedores, (vi) garantías ofrecidas para la Deuda Permitida, (vii) entre otras estipuladas en el Contrato de Garantías y Cuentas.
} 
d) Contabilidad: El emisor no podrá cambiar sus políticas contables al menos que sea exigido por los IFRS.

e) Contratos Adicionales ${ }^{27}$ : El emisor no podrá:

a. Suscribir ningún contrato Adicional, a menos que:

i. Haya enviado reafirmaciones de su rating crediticio al Indenture Trustee.

ii. La otra parte sea una afiliada del emisor o un tercero y haya enviado al Indenture Trustee un Consent ejecutado de dicho tercero.

iii. Se han obtenido todos los permisos de la contraparte para que los derechos derivados del Contrato Adicional sean cedidos a los Agentes de Garantías.

b. Suscribir o modificar algún acuerdo de libre acceso que perjudique los intereses de los bonistas, al menos que sea requerido por una entidad gubernamental.

c. Suscribir o modificar contratos de fibra óptica, al menos que dicha suscripción o modificación limite la responsabilidad del emisor a menos de USD 10MM.

f) Préstamo y Garantías: Excepto por los Pagos Restringidos, el emisor no podrá:

a. Realizar préstamos o adelantos a algún tercero.

b. Crear una garantía o asumir como aval de una deuda u obligación de algún tercero, excepto por (a) el endoso de instrumentos negociables para la recaudación de transacciones similares en el curso del negocio, y (b) ser garante de obligaciones de proveedores, contratistas u otras personas en el curso de su negocio que no sean afiliadas, que no excedan los USD 100,000 .

g) Cuentas Bancarias: El emisor no podrá tener otras cuentas bancarias salvo las establecidas por los contratos del financiamiento, las cuentas de Fibra Óptica, las cuentas del confirming y la cuenta de Fondeo Voluntario ${ }^{28}$.

27 Los Contratos Adicionales son aquellos contratos que suscriba el emisor (incluidas adendas y modificaciones) que cumplan lo siguiente (i) no obligue al emisor a realizar gastos mayores a USD 1MM y (ii) los Contratos Excluidos (Excluded Contracts): (a) Contratos de Fibra Óptica, (b) Acuerdos de Libre Acceso, (c) acuerdos para reemplazar o reparar el proyecto de inversión que no exceda USD 10MM, (d) contratos por las inversiones permitidas de acuerdo al Contrato de Garantías y Cuentas y (e) los contratos existentes con afiliadas.

28 Esta cuenta será fondeada por los aportes de caja voluntarios de los accionistas o afiliadas, transferencias de la Cuenta de Pagos Restringidos, pagos de accionistas o afiliadas por préstamos brindados por ATS, entre otros. Servirá para pagar deuda subordinada y hacer Pagos Restringidos. 
h) Adquisición y mantenimiento de activos: El emisor no deberá:

(i) Adquirir activos salvo por lo establecido en los Contratos EPC, capex realizado para el curso ordinario del negocio o para cumplir con los Documentos del Proyecto, realización de refuerzos o por algún contrato de libre acceso.

(ii) Vender, arrendar, transferir o disponer de las instalaciones del proyecto de inversión a menos que sea para el curso ordinario del negocio y por activos menores a USD 100,000, según lo requerido por el Numeral 12.14 del Contrato de Concesión o disposiciones de capacidad respecto a los contratos de fibra óptica.

i) Transacciones con afiliadas: El emisor no podrá suscribir, modificar o renovar acuerdos o transacciones con afiliadas, salvo por lo siguiente respecto a los contratos existentes con afiliadas:

a. Podrá suscribir, modificar o renovar contratos con afiliadas por más de USD 1M, si envía un certificado al Indenture Trustee con la decisión del Directorio sobre ese asunto.

b. Podrá suscribir, modificar o renovar contratos con afiliadas por más de USD 10M, si envía una opinión de un tercero (auditor independiente, banco de inversión, etc) acreditando la validez de dicha transacción, junto con un certificado de un representante del emisor y del Ingeniero Independiente.

c. Podrá renovar o extender el plazo de un contrato con una afiliada si se mantienen los mismos términos y condiciones.

d. Renovar el contrato de O\&M de acuerdo a lo estipulado en los Covenants Afirmativos.

j) Operaciones de cobertura: El emisor sólo podrá suscribir contratos de cobertura para el propósito de coberturas respecto a riesgo de mercado de tasas de interés o tipo de cambio y no para fines especulativos.

k) Pagos Restringidos ${ }^{29}$ : El emisor no podrá declarar o pagar Pagos Restringidos al menos que se cumplan esta condiciones inmediatamente antes y después del pago del Pago Restringido:

\footnotetext{
${ }^{29}$ Se ahondará en este término en la sección del Contrato de Garantías y Cuentas.
} 
a. No existe algún incumplimiento o evento de incumplimiento en dicho momento.

b. El ratio de Cobertura de Servicio de Deuda no es menor a 1.20 veces.

c. El ratio Proyectado de Cobertura de Servicio de Deuda no es menor a 1.20 veces.

d. La Cuenta de Reserva del Servicio de Deuda está fondeada de acuerdo al monto requerido de servicio de deuda.

e. La Cuenta de Reserva de O\&M está fondeada de acuerdo al monto requerido en esta cuenta.

f. Se realiza el pago en una Fecha de Pago Restringido.

g. El cumplimiento de todas estas condiciones anteriores deberán estar señaladas en un certificado de un representante legal del emisor que será entregado al Indenture Trustee al menos 5 días hábiles antes (pero no más de 15 días hábiles) de la Fecha de Pago Restringido.

A pesar de lo estipulado líneas arriba, el emisor podrá:

a. Condicionado a que no exista incumplimiento, realizar pagos de IGV de acuerdo a lo estipulado en el Contrato de Garantías y Cuentas.

b. Aplicar los fondos provenientes de Deuda Subordinada Permitida para pagar, cancelar o refinanciar otra Deuda Subordinada Permitida, con la condición que dichos fondos no sean requeridos bajo los contratos de financiamiento.

c. Aplicar los fondos provenientes de los Contratos de Fibra Óptica para realizar Pagos Restringidos.

d. Aplicar los fondos de los bonos de acuerdo a la cláusula de Uso de Fondos descrita en los Covenants Afirmativos.

1) Documentos del Proyecto: El emisor no deberá:

a. Cancelar o terminar cualquier Documento del Proyecto, al menos que dicha terminación sea causada por la bancarrota o violación grave de la contraparte.

b. Modificar o realizar una adenda sobre cualquier aspecto material de algún Documento del Proyecto, al menos que:

i. En el caso de los Contratos EPC, dichos modificaciones se hayan realizado o se realicen con contribuciones de caja por los 
accionistas, las afiliadas del emisor y/o los prestamistas de deuda subordinada y no sobrepasen el monto de USD 10MM. Además dicha adenda o modificación no deberá incumplir los estándares técnicos de construcción, las leyes aplicables, el Contrato de Concesión, entre disposiciones similares. Se le enviará al Indenture Trustee un certificado del Ingeniero Independiente asegurando las estipulaciones anteriores, 10 días hábiles antes de la ejecución de dicha adenda o modificación.

ii. En el caso del Contrato de O\&M, se procederá a la modificación de dicho contrato o a la cesión de posición si: (i) esta no afecta el alcance del servicio y no es menos favorable para el emisor, (ii) el pago anual denominado en dólares no es mayor a USD 2MM (sin considerar el ajuste por inflación), (iii) el Contrato de O\&M modificado se sujeta a los mismos gravámenes constituidos bajos los Contratos de Financiamiento, (iv) la modificación no resultará en un incumplimiento del Contrato de Concesión, (v) el Indenture Trustee ha recibido un certificado del Ingeniero Independiente 10 días hábiles antes de la ejecución de dicha adenda o modificación y (vi) en el caso de cesión de posición contractual, el nuevo operador ha firmado el debido acuerdo de consentimiento.

iii. En el caso del Contrato de Concesión, se procederá a la modificación de dicho contrato si, (i) la modificación es inmaterial, es beneficiosa para el emisor y los bonistas o el emisor entrega al Indenture Trustee las reafirmaciones de ratings, (ii) esta modificación no afectará la capacidad y derechos del emisor de recibir los pagos bajo el Contrato de Concesión, y (iii) al menos 10 días hábiles antes, se le envía al Indenture Trustee un certificado de un representante del emisor junto con el certificado del Ingeniero Independiente.

m) Emisión de acciones: El emisor no podrá emitir acciones a favor de nadie si luego de hacerlo, se esperaría que ocurra un incumplimiento o evento de incumplimiento, salvo por lo estipulado en los Documentos del Financiamiento o el Contrato de Concesión. 
n) Presupuesto Anual: El emisor no incurrirá en costos operativos, CAPEX u otros gastos y montos que anualmente sobrepasen en $110 \%$ el Presupuesto Anual enviado al Indenture Trustee cada año. Sin embargo, podrá presentarle al Ingeniero Independiente una adenda a dicho presupuesto, con el nuevo ratio Proyectado de Cobertura de Servicio de Deuda, la cual deberá ser certificada por esta.

\section{Eventos de Incumplimiento (Events of Default)}

Los siguientes eventos, actos, ocurrencias o condiciones serán calificados como Eventos de Incumplimiento:

a) La falta de pago de parte del emisor del principal, Montos Adicionales, primas, intereses de los bonos y que esta falta no haya sido subsanada en 3 días hábiles.

b) Falta de pago por precios de algún tipo de redención, pagos por recompra por cambio de control o cualquier comisión o impuesto pagable bajo los Documentos del Financiamiento, y que tal falta prosiga por más de 15 días hábiles.

c) Cualquier garantía, certificado, estado financiero, documento que haya sido probado que es falso y que pueda causar un efecto materialmente adverso y que no se haya resuelto luego de 30 días hábiles de que el emisor obtuvo conocimiento de dicho evento, o que el emisor esté tratando de resolver pero falla en hacerlo en 60 días hábiles.

d) Si el emisor, los accionistas o el Sponsor no cumplen sus obligaciones o covenants bajo cualquier Documento del Financiamiento y dicho evento no es subsanado en 30 días, o en 60 días si el emisor está tomando medidas para remediar dicho evento.

e) Si el emisor o cualquier parte del proyecto de inversión no cumple sus obligaciones y causa algún evento establecido en los numerales $12.3,12.4$ y $12.5^{30}$ del Contrato de Concesión o alguno de los acuerdos de consentimiento o Documentos del Proyecto son declarados inválidos o terminados.

f) Si el Indenture, cualquier bono o los Documentos del Financiamiento son declarados inválidos por alguna autoridad gubernamental o leyes aplicables.

g) Si cualquier participante de los Documentos del Financiamiento desiste de sus obligaciones de manera escrita o perjudica la validez de dichos documentos.

\footnotetext{
30 Son los numerales de causales de terminación por falla del Operador Técnico (conservar la participación mínima, que no cumpla sus obligaciones técnicas, o fuese declarado en quiebra o insolvencia, incumplimiento injustificado y grave por parte del Concedente sobre sus obligaciones y pro eventos de fuerza mayor que duraran más de 12 meses.
} 
h) La falta de pago de principal e interés de cualquier Deuda Permitida del emisor por montos mayores a USD 5,000,000.

i) Ocurre un abandono de las instalaciones de la línea.

j) Ocurre una expropiación de las instalaciones que causa un efecto materialmente adverso.

k) Si ocurriese cualquier causal de terminación bajo el Contrato de Concesión bajo los numerales 12.2, 12.3, 12.4 y 12.5 .

1) Si cualquier gravamen creado para la protección de los bonos deja de ser válido y pierde prioridad de pago.

m) Si el emisor pierde alguna aprobación gubernamental (incluido el EIA) necesaria para la construcción u operación del proyecto de inversión, al menos que el emisor envíe un certificado al Indenture Trustee y al Ingeniero Independiente estableciendo que dicho evento no afectará materialmente el desarrollo del proyecto de inversión, que será subsanado en 60 días, que no resultará en un efecto sustancialmente adverso y el Ingeniero Independiente no se pronuncie en contra en dicho plazo de 60 días.

n) Si ocurriese una pérdida total que podría resultar en un efecto materialmente adverso.

o) Cualquier medida de un poder gubernamental que afecte o atrase la capacidad de pago del emisor o la disponibilidad de la moneda en Perú o que el emisor participe de manera voluntaria o involuntaria en el refinanciamiento de sus deudas o la reestructuración de la moneda en la que se encuentran sus obligaciones.

Si un evento de incumplimiento ocurriese, dentro de 5 días hábiles de recibida la comunicación al respecto, deberá notificar a los bonistas. Los bonistas que posean al menos el $25 \%$ del monto de principal de los bonos podrán solicitar al Indenture Trustee el acelerar el vencimiento de los bonos y: (a) instruir a los Agentes de Colateral a hacer disposición de las garantías según los estipulado en los respectivo documentos de garantías, (b) pedir al Concedente la sustitución de la sociedad concesionaria según lo estipulado en el Contrato de Concesión y (c) tomar cualquier medida permitida por las Leyes Aplicables y remedios bajos los Documentos del Financiamiento.

\section{$\underline{\text { Recompra ante Cambio de Control }}$}

Un Cambio de Control es aquella situación en la que el Sponsor (i) deja de poseer directa o indirectamente más del $50 \%$ de las acciones con derecho a voto del 
emisor, antes del segundo aniversario de la fecha de emisión, o después de dicha fecha, dejara de tener más del 35\% de las acciones con derecho a voto, o (ii) el Sponsor dejará de ejercer la dirección operativa diaria del proyecto de ATS, directamente o a través de una afiliada.

En el caso de que ocurra un Cambio de Control y dentro de los 30 días de ocurrido, el emisor deberá emitir una comunicación al Indenture Trustee donde se ofrezca a comprar todos los bonos adeudados en no más de 60 días. Dicha oferta estará vigente por al menos 20 días pero no más de 30 días. El emisor no estará obligado a esta recompra si es que faltan menos de 6 meses para el vencimiento de los bonos cuando ocurra el evento.

El precio de compra será igual al $101 \%$ de la porción del principal adeudado más todos los intereses devengados y no pagados, más cualquier Monto Adicional aplicable.

El emisor cumplirá esta recompra, en lo que sea aplicable, con los requerimientos de la Regla 14e-1 bajo la Exchange Act y otras leyes aplicables.

\section{$\underline{\text { Obligaciones del Indenture Trustee }}$}

Las obligaciones del Indenture Trustee (entre otras) frente a este contrato son las siguientes:

1. Mantener el registro de la tenencia de los bonos y permitir el intercambio y registro de las trasferencias de estos.

2. Realizar los pagos de principal e intereses de los bonos, siempre que los fondos para dichos pagos estén disponibles.

3. Transmitir los comunicados de los bonistas hacia el emisor y viceversa (de acuerdo a las provisiones de revelación de información definidos en este contrato).

4. Otras obligaciones operativas.

Después de la revisión de esta sección que entró en detalle sobre el Indenture de la emisión de ATS, se puede concluir que el Indenture es aquel contrato que establece las obligaciones más importantes de hacer y no hacer que debe cumplir el emisor y los eventos que desencadenarán un evento de incumplimiento frente a las obligaciones en falta. Asimismo, se ha podido apreciar que dichas obligaciones tratan de cubrir los 
distintos riesgos del proyecto, tanto los derivados del mismo Contrato de Concesión, como los riesgos de completion, operación, de mercado, cambios en leyes y otros.

III. Contrato de Apoyo del Promotor

Este contrato firmado entre el Sponsor, los Accionistas Iniciales, FIEX y Citibank N.A. como Indenture Trustee y Agente de Garantías Exterior, se rige bajo las leyes de Nueva York.

Bajo este contrato los accionistas (incluidos los futuros) se obligan y el Sponsor debe obligarlos a realizar (a los accionistas o alguna subsidiaria), los siguientes aportes de equity o de deuda subordinada en los siguientes casos:

- El emisor deberá realizar un "Aporte Contingente en Efectivo" (Contingent Cash Contribution) cuando exista una "Insuficiencia de Fondos Base" (Base Funding Insuffiency). Este término significa el monto de fondos faltante en la Cuenta Local para CAPEX Específico (Onshore Specified Capex Account) para poder cubrir los costos del proyecto pendientes de pago. Dicha obligación sólo estará vigente hasta el primer pago programado de octubre de 2014.

- El emisor deberá realizar una "Contribución en Efectivo por Déficit" (Shortfall Cash Contributon) cuando exista Déficit (Shortfall Amount). Este término está explicado por el monto faltante en las cuentas para pago de los bonos para poder hacer frente al pago de servicio de deuda programado a octubre de 2014.

- Eventualmente, se realizarán "Contribuciones por Adendas a los Contratos EPC" de acuerdo a las disposiciones establecidas en los covenants negativos para poder llevar acabo adendas a dichos contratos.

Además, el Sponsor se compromete incondicional e irrevocablemente a (a) causar, y tomar todas las medidas necesarias o apropiadas, incluyendo el gasto de fondos para causar la terminación de las obras de la subestación Montalvo de conformidad con lo acordado con el MINEM y (b) para garantizar el pronto pago y la ejecución, cuando sea aplicable, de todas las obligaciones de garantía bajo los Contratos EPC. A su vez, el Sponsor se compromete a proveer o causar la provisión de las fianzas 
bancarias requeridas bajo el Contrato de Concesión (sin embargo, el emisor reembolsará al Sponsor aquellos costos incurridos para la emisión de dichas fianzas). Por último, el Sponsor velará por no causar un evento de Cambio de Control y que no se transfiera su posesión en el emisor al menos que se cumplan los requerimientos establecidos en este mismo contrato.

Este contrato se mantendrá en efecto hasta la fecha en que todas las obligaciones garantizadas senior y subordinadas sean pagadas en su totalidad.

Como se puede apreciar de este resumen de Contrato de Apoyo del Promotor, las obligaciones del Sponsor respecto a proveer fondos directamente se acotaron sólo hasta la primera fecha de pago del primer servicio de deuda de la vida de bono. Esto se debe principalmente a que el proyecto de inversión se encuentra en etapa de operación y por lo tanto, puede generar los recursos necesarios para costear sus gastos, sin necesidad del respaldo del Sponsor. Luego de ello, su actuar se limita más que todo a una tarea de respaldo como supervisor más que de un proveedor directo de fondos.

De esta manera, el Sponsor lograr liberar sus recursos en el proyecto de ATS de acuerdo a lo esperado en un Project Finance.

\section{Purchase Agreement}

El contrato de compra-venta o Purchase Agreement, firmado el 8 de abril del 2014, regula las condiciones de la venta de la emisión por USD 432,000,000 a una tasa cupón de $6.875 \%$ de parte de ATS a los Compradores Iniciales, conformados por BNP Paribas Securities Corp. y HSBC Securities (USA) Inc., los cuales califican como Inversionistas Institucionales Calificados bajo la Regla 144A.

Sin embargo, esta compra de parte los Compradores Iniciales sólo sería realizada si el emisor cumplía con algunas condiciones precedentes establecidas en dicho contrato que incluyen la presentación de las opiniones legales de los respectivos asesores legales del emisor, el Sponsor y los accionistas, así como la presentación del comfort letter del Auditor Independiente, entre otras condiciones similares a los covenants del Indenture.

La manera en que procede esta transacción de compra es la siguiente: 
1. El emisor entregará los bonos (separados por los que correspondan a la Regulación S y Regulación 144A) contra la entrega del pago del precio de compra por parte de los Compradores Iniciales.

2. El pago del precio de compra se realizó el 16 de abril del 2014 (seis días hábiles luego de la firma de este contrato) de acuerdo a los estipulado en este contrato, fecha que se denomina "Fecha de Cierre".

3. Luego del pago, los bonos bajo la Regulación $\mathrm{S}$ serán depositados con el Indenture Trustee como custodio de DTC para la debida contabilización de los participantes DTC, incluyendo a Euroclear Bank S.A./N.V, como operador del sistema Euroclear y Clearstream Banking, société anonyme y serán registrados a nombre de Cede \& Co, como empresa nombrada por DTC. Los bonos bajo la Regulación 144A serán depositados con el Indenture Trustee como custodio de DTC y serán registrados a nombre de Cede \& Co, como empresa nombrada por DTC. Ambos tipos de bonos cuentan con diferente número CUSIP y deberán tener las leyendas debidas por sus restricciones de transferencia.

4. Posteriormente al pago de parte de los Compradores Iniciales, se acuerda que estos ofrecerán un precio al público de 99,995\% más intereses corridos si los hubiera, desde el 16 de abril de 2014.

Queda acordado bajo este contrato, que la reventa de los bonos por parte de los Compradores Iniciales, no podrá ser realizada en emisiones públicas y que los bonos sólo serán ofrecidos a Inversionistas Institucionales Calificados cuando la oferta sea dirigida dentro de los Estados Unidos de América y sólo a personas no domiciliadas en Estados Unidos cuando sea dirigida fuera de dicho país.

Asimismo, quedó acordado que no se realizarían ofertas públicas dentro del territorio peruano bajo las leyes peruanas. Las ofertas privadas en Perú sólo pueden ser realizadas a inversionistas institucionales peruanos ${ }^{31}$, por lo que se registraron los bonos bajo el Registro de Instrumentos de Inversión Extranjeros de la Superintendencia de Banca, Seguros y Administradoras Privadas de Fondos de Pensiones para que estos

\footnotetext{
${ }^{31}$ Según lo dispuesto por la SMV, son Inversionistas Institucionales las siguientes personas: Los bancos, financieras y compañías de seguros y demás empresas señaladas por el artículo 16 de la Ley General del Sistema Financiero y del Sistema de Seguros y Orgánica de la Superintendencia de Banca y Seguros, Ley $\mathrm{N}^{\circ} 26702$ y sus normas modificatorias; los agentes de intermediación; las administradoras privadas de fondos de pensiones; las sociedades administradoras de fondos de inversión; las sociedades administradoras de fondos mutuos y las sociedades titulizadoras.
} 
sean denominados como inversiones elegibles para las Administradoras de Fondos de Pensiones peruanas.

Igualmente, el emisor acordó pagarle a los Compradores Iniciales, además de su respectiva comisión por la estructuración de la emisión, aquellos gastos en los que incurran ligados a la emisión de los bonos.

De esta manera, como resultado de este contrato, el monto comprado por cada Comprador Inicial a ATS, fue el señalado en la Tabla 2.11. Con estos montos recibidos, se procedió a realizar los pagos especificados sobre el Uso de Fondos del Indenture.

\section{Tabla 2. 11}

Distribución de emisión entre Compradores Iniciales

\begin{tabular}{lc} 
& USD \\
Compradores Iniciales & Monto Principal de los Bonos \\
BNP Paribas Securities Corp. & $216,000,000$ \\
HSBC Securities (USA) Inc. & $216,000,000$ \\
\hline Total & $432,000,000$ \\
\hline
\end{tabular}

Fuente: Offering Memorandum (2014), p. 212.

\section{Garantías}

Como ya se ha descrito previamente, el presente bono cuenta con diversas garantías que buscan ofrecer mayor solidez a la emisión al permitir que el bonista cuente con diversos gravámenes ejecutables en el caso de un evento de incumplimiento. Como está establecido en el Indenture, las garantías de este bono serán de primer rango y de prelación senior frente a las garantías ofrecidas a los acreedores de deuda subordinada.

Los Agentes de Garantías son los encargados de velar que las garantías se mantengan y sean ejecutadas de acuerdo a lo estipulado en cada contrato aplicable ${ }^{32}$. En el caso del Fideicomiso de Flujos local, es el Fiduciario el encargado de mantener la administración y garantía de dicho fideicomiso.

Asimismo, se ha mencionado la lista de contratos de garantías de este bono, pero en la Figura 2.8 se vuelven a mencionar, detallando cuales son las garantías constituidas

\footnotetext{
${ }^{32}$ Excepto en el Contrato de Garantías y Colateral, donde el Indenture Trustee mantiene protagonismo frente al Agente de Garantías.
} 
en el Perú y en el exterior; además, se indica el activo del emisor que es ofrecido como colateral en el objeto de cada contrato.

Figura 2.8

Garantías ofrecidas bajo el bono de ATS

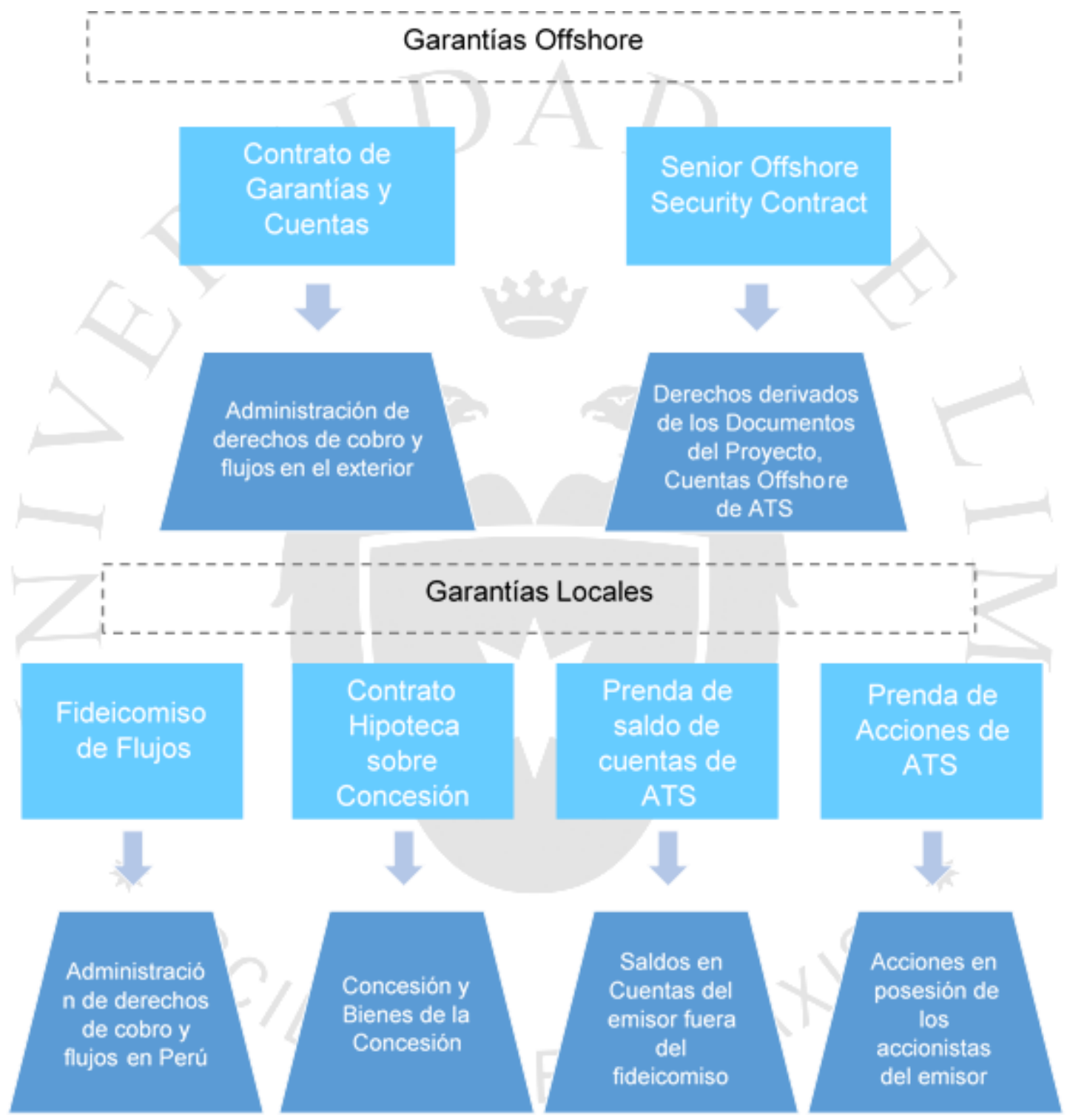

Elaboración propia.

Por su nivel de complejidad y funcionalidad, en la siguiente sección se pasará a detallar el objeto y operación de los Contratos de Garantía y Colateral y el Senior Offshore Security Contract. Los demás contratos serán resumidos en los siguientes párrafos. 
El Contrato de Hipoteca de primer rango sobre la Concesión y los Bienes de la Concesión, también es un contrato que existía previamente para el préstamo sindicado, por lo que fue modificado mediante adenda para adaptarse a la emisión del bono. De acuerdo al Oficio No. 236-2012-MEN-DGE, del 9 de febrero de 2012, el MINEM otorgó su consentimiento para crear una hipoteca sobre la concesión del proyecto de inversión (incluidos los bienes de la concesión), por lo que ATS ha cedido a favor del Agente de Garantías Local dicha hipoteca para garantizar el pago de las obligaciones bajo los Documentos del Financiamiento. La ejecución dela hipoteca la realizará el Agente de Garantías Local siguiendo las instrucciones del Indenture Trustee, a través de un procedimiento judicial de ejecución hipotecaria o en una ejecución fuera de corte, sin perjuicio de las disposiciones establecidas en el Contrato de Concesión y la ley aplicable.

El Contrato del Fideicomiso de Flujos local tiene el objetivo de constituir un fideicomiso donde sea posible la administración de los activos cedidos por los Fideicomisarios y como garantía de las obligaciones asumidas bajo los Documentos del Financiamiento. El beneficiario de este fideicomiso es el Agente de Garantías Exterior que actúa en beneficio de los bonistas. Los activos cedidos por el emisor a este fideicomiso son el $100 \%$ de los derechos de cobro (derivados del Contrato de Concesión, seguros, recuperación del IGV, entre otros) y los flujos del proyecto de inversión (derivados de las deudas subordinadas con afiliadas, aportes de capital, cierto flujos provenientes del exterior, entre otros). El Fiduciario Local administrará las cuentas locales del Fideicomiso de acuerdo a los términos establecidos en el Contrato de Garantías y Cuentas. Al recibir una orden de ejecución, el Fiduciario Local transferirá los flujos de todas las cuentas locales en soles a la Cuenta en Soles de Flujos de Ejecución de Garantías (Sol Collateral Proceeds) y los flujos en dólares a la Cuenta en Dólares de Flujos de Ejecución de Garantías (Offshore Collateral Proceeds Account), para aplicar el pago de las obligaciones del bono y bajo lo dispuesto en el Contrato de Garantías y Cuentas, respectivamente.

Los contratos Contrato de Garantía Mobiliaria sobre cuentas bancaria y saldos en el Banco de Crédito del Perú, Citibank e Interbank son prendas realizadas sobre las cuentas prexistentes antes de la emisión del bono, las cuales también resultaron en prenda a favor del préstamo sindicado. De esta manera, el emisor garantiza a favor del Agente de Garantías Local una prenda sobre las cuentas, saldos, y depósitos realizados 
en cada cuenta de los bancos en mención. Estas cuentas son usadas para propósitos operativos que están definidos en el Contrato de Garantías y Cuentas.

Los Contratos de Garantía Mobiliaria sobre Acciones de Abengoa y FIEX entregan a favor del Agente de Garantías Local una prenda sobre el 100\% de las acciones existentes y futuras que posean del emisor para garantizar las obligaciones bajo los Documentos de Financiamiento. De esta manera, en el caso de un evento de incumplimiento, el Agente de Garantías Local podrá ejecutar dicha garantía (previa instrucción del Indenture Trustee) mediante la venta de dichas acciones gravadas.

A continuación se procederá a describir en detalle los Contratos de Garantía y Colateral y el Senior Offshore Security Contract.

\section{Contrato de Garantías y Cuentas}

Si bien esta emisión de bonos se sustenta principalmente en el Indenture, el Contrato de Garantías y Colateral es otro de los contratos importantes que conforman los Documentos del Financiamiento, puesto que este regula la operativa de cómo deben aplicarse los flujos provenientes de los ingresos generados por la concesionaria y de qué manera particular deben ser distribuidos para pagar los costos y gastos operativos, el servicio de deuda y los Pagos Restringidos de ser el caso. Este contrato está gobernado bajo las Leyes de Nueva York.

El objeto de este contrato es establecer de las cuentas bancarias que serán parte del colateral de los documentos del Financiamiento y definir el esquema operativo para la realización de depósitos y débitos de las cuentas que forman parte de este colateral y otras que no. El emisor se compromete bajo este contrato, a no mantener otras cuentas a nombre propio que no sean las descritas a continuación:

Las denominadas Cuentas Locales (Onshore Accounts) están compuestas por:

(i) Las cuentas locales del fideicomiso establecidas por el Fiduciario local (Onshore Trust Accounts):

a) Cuenta de Ingresos Local Soles

b) Cuenta de Operación y Mantenimiento Soles

c) Cuenta Ingresos Local Dólares

d) Cuenta Operación y Mantenimiento Dólares 
e) Cuenta de Capex Específica

f) Cuenta de Contingencias Soles

g) Cuenta de Contingencias Dólares

(ii) Las cuentas locales a nombre de ATS y prendadas mediante los respectivos contratos de garantía mobiliaria de cuenta bancaria y saldos:

a) Cuenta Operativa en Soles (Sol Operating Account) del Banco de Crédito del Perú.

b) Cuenta Operativa en Dólares (Dollar Operating Account) del Banco de Crédito del Perú.

c) Cuenta de Aportes de Capital (Capital Contribution Account), denominada en dólares, en Citibank del Perú.

d) Sol Payment Service Account del Banco Interbank.

e) Dollar Payment Service Account del Banco Interbank.

Las denominadas Cuentas Exteriores (Offshore Accounts) serán las siguientes:

(i) Las cuentas exteriores de emisor creadas por el Depositario de las Cuentas (Citibank N.A.), otorgadas en garantía bajo el Senior Offshore Security Agreement y denominadas en dólares (Offshore Issuer Accounts):

a) Offshore Revenue Account

b) Note Payment Account

c) Cuenta de Reserva de Servicio de Deuda (Debt Service Reserve Account)

d) Cash Retention Account

e) Restricted Payment Account

f) Offshore Contingency Account

g) Note Proceeds Account

h) Cuenta de Reserva de Servicio de Deuda (O\&M Reserve Account)

(ii) Offshore Collateral Proceeds Accounts: Cuenta establecida por el Depositario de Cuentas en nombre del Agente de Garantías Exterior a favor de los bonistas y los acreedores de la deuda subordinada

(iii) Restricted Collateral Proceeds Accounts La cuenta establecida por el Depositario de Cuentas en nombre del Agente de Garantías Exterior sólo a favor de los bonistas. 
Está permitido bajo este documento, que el emisor abra y mantenga sólo las siguientes cuentas, que no serán parte del colateral ofrecido (denominadas Cuentas Excluidas) tales como las Cuentas de HSBC PPB (por motivos de confirming), las Subsequentes Cuentas de PPB, la Cuenta de Fondeo Voluntario y las Cuentas de Fibra Óptica.

Para poder comprender el funcionamiento de estas cuentas y la cascada de los flujos, usaremos la Figura 2.9:

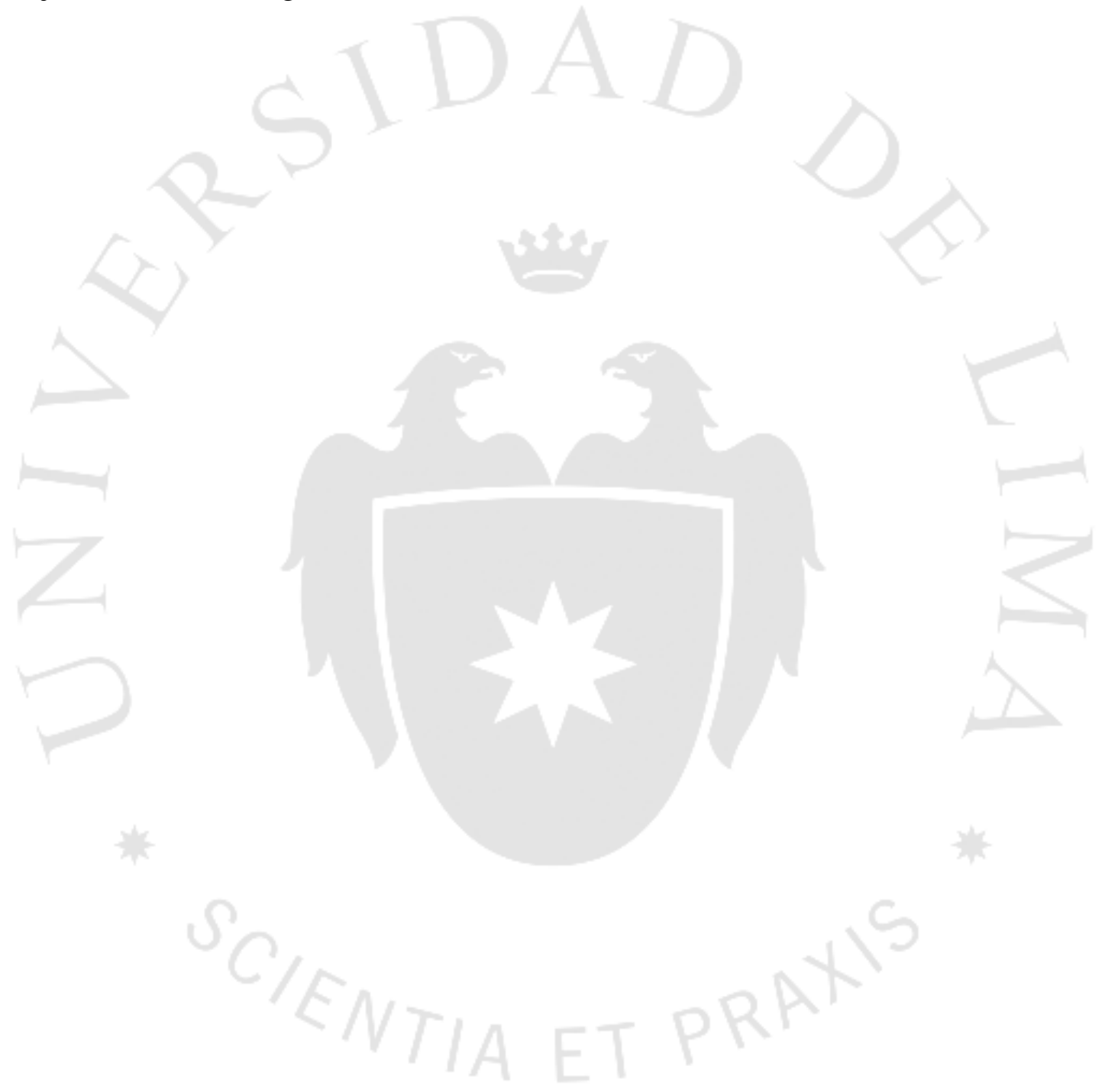


Figura 2.9

Cascada de Flujos entre Cuentas

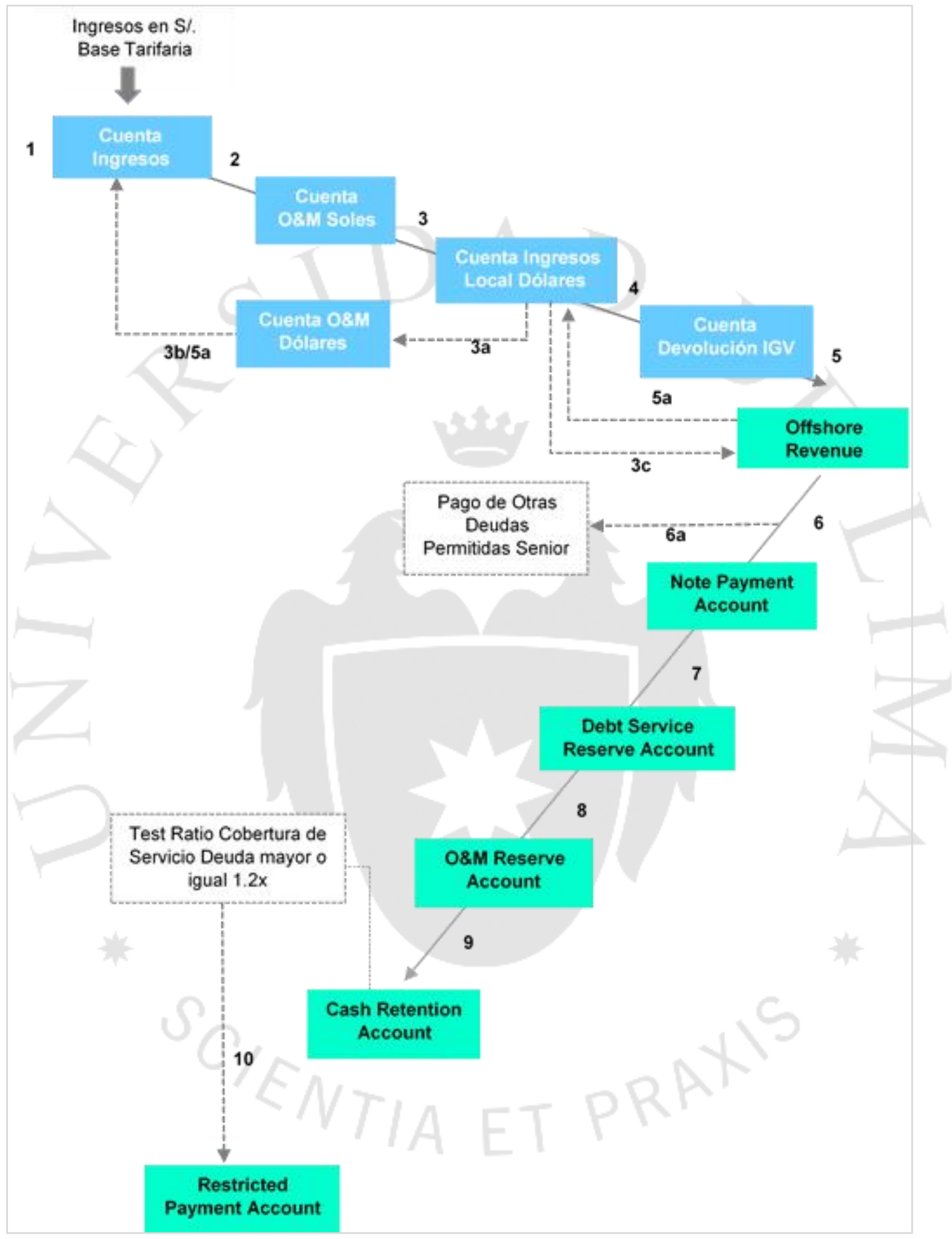

Fuente: Offering Memorandum (2014).

Elaboración Propia 
El proceso de la entrada de flujos a las cuentas en garantía, establecido en una base mensual, es el siguiente:

1. Se depositan en la Cuenta Ingresos Soles, los ingresos provenientes de la Base Tarifaria, ingresos provenientes del uso de la línea (excepto por los contratos de Fibra Óptica y las devoluciones de IGV), flujos de seguros por interrupción de negocios, entre otros.

2. Luego, de la Cuenta Ingresos Soles, se transfieren a la Cuenta O\&M Soles, los montos necesarios para cubrir gastos de operación y mantenimiento mensuales en soles, OPEX e impuestos necesarios para mantener el curso normal del negocio.

3. Los montos restantes, serán convertidos a dólares y serán transferidos a la Cuenta Ingresos Local en Dólares. De existir Costos de O\&M exigibles en dólares, desde esta cuenta de ingresos, se transferirán los montos necesarios a Cuenta Local O\&M en Dólares (3a). Si existiese déficit de fondos en la Cuenta O\&M Soles, se transferirán los fondos necesarios desde esta cuenta (3b). Finalmente, luego de haber hecho las distribuciones aplicables, los montos remanentes en la Cuenta Ingresos Local en Dólares serán transferiros a la Offshore Revenue Account (3c).

4. La última cuenta local que recibe el flujo proveniente de la Cuenta Ingresos Soles es la Cuenta de Devolución de IGV, donde deberá depositarse un monto equivalente al necesario para hacer los pagos de IGV.

5. Luego de la distribución previa, los fondos restantes que queden de la Cuenta Ingresos Soles serán transferidos totalmente a la Offshore Revenue Account. Sin embargo, de no existir dinero en las otras cuentas, se podrá transferir desde esta cuenta exterior los montos necesarios para cubrir el déficit en las Cuentas de O\&M en soles y dólares (5a).

6. Luego del punto 5a anterior, se procederá a fondear la Note Payment Account con los fondos provenientes de la Offshore Revenue Account. Esta cuenta será fondeada mensualmente de esta manera, hasta llegar al monto del servicio de deuda requerido bajo cronograma. Luego de esta transferencia, se podrán realizar transferencias para pagar principal e intereses de Deudas Permitidas (6a).

7. Los fondos restantes de la cuenta Offshore Revenue Account, luego de aplicada la distribución en 6, serán usados para fondear la Cuenta de Reserva de Servicio de 
Deuda en el monto requerido para cumplir con el próximo servicio de deuda programado.

8. Después de la distribución en 8 , se fondeará la Cuenta de Reserva de O\&M en el monto suficiente para cumplir con lo requerido para cubrir los gastos de O\&M equivalentes a 6 meses.

9. Si quedasen fondos disponibles en la Offshore Revenue Account luego de todas las distribuciones aplicadas en los numerales anteriores, estos serán trasladados a la Cash Retention Account.

10. Luego del 30 de abril de 2038, se retendrá de manera definitiva (no será aplicable el numeral 10 inferior) el monto faltante para pagar el servicio de deuda restante por los últimos 5 años.

11. Luego de realizado un pago de servicio de deuda programado, el emisor podrá solicitar liberar los fondos en la Cash Retention Account si es que cumple que el Ratio de Cobertura de Servicio de Deuda sea mayor o igual a 1.2 veces para los últimos 12 meses. De cumplirse esto, los fondos podrán ser transferidos a la Restricted Payment Account. La Restricted Payment Account es la cuenta donde estarán los fondos disponibles para realizar los Pagos Restringidos. Los Pagos Restringidos son los siguientes:

- Dividendos o distribuciones relacionadas con las acciones del emisor.

- $\quad$ Pagos de deuda subordinada.

- Préstamos a los accionistas o afiliadas.

- Pago por transacciones con afiliadas para el desarrollo del proyecto de inversión.

Si mediante el test mensual, se llega a determinar que el ratio es menor a 1.2 veces, los fondos se mantendrán en la Cash Retention Account. Es más, si por tercera vez consecutiva el ratio ha fallado en ser mayor a 1.2 veces, se tendrá que realizar una Redención Obligatoria con los montos previamente retenidos en la Cash Retention Account mediantes las mediciones anteriores del ratio. 
Sin embargo, de cara a la retención de caja de los últimos 5 años explicado en el numeral anterior, en dicho período sólo se podrá trasladar a la Restricted Payment Account, el exceso que hubiese de (i) la suma de los saldos en la Cash Retention Account, Notes Payment Account y la Cuenta de Reserva del Servicio de Deuda, sobre (ii) el servicio de deuda programado hasta el vencimiento del bono.

Como podemos apreciar, este esquema de cuentas está diseñado para garantizar que los flujos provenientes del proyecto de inversión finalmente estén en posesión del Agente de Garantías Exterior al transferirlos todos a la Cash Retention Account. De esta manera, en el caso de un evento de incumplimiento, permitirá que se ejecute la garantía de acuerdo a las leyes de Nueva York. La retención de caja en los últimos 5 años y mediante el test del RCSD representa una de las fortalezas más importantes de esta estructuración, ya que así se asegura el pago del servicio de deuda al bonista en condiciones de estrés.

Por otro lado, podemos apreciar que esta cascada, si bien implica varios movimientos de cuentas y severas restricciones al libre movimiento que podría experimentar una empresa que no cuenta con este tipo de fideicomisos, finalmente no impide la normal operación del proyecto de inversión y vela que primero sean cubiertos los gastos y costos que permiten que la empresa siga realizando su negocio.

Asimismo, es importante notar como una ventaja a favor del emisor, que se acordó la exclusión de los ingresos provenientes por contratos de fibra óptica, los cuales pueden representar una significativa fuente de ingresos para la compañía y que no tendrán que estar regulados operativamente bajo este contrato.

\section{Offshore Security Agreement}

Para ofrecer garantías amparadas bajo las leyes de Estados Unidos de América, se debe cumplir con el artículo 9 de la Código Comercial Uniforme (UCC por sus siglas en inglés). Es así que mediante este contrato, surgen todas las garantías ofrecidas a los bonistas que han sido creadas en el exterior y por lo que radica la importancia de su existencia.

De esta manera, el Offshore Security Agreement, deberá garantizar el pago y la realización de todas las obligaciones garantizadas, ya sea directa o indirectamente, por lo que se concederá en garantía la propiedad identificada a continuación (el Colateral 
Garantizado) al Agente de Garantías Exterior, excepto por los contratos de fibra óptica y todos los ingresos relacionados con el mismo, la Cuenta PPB HSBC, las cuentas de confirming posteriores, las cuentas de fibra óptica, la cuenta de Fondeo Voluntario y los importes pagados en relación con los préstamos a los afiliadas según los términos del Indenture:

Todos los contratos y documentos, incluidos cada Documento del Proyecto en el cual el emisor incurra, incluidos los derechos por dichos contratos, los derechos por flujos de seguros, cobros por daños y perjuicios bajos los contratos, entre otros.

- $\quad$ Las Cuentas Exteriores del emisor y los activos financieros (bajo la Sección 8102(a)(9) del UCC) derivados de dichas cuentas, así como los fondos provenientes del Colateral Garantizado.

- $\quad$ Todos los equipos (definidos en el UCC).

- $\quad$ Reclamaciones de responsabilidad civil comerciales (definidos en el UCC).

- $\quad$ Propiedad de inversión (definidos en el UCC).

- $\quad$ Propiedad personal tangible e intagible del emisor.

Todos los derechos, títulos y beneficios relacionados con el emisor, en contra de cualquier persona en relación con el equipo adquirido por ATS, incluyendo cualquier tipo de derechos, reclamaciones o beneficios contra cualquier persona que almacenen o transporten tales equipos.

- $\quad$ Todos los bienes (definidos en el UCC).

- $\quad$ Libros contables o registros referidos al Colateral Garantizado.

- Todo el efectivo, productos, rentas, ingresos, beneficios, pagos intangibles, regalías, adhesiones, derechos de carta de crédito, obligaciones de apoyo, adiciones, sustituciones y reemplazos, incluyendo todos los ingresos de y cualquiera del Colateral Garantizado.

Este Contrato se mantendrá existente hasta que se realice el pago de todas las obligaciones garantizadas. Sin embargo, el contrato y las garantías creadas mediante este, seguirán vivas si es que el pago realizado por el emisor sobre las obligaciones tiene que ser devuelto o rechazado por el Agente de Garantías Exterior o algún bonista, como resultado de un proceso de leyes de bancarrota, liquidación o disolución. 


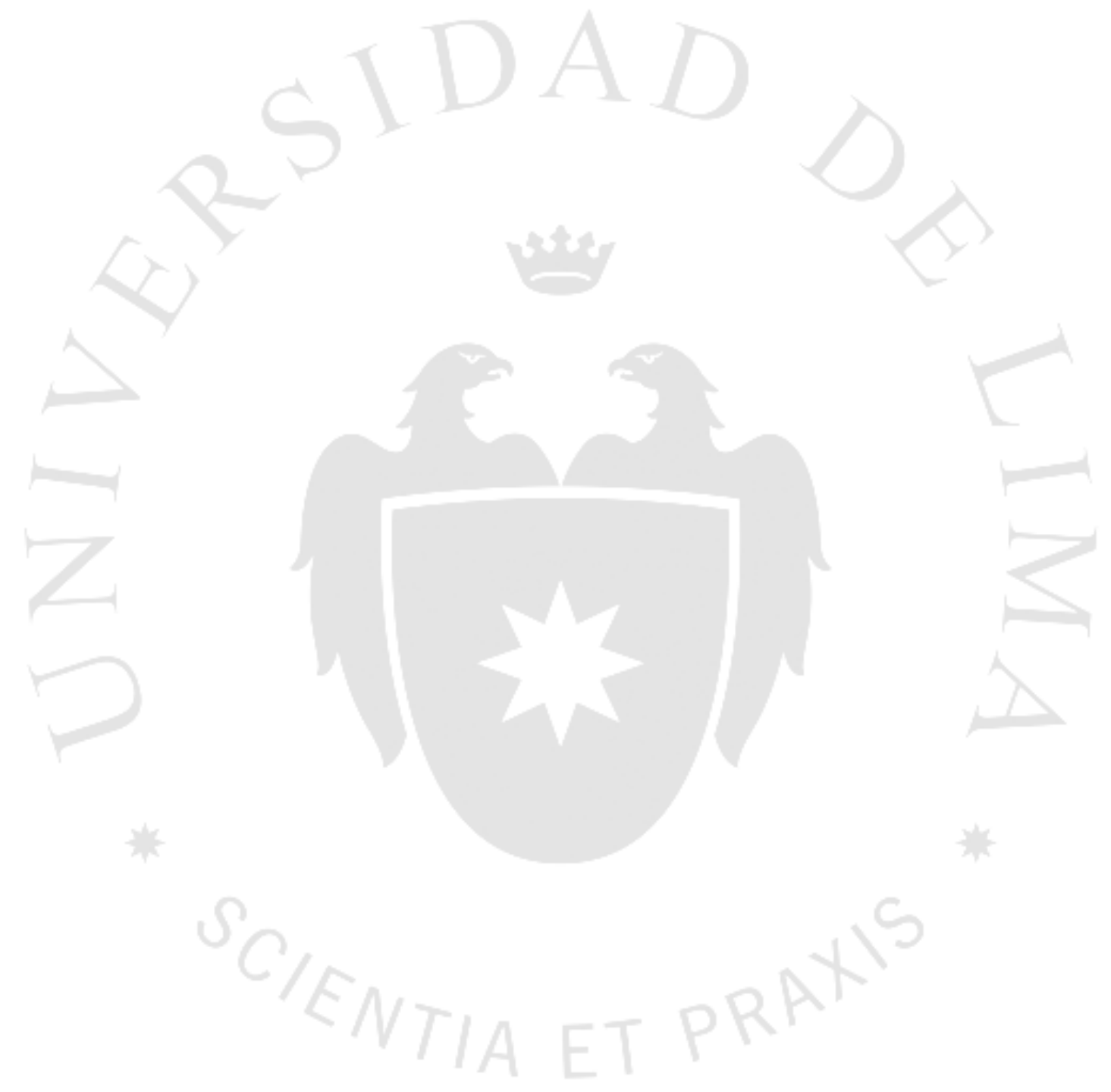




\section{Modelo Financiero}

En los numerales anteriores hemos podido entender el funcionamiento de los Documentos del Financiamiento y como ayudan a regular todo la estructuración del bono para que funcione adecuadamente, reflejando la administración de aquellos riesgos provenientes del proyecto de inversión. Sin embargo, además de las herramientas legales representadas por estos contratos, también se utilizó una herramienta financiera muy importante para poder proyectar los flujos de caja futuros y determinar las distintas cifras que vemos reflejadas en los contratos.

Este modelo financiero aplicado a la emisión de bonos de ATS, fue revisado por el Auditor de modelo financiero y el Ingeniero Independiente. El primero revisó el adecuado funcionamiento del modelo en tanto a proyecciones y uso de inputs macroeconómicos y tributarios, y el segundo, revisó que los costos de construcción, operación y mantenimiento sean los correctos según el estándar en la industria.

En el Offering Memorandum se presenta una sección donde se discute el resumen de los principales supuestos del modelo y sus proyecciones. Las proyecciones incluyen ingresos, costos operativos, caja disponible para el pago de servicio de deuda, monto del servicio de deuda, ratios de cobertura de servicio de deuda y el saldo de principal de los bonos.

Los principales supuestos del modelo financiero son (de acuerdo a la información disponible en el Offering Memorandum publicado en la página web de la Bolsa de Luxemburgo):

Monto de emisión: USD 432,000,000

Tasa cupón anual: $6,875 \%$

Tasa anual de inflación (Índice U.S. Finished Goods Less Food and Energy): $2 \%$. Aplicable a ingresos y costos operativos.

Las proyecciones obtenidas gracias al modelo financiero se resumen en la Tabla 2.12. Estas proyecciones han sido realizadas principalmente para predecir el flujo de caja que el proyecto generará en el futuro y que servirá para realizar el pago del servicio de deuda del bono. Uno de los principales outputs que arroja el modelo financiero aplicado, es el ratio de cobertura de servicio de deuda aplicable a las retenciones de caja y endeudamiento adicional permitido para el emisor. Si bien las proyecciones son 
utilizadas, el RCSD es también determinado mediante la negociación con los estructuradores y su conocimiento sobre el nivel del ratio que será aceptado por los bonistas en base a la práctica comercial para proyectos de inversión similares. Asimismo, el modelo ayuda a determinar, en base a los flujos de caja disponibles, el monto requerido en las cuentas de reserva del servicio de deuda y de O\&M.

Como se puede apreciar en la Tabla 2.12, según los supuestos tomados para las proyecciones, se espera que el RCSD nunca baje de 1.20 veces, nivel que activa instantáneamente la retención de los flujos en el Cash Retention Account o de ser aplicable, obliga a realizar una Redención Obligatoria. 
Tabla 2.12

Proyecciones del Modelo Financiero aplicado

\begin{tabular}{|c|c|c|c|c|c|c|}
\hline Período & Ingresos & Costos O\&M & $\begin{array}{c}\text { Caja } \\
\text { Disponible }\end{array}$ & $\begin{array}{c}\text { Servicio } \\
\text { Deuda }\end{array}$ & RCSD & $\begin{array}{c}\text { Saldo } \\
\text { Principal }\end{array}$ \\
\hline 31-Oct-14 & 23 & (2) & 20 & 16 & 1.31 & 432 \\
\hline 30-Apr-15 & 23 & (2) & 20 & 16 & 1.30 & 432 \\
\hline 31-Oct-15 & 23 & (2) & 21 & 16 & 1.32 & 432 \\
\hline 30-Apr-16 & 23 & (3) & 21 & 16 & 1.33 & 432 \\
\hline $31-O c t-16$ & 24 & (3) & 21 & 17 & 1.31 & 431 \\
\hline 30-Apr-17 & 24 & (3) & 21 & 16 & 1.29 & 430 \\
\hline 31-Oct-17 & 24 & (3) & 22 & 17 & 1.30 & 429 \\
\hline 30-Apr-18 & 24 & (3) & 22 & 17 & 1.30 & 428 \\
\hline 31-Oct-18 & 25 & (3) & 22 & 17 & 1.30 & 427 \\
\hline 30-Apr-19 & 25 & (3) & 22 & 17 & 1.30 & 425 \\
\hline 31-Oct-19 & 25 & (3) & 23 & 17 & 1.30 & 423 \\
\hline $30-\mathrm{Apr}-20$ & 25 & (3) & 23 & 17 & 1.30 & 421 \\
\hline 31-Oct-20 & 26 & (3) & 23 & 18 & 1.30 & 419 \\
\hline 30-Apr-21 & 26 & (3) & 23 & 18 & 1.30 & 416 \\
\hline 31-Oct-21 & 26 & (3) & 23 & 18 & 1.30 & 413 \\
\hline $30-A p r-22$ & 26 & (3) & 23 & 18 & 1.30 & 410 \\
\hline 31-Oct-22 & 27 & (3) & 24 & 18 & 1.30 & 407 \\
\hline $30-A p r-23$ & 27 & (3) & 24 & 18 & 1.30 & 403 \\
\hline 31-Oct-23 & 27 & (3) & 24 & 19 & 1.30 & 399 \\
\hline 30-Apr-24 & 27 & (3) & 24 & 18 & 1.33 & 395 \\
\hline 31-Oct-24 & 28 & (3) & 24 & 18 & 1.35 & 391 \\
\hline 31-Oct-24 & 28 & (3) & 24 & 18 & 1.35 & 391 \\
\hline 30-Apr-25 & 28 & (3) & 24 & 18 & 1.35 & 387 \\
\hline 31-Oct-25 & 29 & (3) & 25 & 18 & 1.35 & 383 \\
\hline 30-Apr-26 & 29 & (3) & 25 & 18 & 1.35 & 378 \\
\hline 31-Oct-26 & 29 & (3) & 25 & 19 & 1.35 & 374 \\
\hline 30-Apr-27 & 29 & (3) & 25 & 19 & 1.35 & 368 \\
\hline 31-Oct-27 & 30 & (3) & 26 & 19 & 1.35 & 363 \\
\hline 30-Apr-28 & 30 & (3) & 26 & 19 & 1.35 & 357 \\
\hline 31-Oct-28 & 30 & (3) & 26 & 19 & 1.35 & 351 \\
\hline 30-Apr-29 & 30 & (3) & 26 & 19 & 1.35 & 344 \\
\hline 31-Oct-29 & 31 & (3) & 26 & 19 & 1.35 & 337 \\
\hline 30-Apr-30 & 31 & (3) & 26 & 19 & 1.35 & 330 \\
\hline 31-Oct-30 & 31 & (3) & 27 & 20 & 1.35 & 322 \\
\hline $30-A p r-31$ & 31 & (3) & 27 & 20 & 1.35 & 314 \\
\hline 31-Oct-31 & 32 & (3) & 27 & 20 & 1.35 & 305 \\
\hline 30-Apr-32 & 32 & (3) & 27 & 20 & 1.35 & 296 \\
\hline 31-Oct-32 & 33 & (3) & 28 & 20 & 1.35 & 287 \\
\hline 30-Apr-33 & 33 & (3) & 27 & 20 & 1.37 & 277 \\
\hline 31-Oct-33 & 33 & (4) & 28 & 20 & 1.40 & 267 \\
\hline 30-Apr-34 & 33 & (4) & 28 & 20 & 1.40 & 257 \\
\hline 31-Oct-34 & 34 & (4) & 28 & 20 & 1.40 & 246 \\
\hline 30-Apr-35 & 34 & (4) & 28 & 20 & 1.40 & 235 \\
\hline 31-Oct-35 & 35 & (4) & 29 & 21 & 1.40 & 223 \\
\hline 30-Apr-36 & 35 & (4) & 29 & 20 & 1.40 & 211 \\
\hline 31-Oct-36 & 35 & (4) & 27 & 19 & 1.41 & 199 \\
\hline 30-Apr-37 & 35 & (4) & 26 & 19 & 1.40 & 188 \\
\hline 31-Oct-37 & 36 & (4) & 27 & 19 & 1.40 & 175 \\
\hline 30-Apr-38 & 36 & (4) & 27 & 19 & 1.40 & 163 \\
\hline 31-Oct-38 & 37 & (4) & 27 & 19 & 1.40 & 149 \\
\hline 30-Apr-39 & 37 & (4) & 27 & 19 & 1.40 & 135 \\
\hline 31-Oct-39 & 38 & (4) & 27 & 19 & 1.40 & 121 \\
\hline 30-Apr-40 & 38 & (4) & 27 & 19 & 1.40 & 106 \\
\hline 31-Oct-40 & 38 & (4) & 27 & 19 & 1.40 & 91 \\
\hline 30-Apr-41 & 38 & (4) & 27 & 19 & 1.40 & 74 \\
\hline 31-Oct-41 & 39 & (4) & 27 & 20 & 1.40 & 58 \\
\hline 30-Apr-42 & 39 & (4) & 27 & 19 & 1.40 & 40 \\
\hline 31-Oct-42 & 40 & (4) & 28 & 20 & 1.40 & 22 \\
\hline 30-Apr-43 & 40 & (4) & 27 & 23 & 1.29 & 0 \\
\hline
\end{tabular}

Nota: Cifras en millones de USD.

Fuente: Offering Memorandum (2014), p. 35-36

El tema delicado respecto a cualquier modelo financiero es que al trabajar en base a supuestos, sus proyecciones podrían no ser cumplidas en el tiempo. Por ello, es necesaria la importancia de aplicar supuestos que se encuentren muy cercanos a la realidad y que estos sean validados por los consultores para que el inversionista tenga la seguridad de que el emisor no está siendo demasiado optimista al momento de proyectar los flujos futuros del proyecto de inversión. Debido a esto, es también importante que se realicen corridas del modelo financiero en diferentes escenarios de 
sensibilidad para que se cuantifiquen las probabilidades de impago en el caso de situaciones de estrés en las variables medidas.

VII. Evaluación de Rating

Finalmente, luego de realizado el cierre de los Documentos del Financiamiento y realizadas las proyecciones de los flujos futuros del proyecto de inversión considerando la deuda del bono, se debe realizar la evaluación crediticia por parte de las Agencias de Rating.

En el caso del bono de ATS, la agencias escogidas para realizar esta revisión fueron S\&P y Fitch. Ambas empresas realizaron su evaluación previamente a la emisión del bono y emitieron una calificación de BBB- a la emisión. Ambas agencias utilizan una metodología establecida para evaluar los Project Finance. Entre los criterios claves utilizados por Fitch (2016) para realizar esta evaluación están:

- Riesgo de completion: En el caso de que el proyecto se encuentre en etapa de construcción, se evalúa el riesgo de no terminar la construcción o incurrir en sobrecostos.

- Riesgos operativos y de ingresos: Se evalúa la habilidad del emisor para generar flujos de caja estables basados en el marco legal y base financiera.

- Estructura de deuda: Se toma en cuenta la estructura de la deuda (amortización, vencimiento, riesgo de tasa de interés, liquidez, covenants financieros y gatillos) y el paquete de garantías. También se podrá evaluar a la matriz.

- Perfil financiero: Se realizan medidas para analizar la flexibilidad financiera de la estructura ante escenarios de estrés. También se evalúa el impacto del riesgo de contraparte en la deuda.

- Estructura e información: Se toma en cuenta la experiencia y calidad del sponsor, fortaleza de la estructura legal y la calidad de la información. 
- Riesgos macros: Considera el riesgo del país, riesgos de la industria y la exposición de la deuda a tales riesgos.

Entre los criterios utilizados por S\&P (2014a, 2011b) para la evaluación de project finance, tenemos:

- Se determina si el proyecto está en fase constructiva u operativa. Dependiendo de esto, se evalúa el riesgo de construcción o el riesgo de operación y de mercado y se toma en cuenta los términos contractuales del proyecto y el riesgo del país.

- Se analizan los riesgos financieros relacionados a la deuda en evaluación. Se hacen análisis de escenarios de estrés y se evalúa la liquidez y el riesgo de refinanciamiento.

- Se evalúa el riesgo de contraparte (off-takers, Concedente), determinando la dependencia del emisor con este, el grado en que la contraparte es reemplazable, mejoradores de crédito y el tipo de contrato.

- Se evalúa la estructura financiera de la deuda. Se determina en qué magnitud está ligada la calidad crediticia del proyecto a la de su matriz, la protección brindada por los covenants financieros y los covenants que regulan el manejo de caja hacia la estructura.

- Se evalúa la estructura de la empresa y su conexión con sus promotores y su respaldo. Se determina el grado de independencia de la compañía con su matriz y la existencia de cláusulas de cross-defaults.

- Se evalúa el apoyo y el rating del gobierno donde se desarrolla el proyecto.

- Se analizan las garantías de la estructura y se consideran si pueden haber mejoradores de crédito.

Los ratings de BBB- fueron confirmados por las agencias, posteriormente a la emisión y en la actualidad su calificación ha sido elevada a BBB por S\&P (2016) y se mantiene igual para Fitch. Las agencias de rating constantemente revisan su 
metodología, por lo que en el futuro podrían agregar criterios que actualmente no son tomados en cuenta y que podrían modificar el rating otorgado a ATS.

Volviendo a la calificación otorgada en la fecha de emisión, esta pudo ser obtenida no sólo basada en el sólido esquema del sector de transmisión que garantiza el flujo de ingresos de la concesión, sino también gracias a las garantías ofrecidas por la empresa para recompensar cualquier riesgo derivado del proyecto de inversión que pudiera incurrir en un incumplimiento de las obligaciones del bono.

La importancia de los ratings como se explicó antes, es que sirven de indicador para los inversionistas para llevar a cabo una inversión en un activo determinado. De esta manera, cualquier downgrade o baja puede ocasionar un efecto adverso en el precio de mercado del bono y en su promoción, lo cual puede afectar a los bonistas que poseen estos valores y que lo comercializan en el mercado secundario.

Asimismo, bajo los Documentos del Financiamiento del bono en estudio, la reafirmación del rating inicial es importante para el emisor para (i) poder incurrir en deuda permitida adicional, (ii) suscribir Contratos Adicionales, (iii) realizar la cesión del Contrato de O\&M a una empresa no relacionada a Abengoa y (iv) realizar adendas al Contrato de Concesión, entre otras obligaciones descritas en el Indenture.

A lo largo de este capítulo se ha descrito la estructuración del bono y las partes involucradas para que la estructuración funcione adecuadamente y permita al proyecto de inversión seguir sus operaciones y generar el flujo necesario para el repago la deuda. Es así que podemos concluir que prácticamente todo el proyecto de inversión, incluidos sus bienes y derechos generados en base a estos bienes, son entregados en garantía y minuciosamente regulados para asegurar el repago de la deuda a los bonistas. Por ello, es de suma importancia que la estructuración del financiamiento mediante el Project Finance sea meticulosa y responsable, ya que la generación de un efecto materialmente adverso o el incurrir en un evento de default podrá generar, agotados los remedios previos para subsanar el incumplimiento, la inmediata ejecución del colateral entregado en garantía y por tanto, la pérdida de la concesión y un incumplimiento frente al Estado bajo el Contrato de Concesión. 


\section{CAPÍTULO III: EVALUACIÓN DE RESULTADOS Y ÉXITO DE LA EMISIÓN DEL BONO}

Después de haber descrito el proceso de estructuración del Bono 144A/Regulación S de Abengoa Transmisión Sur, el presente capítulo analizará de manera cuantitativa y cualitativa si dicha emisión logró alcanzar los objetivos por los cuales se realizó.

\subsection{ANÁLISIS CUANTITATIVO}

El presente análisis se realiza en base a las proyecciones disponibles en el Offering Memorandum para el caso del bono. Sobre el préstamo sindicado, las cifras se basan en información obtenida durante la experiencia laboral y la cual, por cuestiones de confidencialidad, no pueden ser divulgadas detalladamente en este trabajo.

\subsubsection{Flujo de caja}

Como se mencionó en el segundo capítulo, una de las razones para realizar esta emisión fue que el plazo de préstamo sindicado era muy corto y por lo tanto, amenazaba en afectar el flujo de caja de la empresa a poco tiempo de haber comenzado la operación comercial. Por lo tanto, una forma de medir el éxito de la emisión es mediante la comparación del flujo de caja proyectado de la empresa luego de realizado el pago del servicio de deuda en ambas situaciones.

En la Tabla 3.13, podemos apreciar la comparación de la caja restante para la empresa luego de aplicados los respectivos pagos de servicio de deuda. El préstamo sindicado tenía una vida de 7 años y una amortización creciente con un balloon considerable al vencimiento de este (entre $60-70 \%$ del principal). Es por ello que apreciamos una caja negativa en el año 2019 para poder realizar la amortización de dicho balloon. Esta caja negativa sólo hubiese podido ser superada mediante el refinanciamiento de dicho préstamo a través de un financiamiento a largo plazo. 
Tabla 3.13

Comparativo de Proyecciones de Flujo de Caja Bono vs. Préstamo Sindicado

\begin{tabular}{|c|c|c|c|c|c|c|c|}
\hline Flujo de Caja & 2014 & 2015 & 2016 & 2017 & 2018 & 2019 & 2020 \\
\hline \multicolumn{8}{|l|}{ BONO } \\
\hline Caja Disponible Servicio Deuda & 20 & 41 & 42 & 43 & 44 & 45 & 46 \\
\hline Servicio de Deuda & 15 & 30 & 31 & 31 & 32 & 33 & 34 \\
\hline Caja Después del Servicio Deuda & 5 & 11 & 11 & 12 & 12 & 12 & 12 \\
\hline \multicolumn{8}{|l|}{ PRÉSTAMO SINDICADO } \\
\hline Caja Disponible Servicio Deuda & 20 & 41 & 42 & 43 & 44 & 45 & 46 \\
\hline Servicio de Deuda & 9 & 34 & 34 & 34 & 35 & 300 & 0 \\
\hline Caja Después del Servicio Deuda & 11 & 7 & 8 & 9 & 9 & (255) & 46 \\
\hline Diferencias Caja Bono vs. Sindicado & 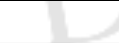 & 18 & 15 & 16 & 18 & (246) & \\
\hline
\end{tabular}

Nota: Las cifra están en millones de USD.

Fuente: Offering Memorandum (2014).

Elaboración Propia.

La pregunta adecuada luego de lo expuesto anteriormente, sería por qué no esperar a casi el término del préstamo sindicado para realizar la estructuración del bono. Esto no era adecuado, tomando en cuanto que una porción de la tasa de interés del préstamo sindicado estaba sujeto a una tasa Libor que era variable. La tasa del préstamo sindicado era igual a un Margen (creciente cada 2 años) más la tasa Libor. Si bien existía un cap de tasas de interés que determinaba un techo máximo para la fluctuación de la tasa Libor, la suma de los márgenes crecientes podría provocar que la tasa total fuese de hasta un poco más de 6,5\%. Además el cap no aplicaba al 100\% del principal del préstamo. Por tanto, esta tasa no resultaba atractiva en comparación al mercado de capitales y dado el plazo del préstamo sindicado que era relativamente corto.

Por ello, se puede concluir que era conveniente realizar la emisión de bonos y cancelar el préstamo sindicado, ya que había presiones de caja por el servicio de la deuda (tanto del principal como los intereses) del préstamo sindicado anterior al bono.

\subsubsection{Costo All-In}

Una forma de comparar los costos asociados a una transacción financiera, es mediante el cálculo del Costo All-In, el cual permite al emisor no sólo evaluar aquellos costos derivados de los intereses cobrados, sino también de las comisiones y demás costos de cierre ligados a un financiamiento. 
En el caso de ATS, es necesario comparar los Costos All-In de la alternativa del préstamo sindicado con el del bono. En la Tabla 3.14, se listan aquellos gastos asociados con ambos financiamientos y el Costo All-In calculado tomando en consideración los gastos aplicables.

Tabla 3.14

Consideraciones para el cálculo del Costo All-In

\begin{tabular}{l}
$\quad$ Descripción \\
Costos de Cierre \\
Comisión Estructuración \\
Upfront Fee \\
\hline Gastos por asesores \\
Gastos Clasificadoras Rating Emisión \\
\hline Costo de Cancelación Swap \\
Gastos Anuales \\
Comisión Admin. Fideicomiso \\
\hline Tasa de interés fija \\
\hline Comisión Listado en Bolsa \\
\hline Comisión de compromiso \\
\hline Revisión rating \\
\hline Costo All-In
\end{tabular}

Nota: Se ha usado el check para indicar aquellos gastos en los que incurre cada alternativa de financiamiento y la equis para aquellos gastos que no son aplicables.

Elaboración propia.

$\mathrm{Si}$ bien el Costo All-In del préstamo sindicado es menor por $0.12 \%$, esta diferencia no es relevante si se considera que el plazo del bono es 22 años mayor que del préstamo y por tanto, presenta una mayor sensibilidad a las variaciones de las tasas de interés a través de toda su vida, bajo el concepto de la curva de rendimiento (Fabozzi, 2012, p. 23). Así, tomando en cuenta ambos costos, el Costo All-In del bono, a pesar de considerar gastos relacionados al financiamiento anterior (la cancelación del swap), es más beneficioso comparado con el préstamo sindicado. 


\subsection{ANÁLISIS CUALITATIVO}

Otros criterios a tomar en cuenta para analizar el éxito de la emisión, no pueden medirse cuantitativamente, pero si pueden ser observados en cuanto a ventajas cualitativas generadas para la empresa.

Debido a la alta demanda que obtuvo el bono en la Fecha de Cierre a pesar de su largo vencimiento, la emisión de este bono ha ganado al menos 2 premios que lo han reconocido como la transacción del año: Americas Bond Deal según los Premios Project Finance International y mejor transacción del año en Latinoamérica por los premios IJGlobal, ambos entregados en el año 2015. Lo que se ha sido resaltado por ambas entidades es la alta demanda que hubo por este bono a pesar de de que el mercado tradicionalmente no invierte en bonos a tan largo plazo y en el formato como fue estructurado el de ATS. Es así, que al año 2015, esta emisión fue la del vencimiento más largo de Project Bond tipo greenfield en Latinoamérica (Americas Awards PFI Yearbook 2015, sección Americas Bond Deal of the year, párr. 1.). Por ello, esta transacción se considera un ejemplo a seguir para aquellos proyectos de infraestructura en el Perú que cuenten con un contrato de concesión y bases estables y claras que permitan predecir flujos de caja estables que soporten un financiamiento de grandes magnitudes.

Estos premios han resaltado la capacidad de estructuración de Project Finance por parte de Abengoa en Perú, lo que puede ser utilizado por sus sociedades peruanas para indicar que los proyectos de concesión otorgados administrados por la empresa, son gestionados adecuadamente y contarán con financiamientos sólidos y seguros para los inversionistas. De esta manera, el bono trae consigo prestigio para las empresas peruanas de Abengoa tanto administrativa como financieramente.

Por otro lado, desde la perspectiva del Sponsor, haber realizado el repago del préstamo sindicado lo liberó de obligaciones vinculadas a aportaciones obligatorias de caja por sobrecostos en el proyecto que eran de un compromiso mayor que las que presenta el Contrato de Apoyo del Promotor de la emisión de bonos. 


\section{CONCLUSIONES}

El presente trabajo fue elaborado para exponer el proceso de estructuración detrás de la emisión del bono de Abengoa Transmisión Sur S.A. y evaluar el éxito de la emisión para la empresa. Después de realizadas las presentaciones y análisis debidos, las conclusiones al respecto, son las siguientes:

- El éxito del bono se ha basado en el adecuado marketing del proyecto de inversión y de la transmisión precisa de la solidez de las fortalezas del marco legal de la concesión, la sólida estructura financiera, así como las garantías ofrecidas a los inversionistas. Esta correcta canalización de información del emisor al inversionista objetivo ha sido lograda mediante el Road Show.

- El paquete de garantías ofrecido en esta emisión, no ha incluido garantías líquidas (tales como standby letters) y se ha establecido el apoyo del Sponsor mediante contribuciones en el proyecto eventuales y muy limitadas (garantía corporativa). Estas garantías se denominan mejoradores de créditos externos. Por lo tanto, se puede concluir que el mercado ha considerado que los mejoradores externos, no eran necesarios y que la regulación de la cascada de flujos, las cuentas de reserva, la retención de caja, las prendas de acciones y cuentas y la hipoteca sobre la concesión han sido suficientes para cubrir el riesgo de incumplimiento de la empresa (los denominados mejoradores internos).

- Este bono se encuentra en el límite de la calificación crediticia considerada como Grado de Inversión y presentó una gran demanda en la fecha de emisión por aproximadamente USD 2,000 millones $^{33}$ por parte del mercado. Esto indica el mayor atractivo que los proyectos de infraestructura en Latinoamérica están generando a los inversionistas, los cuales buscan inversiones que paguen un YTM mayor a los que obtienen por inversiones tradicionales y con bonos de deuda corporativa.

33 Extraído del Portal web de Abengoa Perú. http://www.abengoa.pe/web/es/noticias/historiconoticias/noticia/ATS-galardonada-con-el-Premio-IJGlobal-a-la-mejor-transaccion-del-ano-en-

Latinoamerica-en-el-sector-de-transmision/ 
- Para el Perú, este tipo de bono marca un hito para aquellos proyectos de transmisión eléctrica que busquen financiarse en el futuro mediante bonos de oferta privada bajo el formato 144A/Regulación S y a un vencimiento amplio que les permita calzar sus necesidades de financiamiento junto con el plazo de la concesión. 


\section{RECOMENDACIONES}

En base a las conclusiones anteriores, detallaremos las recomendaciones:

- Se recomienda a las empresas dedicadas al desarrollo de proyectos de infraestructura, el uso de la alternativa del Project Finance como un mecanismo que facilita el financiamiento a las empresas que carecen generación de flujo de caja inmediato.

- Es importante tener un énfasis especial en la estructuración del paquete de garantías, ya que el éxito de una estructura de Project Finance radica principalmente en las garantías ofrecidas, las cuales mejoran el riesgo crediticio del emisor.

- Las garantías para la mejora del rating crediticio deben ser de preferencia internas y no externas. Los mejoradores externos provienen de terceros y cualquier baja en el rating crediticio de dicha contraparte puede afectar el rating crediticio de la emisión debido a la metodología utilizada por las agencias de rating (Fabozzi, 2007, p. 69).

- Si bien las garantías emplean mecanismos que ayudan a controlar el actuar de la empresa, se recomienda que este control no sea limitativo y que no afecte las operaciones del curso ordinario del negocio.

- De la misma manera, es importante que las empresas que ofrezcan este tipo de garantías, lleven un seguimiento riguroso y minucioso de las obligaciones comprometidas para no incurrir en incumplimientos y ver ejecutadas las garantías ofrecidas. Es importante esto para no dar señales incorrectas al inversionista en cuanto a la administración del proyecto.

- Dentro de la estructura de la emisión, es recomendable evitar volatilidades en el riesgo crediticio que afecten la calificación crediticia de los bonos. Si bien los Documentos del Financiamiento no califican la baja del rating como un Evento de Incumplimiento y gatillan la Redención Obligatoria de los bonos, una sustancial baja del rating puede estar reflejando un bajo Ratio de Cobertura de Servicio de Deuda, lo cual si activa las retenciones de caja y las redenciones obligatorias. 
- Se sugiere la financiación mediante el mercado de capitales y en oferta privada del tipo 144A/Regulación S para aquellas concesionarias peruanas con grandes necesidades de recursos y que desean realizar poca divulgación de información. El éxito de la emisión dependerá del grado de divulgación de información presente en el Offering Memorandum y en el Road Show.

- Asimismo, es recomendable que aquellos proyectos de inversión en transmisión eléctrica que busquen financiamiento mediante el formato 144A/Regulación S, hayan mitigado a un porcentaje mínimo el riesgo de construcción del proyecto. De lo contrario, (i) las tasas cupón obtenidas podrían ser demasiado altas y por tanto, generar un elevado servicio de deuda, que podría generar un detrimento del flujo de caja de la empresa en etapa pre-operativa, y (ii) podría no generarse la demada adecuada para cubrir el monto de fondos necesarios para el proyecto y cubrir los costos generados por la emisión.

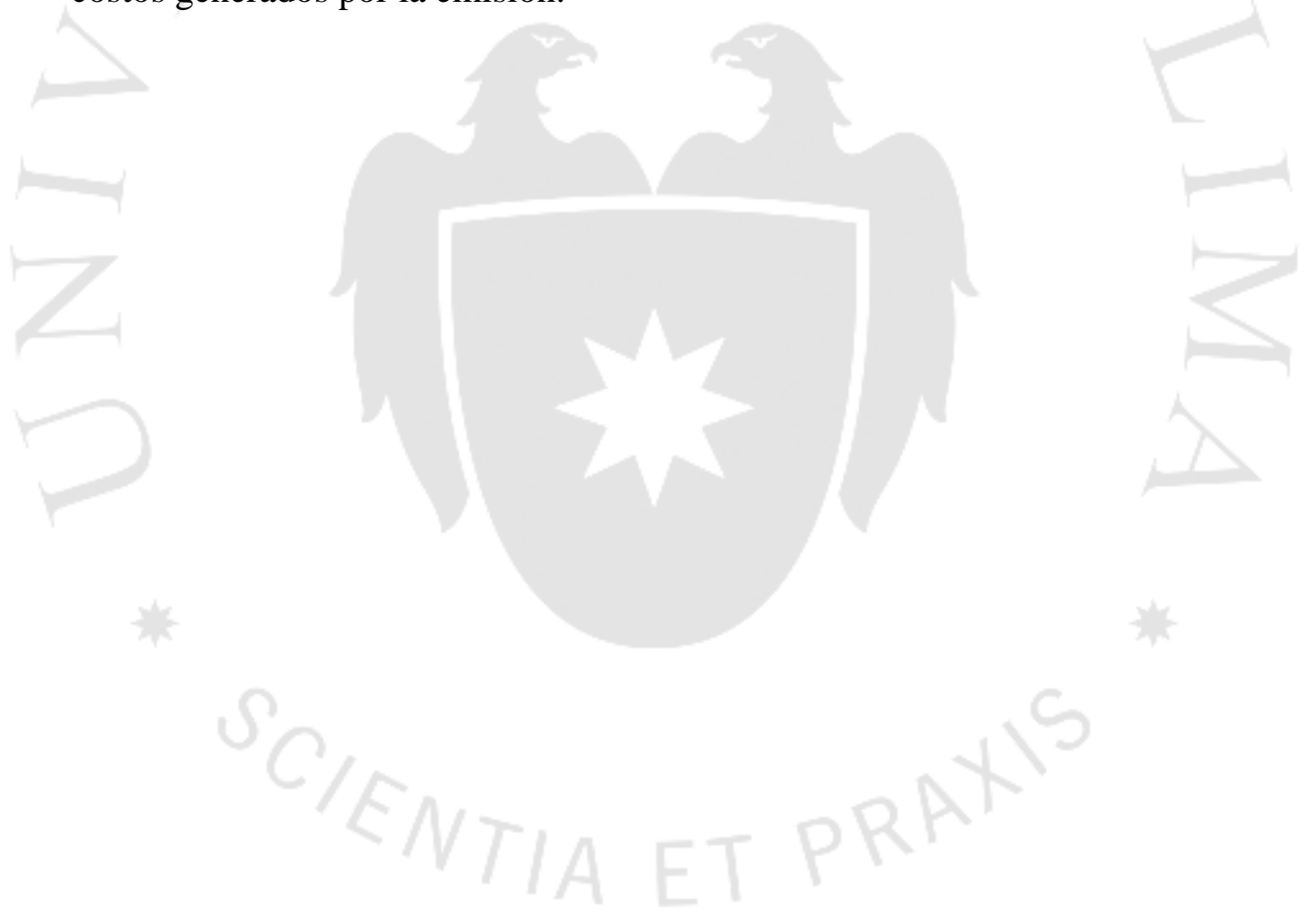




\section{REFERENCIAS}

Bustillo, I., y Velloso, H. (2013). La montaña rusa del financiamiento externo: el acceso de América Latina y el Caribe a los mercados internacionales de bonos desde la crisis de la deuda, 1982-2012. Santiago de Chile: Naciones Unidas.

Carey, M., Prowse, S., Rea, J. y Udell, G. (1993). The economics of the private placement market. Washington, D.C.: Board of Governors of the Federal Reserve System.

Class y Asociados S.A. Clasificadora de Riesgo. (2015). Fundamentos de clasificación de riesgo: Credicorp Capital Sociedad Titulizadora S.A. Recuperado de http://www.classrating.com/2tiana3.pdf

Comité de Operación Económica del Sistema Interconectado Nacional. (14 de marzo de 2016). Memoria COES SINAC 2015.

Contrato de Concesión Línea de Transmisión SGT 500 kV Chilca-Marcona-Montalvo. (2010). Recuperado del sitio de internet de: www.proinversion.gob.pe

Decreto Legislativo No 861, Ley del Mercado de Valores. (11 de junio de 2002).

Recuperado del sitio de internet de la Superintendencia del Mercado de Valores: http://www.smv.gob.pe/

Deutsche Bank Depositary Receipt Services. (5 de enero de 2011). What is the difference between Reg $S$ and 144A. Recuperado de:

https://www.adr.db.com/drweb/public/en/content/faqs_by_brokers.html

Erhardt, M. C., y Brigham E. F. (2011). Corporate finance: a focused approach (4. ${ }^{\mathrm{a}}$ ed.). Ohio: South-Western.

Fabián Sotelo, L. (2014). Valuación de bonos: teoría y práctica. (1. a ed.). Lima: Universidad Mayor de San Marcos.

Fabozzi, F. J. (2007) Fixed income analysis (2. ed.). New Jersey: John Wiley \& Sons, Inc.

Fabozzi, F. J. (2012). Bond markets, analysis and strategies (8. ${ }^{\mathrm{a}}$ ed.). Boston: Pearson.

Fabozzi, F. J., y Modigliani F. (2013). Capital markets: institutions and instruments (4. ${ }^{\mathrm{a}}$ ed.) Delhi: Prentice Hall Higher Education.

Fitch Ratings. (28 de setiembre de 2015). Rating criteria for infrastructure and project finance. Recuperado del sitio de internet de Fitch Ratings: https://www.fitchratings.com/site/fitch-home/re/870967

Jara, R. (2001). Oferta pública y privada de valores en el mercado norteamericano: una visión comparada. Revista Chilena de Derecho, 28(1), 107. Recuperado de: http://web.uqroo.mx/archivos/jlesparza/acpef140/L8\%20Oferta\%20valores.pdf 
Law 360. (2013). Prepping for projet bonds. (28 de agosto de 2013). Recuperado de: http://www.law360.com/articles/467505/prepping-for-project-bonds

Ley para asegurar el desarrollo eficiente de la generación eléctrica. Ley 28832 (2006). Sistema de Transmisión del SEIN. Recuperado de: http://www2.osinerg.gob.pe/MarcoLegal/pdf/LEY\%2028832.pdf

Molina, A. y Del Carpio, J. (2004). Financiamiento de inversiones mediante el "project finance”. Revista de la facultad de ingeniería industrial, 7(2), pp. 76-82.

Offering Memorandum de Abengoa Transmisión Sur S.A. 6.875\% Senior Secured Notes due 2043 (2014). Recuperado del sitio de internet de la Bolsa de Luxemburgo: https://www.bourse.lu/home

Organismo Supervisor de la Inversión en Energía y Minería. (2014). Línea de Transmisión Chilca-Marcona-Montalvo (operando). Recuperado del sitio de internet del Centro Documental de OSINERGMIN: https://www.osinergmin.gob.pe/seccion/centro_documental/electricidad/Docum entos/PROYECTOS\%20GFE/Acorde\%C3\%B3n/Transmisi\%C3\%B3n/1.1.3.pdf

Pajuelo, M., y Castro, J. (setiembre 2014). Informe sectorial Perú: sector eléctrico. Recuperado del sitio de internet de Pacific Credit Rating: http://www.ratingspcr.com/uploads/2/5/8/5/25856651/sector_electrico_peruano_ 201409-fin.pdf

Proinversión. Régimen de recuperación anticipada del IGV. Recuperado de: http://www.investinperu.pe/modulos/JER/PlantillaStandard.aspx $?$ are $=0 \& p r f=0 \&$ jer $=5849 \& \sec =1$

Project Finance International. (2015). Americas Awards, PFI Yearbook 2015. Recuperado de http://www.pfie.com/americas-awards/21178859.fullarticle

Resolución de la Comisión de Tarifas Eléctricas No. 017-97 P/CTE (11 de octubre de 1997). Recuperado del sitio de internet de OSINERGMIN: http://www2.osinerg.gob.pe/Resoluciones/pdf/RE017-1997.pdf

Resolución de Superintendencia N 00031-2012-SMV/01, Reglamento de Inscripción y Exclusión de Valores Mobiliarios en la Rueda De Bolsa. (26 de julio de 2012). Recuperado del sitio de internet de la Superintendencia del Mercado de Valores: http://www.smv.gob.pe/Frm_SIL_Detalle.aspx?CNORMA=MV0031201200031 $\% 20 \&$ CTEXTO=

S\&P Global Ratings. (20 de diciembre de 2011). Criteria - Corporates - Project Finance: project finance construction and operations counterparty methodology. Recuperado del sitio de internet de S\&P Global Ratings: http://www.standardandpoors.com/en_US/web/guest/article//view/sourceId/7041103 
S\&P Global Ratings. (16 de setiembre de 2014). Criteria - Corporates - Project Finance: project finance framework methodology. Recuperado del sitio de internet de S\&P Global Ratings:

http://www.standardandpoors.com/en_US/web/guest/article//view/sourceId/8707604

S\&P Global Ratings. (16 de setiembre de 2014). Criteria - Corporates - Project Finance: project finance transaction structure methodology. Recuperado del sitio de internet de S\&P Global Ratings: http://www.standardandpoors.com/en_US/web/guest/article//view/sourceId/8708587

S\&P Global Ratings. (29 de abril de 2016). ABY Transmision Sur Debt Rating Raised to 'BBB' On Expected Improvement In Financial Performance, Outlook Still Stable: https://www.standardandpoors.com/en_US/web/guest/article//view/type/HTML/id/1626665

Serfilippi, C. (1 de febrero de 2012). Using Rule 144A to Access the U.S. capital markets. Bloomberg Law Reports-UK Financial Services Law, 4(2).

Thomas, Z. (17 de abril de 2014). Peru Project bond a milestone for accepted practice. International Financial Law Review. Recuperado de: http://www.iflr.com/Article/3332001/Peru-project-bond-a-milestone-foraccepted-practice.html

U.S. Securities and Exchange Comission. (23 de setiembre de 2014). Investor bulletin: private placements under Regulation $D$. Recuperado del sitio web la SEC: https://www.sec.gov/oiea/investor-alerts-bulletins/ib_privateplacements.html

U.S. Securities and Exchange Comission (25 de febrero de 2013). Settling securities transactions, T+3. Recuperado de: https://www.sec.gov/answers/tplus3.htm 


\section{BIBLIOGRAFÍA}

Barker \& McKenzie. (2012). The Luxembourg Stock Exchange: a choice place for listings and cross-border offerings. Recuperado de:

http://www.bakermckenzie.com/files/Uploads/Documents/Locations/Luxembou rg/br_luxembourg_listinginluxembourg_2012.pdf

Eiger, Z. D., y Harmetz, L. S. (2015). Frequently asked questions about Regulation S. Recuperado del sitio web de Morrison \& Foerster: http://media.mofo.com/files/Uploads/Images/FAQs-Regulation-S.pdf

Fitch Ratings. Sitio de internet: https://www.fitchratings.com/site/fitch-home

Harmetz, L. S. (2016). Frequently asked questions about Rule 144A. Recuperado del sitio web de Morrison \& Foerster: http://media.mofo.com/docs/pdf/faqrule144a.pdf

Mascareñas, J. (2006). El Mercado Internacional de Bonos. Madrid: Universidad Complutense de Madrid.

Moody's Investors Service Inc. Sitio de internet: https://www.moodys.com/

S\&P Global Ratings. Sitio de internet: http://www.spratings.com/en_US/home 


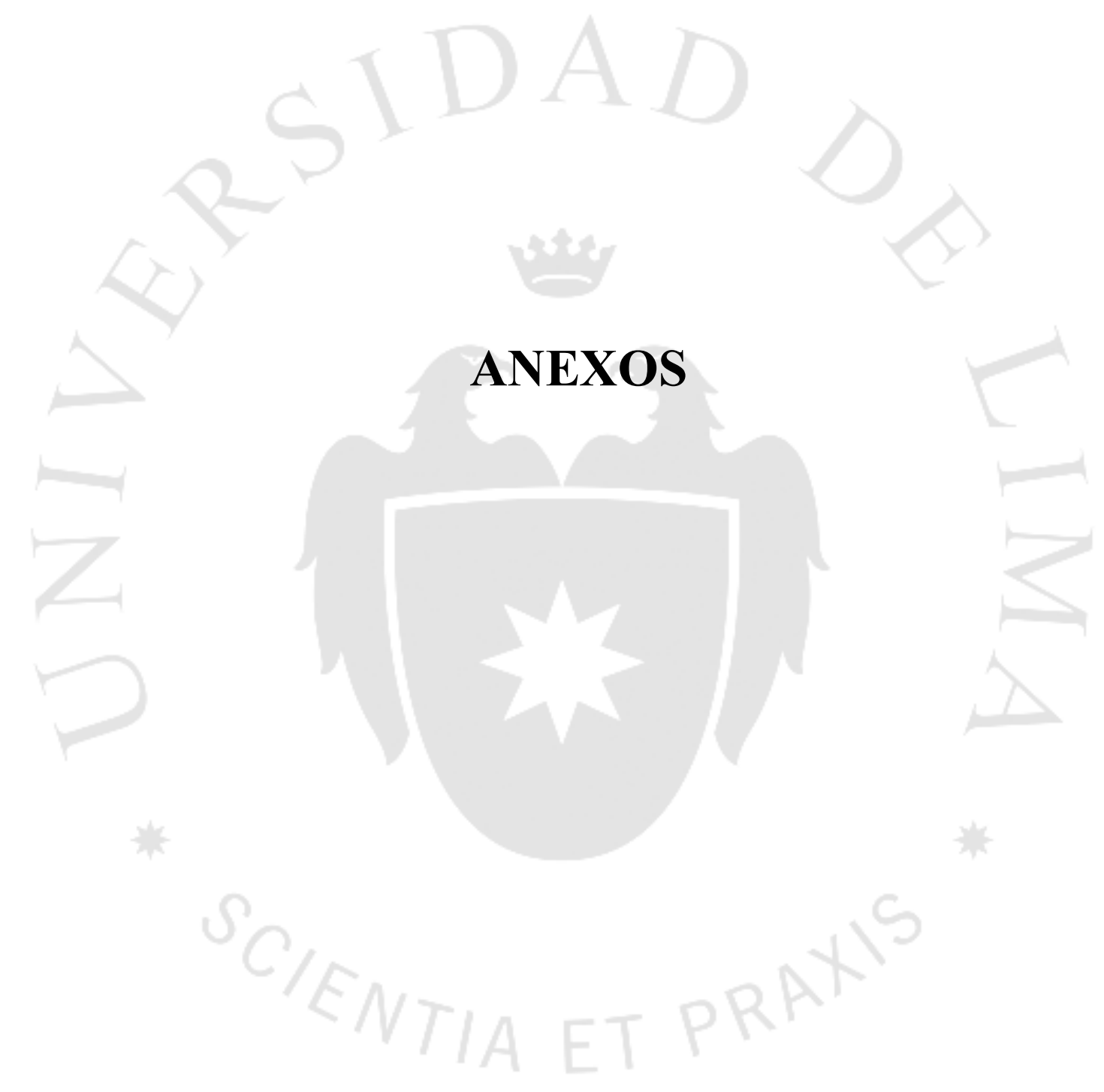




\section{ANEXO 1: Acreedores Permitidos}

Según el Anexo $\mathrm{N}^{\circ} 3$ del Contrato de Concesión (2010), los Acreedores Permitidos que podrán incurrir en la deuda garantizada según lo definido en la Cláusula 9 del Contrato son:

(i) cualquier institución multilateral de crédito de la cual el Estado de la República del Perú sea miembro;

(ii) cualquier institución o cualquier agencia gubernamental de cualquier país con el cual el Estado de la República del Perú mantenga relaciones diplomáticas;

(iii) cualquier institución financiera aprobada por el Estado de la República del Perú y designada como Banco Extranjero de Primera Categoría en la Circular No 027-2009BCRP, emitida por el Banco Central de Reserva del Perú, o cualquier otra circular que la modifique, y adicionalmente las que las sustituyan, en el extremo en que incorporen nuevas instituciones;

(iv) cualquier otra institución financiera internacional aprobada por el CONCEDENTE que tenga una clasificación de riesgo no menor a (“A”), evaluada por una entidad de reconocido prestigio aceptada por la Comisión Nacional Supervisora de Empresas y Valores (CONASEV);

(v) cualquier institución financiera nacional aprobada por el CONCEDENTE que tenga una clasificación de riesgo no menor a ("A") por una empresa clasificadora de riesgo nacional de reconocido prestigio aceptada por la CONASEV;

(vi) todos los inversionistas institucionales así considerados por las normas legales vigentes o bancos extranjeros de primera categoría [según lo indicado en el literal (iii) anterior] que (a) adquieran directa o indirectamente; (b) sean titulares; o, (c) sean tenedores, de cualquier tipo de valor mobiliario o título de deuda emitido directa o indirectamente por el CONCESIONARIO;

(vii) cualquier patrimonio fideicometido o sociedad titulizadora constituida en el Perú o en el extranjero;

(viii) cualquier persona natural o jurídica que adquiera directa o indirectamente cualquier tipo de valor mobiliario o título de deuda emitido directa o indirectamente por el CONCESIONARIO mediante oferta pública o privada; o 
(ix) cualquier representante de obligacionistas, agente fideicomisario o "trustee" que actúe en representación de titulares de valores mobiliarios o títulos de deuda emitidos directa o indirectamente por el CONCESIONARIO.

Los Acreedores Permitidos no deberán tener ningún tipo de vinculación con la Sociedad Concesionaria, conforme a las definiciones previstas en la Resolución CONASEV N ${ }^{\circ}$ 090-2005-EF-94.10, modificada por la Resolución CONASEV Nº 005-2006-EF/94.10, o norma que la sustituya, salvo que se trate de inversionistas institucionales. (p. 74)

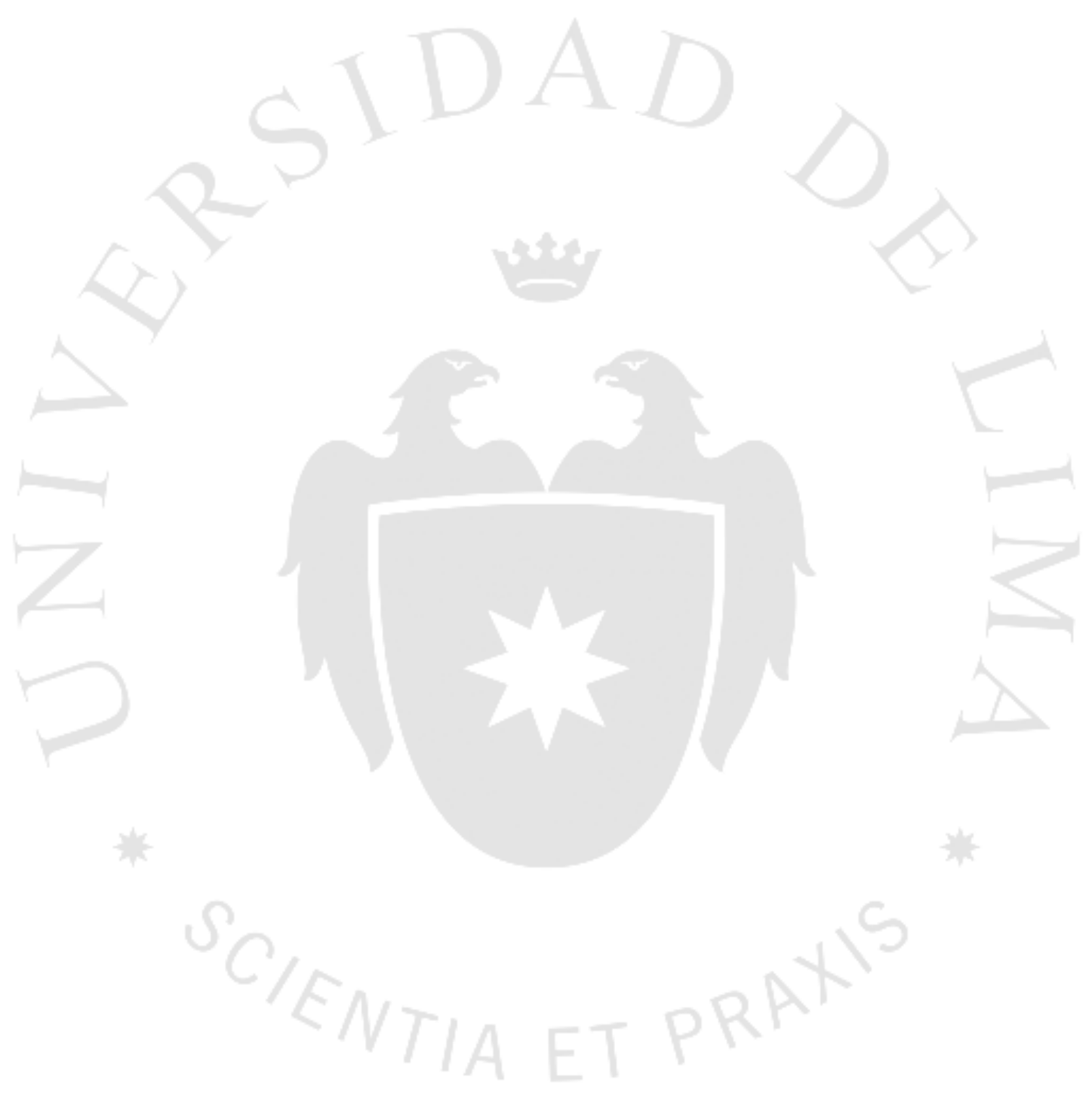




\section{ANEXO 2: Matriz de Riesgos del proyecto de inversión}

\begin{tabular}{l} 
Identificación del Riesgo \\
A. Riesgos de la Base Tarifaria \\
\hline 1. Régimen tarifario \\
- Los montos ofertados como monto de \\
inversión y costo de operación y \\
mantenimiento se consideran expresados a la \\
fecha de Puesta en Operación Comercial. \\
La Tasa de Actualización establecida en el \\
artículo $79^{\circ}$ de la LCE vigente a la fecha es \\
de $12 \%$.
\end{tabular}
Evolución del índice de referencia para la provocará menores ingresos y por tanto un menor retorno. actualización de la Base Tarifaria (índice WPSSOP3500 - Finished Goods Less Food and Energy) diferente al proyectado.

B. Riesgos del Contrato de Concesión

3. Desequilibrio económico de la Sociedad • La redacción ambigua de la Cláusula podría impedir el Concesionaria por cambios en las Leyes Aplicables en la medida que tenga exclusiva relación con aspectos económicos financieros.

Se permite a la sociedad concesionaria $o$ al concedente invocar que el equilibrio económicofinanciero se ha afectado (Numeral 14). La parte afectada podrá invocar ruptura del equilibrio económico-financiero sólo después de transcurridos 2 años luego de la Puesta en Operación Comercial.

2. Factor de Actualización $\quad$ Una variación inferior del índice respecto a lo estimado,

- Riesgo de variaciones en la tasa de actualización del artículo $79^{\circ}$ de la LCE. Si la tasa fijada a la fecha de cierre de $12 \%$, es elevada posteriormente, genera un costo de oportunidad para la empresa ya que tiene una Base Tarifaria menor a la que tendría si la tasa fuese actualizable.

- Riesgo de inflación para la actualización del Costo de inversión y los Costos de OyM, ya que el primer ajuste se realiza en la Puesta en Operación Comercial y no desde la Fecha de Cierre del Contrato. derecho a obtener el restablecimiento en aquellos supuestos que no se consideren cambios "explícitos" o "exclusivos" a las Leyes Aplicables.

- Podría verse afectado los costos e ingresos dentro del período de 2 años luego de la POC sin posibilidad de invocar el equilibrio económico-financiero.
4. Terminación del Contrato por Expropiación de la línea de transmisión (Numeral 12.14) y por incumplimiento, de manera injustificada, grave y reiterada, del Concedente de las obligaciones que le corresponde de acuerdo con el Contrato (Numeral 12.4)

- El Concedente pagará a la Sociedad Concesionaria la cantidad que resulte mayor entre:

a) El valor presente de los ingresos por Base Tarifaria que se hubiera generado durante el saldo del plazo del Contrato, a una tasa de descuento de $12 \%$ nominal en dólares.

b) El Valor Contable (VC) de los Bienes de la Concesión a la fecha de terminación del contrato.

- De la cantidad calculada se descuentan: (i) remuneraciones y demás derechos laborales, (ii) deuda pendiente de pago, (iii) tributos; (iv) multa y penalidad, y (v) otros pasivos.

5. La Sociedad Concesionaria y/o el Operador • El Concedente solicita la Resolución del Contrato y se Técnico incurren en las causales de Resolución del Contrato a que se refieren las Cláusulas 13.2 y 13.3 , respectivamente. ${ }^{34}$ nombra un interventor.

Monto de indemnización insuficiente para recuperar la inversión debido a los descuento realizados.

- Si el valor real de la inversión del Proyecto es mayor al valor ofertado como Monto de Inversión a Proinversión, para los primeros años aplicará VC mientras que para los siguientes el $\mathrm{VA}_{12 \%}$.

La Sociedad Concesionaria asume los gastos que

${ }^{34}$ Causales aplicables al Concesionario: a) Declaraciones falsas (Cláusula 2.1. del Contrato); b) Demora mayor a 150 días en cualquiera de los hitos señalados en el Anexo 7 del Contrato (POC, cierre financiero, aprobación del EIA y llegada de los reactores y transformadores); c) No renueve o no prorrogue las garantías; d) No opere, sin causa justificada, 180 horas, continuas o no, al año; e) No cumpla sus 
- Se convoca a una licitación para la entrega en concesión del Proyecto a otra empresa (máximo 2 convocatorias y con un intervalo máximo de 60 días hábiles entre cada una de ellas). La Sociedad Concesionaria, sus socios principales y las Empresas Vinculadas de ambos, no pueden presentarse como postores.

- El monto base de la primera convocatoria no será menor al Valor Contable de los Bienes de la Concesión. De no existir postores y de haber una nueva convocatoria, el Concedente podrá reducir hasta en $25 \%$ el monto base de la primera convocatoria.

- Si la segunda convocatoria queda desierta o culmina sin adjudicatario, el Concedente queda obligado a pagar un valor igual al monto base de la primera o segunda convocatoria, respectivamente, o el Valor Contable de los Bienes de la Concesión, lo que sea menor.

- De la cantidad indicada se descuentan: (i) gastos de la intervención y la licitación, (ii) remuneraciones y demás derechos laborales, (iii) deuda pendiente de pago, (iv) tributos; (v) multa y penalidad; (vi) pasivos a favor del Estado, y (vii) otros pasivos.

- Sin perjuicio de la ejecución de las garantías correspondiente, el Concedente podrá exigir el pago de daño ulterior. demande la intervención y el proceso de licitación, de ser el caso.

- La Sociedad Concesionaria tiene derecho al resultado de la licitación menos sus pasivos, hasta por un monto equivalente al Valor Contable. Si existiese un saldo remanente, la diferencia corresponderá al Estado.

- Prohibición para participar en proceso de promoción de la inversión privada a que se refiere el Decreto Legislativo $\mathrm{N}^{\circ} 674$, el TUO o la Ley $\mathrm{N}^{\circ} 28059$, Ley Marco de Promoción de la Inversión Descentralizada.

- Riesgo de pago de indemnización al Estado por daño ulterior sin ninguna limitación.

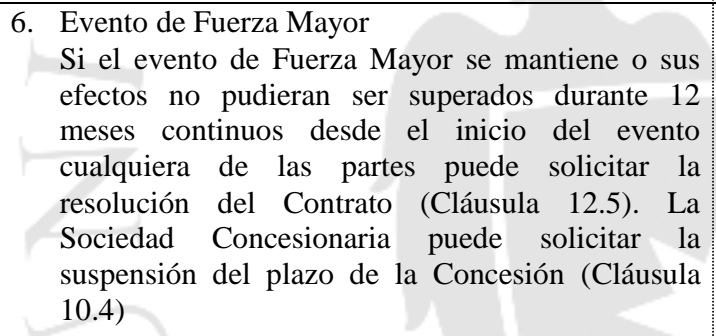

La Fuerza Mayor no libera a la Sociedad Concesionaria del cumplimiento de las obligaciones que no sean afectadas por dichos eventos. Además debe hacer sus mejores esfuerzos para asegurar la reiniciación de la actividad o prestación del servicio correspondiente. En caso no se superen los eventos en 12 meses cualquiera de las Partes puede resolver el Contrato.

Para la etapa de operación, la evaluación de Fuerza Mayor respecto de la variación temporal de las condiciones de suministro, corresponderá Osinergmin y las Leyes Aplicables.
7. Destrucción Total (Cláusula 12.13)

- El beneficiario de la póliza del seguro en caso de Destrucción Total es el Concedente (Cláusula 7.2 c.).

- Las partes evaluarán la conveniencia técnica y económica de restaurar los daños y los términos y condiciones en que se efectuaría la
- En caso no se decida la reconstrucción y reanudación del Servicio se recibirá el remanente del monto asegurado luego de pagar los pasivos de la Sociedad Concesionaria.

- Monto de indemnización insuficiente para recuperar la inversión.

obligaciones de prestar el servicio en los plazos prescritos y de acuerdo con las normas de seguridad y los estándares de calidad establecidos en el Contrato y en las normas técnicas pertinentes, a pesar de haber sido sancionada por Osinergmin; f) Transfiera parcial o totalmente el Contrato sin la previa aprobación del Concedente; g) Sea sancionada con multas administrativas que en un año superen el 10\% de la Base Tarifaria del año anterior (a partir del 2do año de operación); h) Se fusione, escinda o transforme, sin previa aprobación escrita del Concedente; i) Sea declarada en insolvencia, quebrada, disuelta o liquidada; j) No contrate los seguros o no cumplan las condiciones previstas en el Contrato; k) Contrate financiamiento sin cumplir el Contrato; y 1) Incumpla de forma injustificada, grave y reiterada, cualquier otra obligación establecida en el Contrato o las Leyes Aplicables.

Causales aplicables al Operador Técnico: 11) No conserve la Participación Mínima; m) No mantenga o no ejerza el derecho y la obligación de controlar las operaciones técnicas, y n) Sea declarado en insolvencia, quebrado, disuelto o liquidado.

Los supuestos c), e), i), j), k), 1), 1l), m) y n) configuran causales de terminación si no se subsana el incumplimiento en un plazo de 60 días. 
reconstrucción y la reanudación del servicio.

- En caso de reconstrucción y reanudación del servicio, el dinero percibido del seguro se utiliza para reemplazar y/o repara los bienes afectados.

- El Contrato se resuelve automáticamente si dentro de los 60 días hábiles posteriores a la destrucción total las partes no acuerdan la reconstrucción y reanudación del servicio.

- En caso de terminación del Contrato de Concesión por Destrucción Total, con la indemnización obtenida de los seguros y los ingresos generados de la subasta de la parte no afectada del Proyecto, y hasta donde alcancen, el fiduciario designado por el Concedente paga los gastos incurridos por la intervención de la concesión además de (i) remuneraciones y demás derechos laborales, (ii) deuda pendiente de pago, (iii) tributos; (iv) multa y penalidad; (v) pasivos con el Estado, y v) otros pasivos. El saldo remanente, si lo hubiere, será entregado a la Sociedad Concesionaria, hasta un máximo equivalente al Valor Contable de los Bienes de la Concesión.

La definición de "Destrucción Total" de acuerdo con el Contrato es una situación producida por cualquier causa que provoque daños a la Línea Eléctrica, estimados en cincuenta por ciento $(50 \%)$ o más de su Valor Contable.

8. Sociedad Concesionaria garantiza que Operador Resolución del Contrato en caso de no cumplir esta Técnico durante primeros 10 años de operación obligación. comercial será titular de la Participación Mínima y responsable de las operaciones técnicas de la Concesión. (Cláusula 2.3)

$$
\text { C. Riesgos de los Contratos EPC }
$$

9. Los Contratos EPC estipulan claúsulas de garantías que se mantendrán luego de la entrega de las instalaciones (12 meses posteriors).

10. Se le hace responsable a la UTE InabensaAbencor por los retrasos en el cumplimiento de hitos o el mal desempeño de las líneas de transmisión y subestaciones hasta por penalidades de $10 \%$ del monto del Contrato de Construcción

- El Contratista podría deicdir unilateralmente no mantener las garantías ofrecidas posteriores a la entrega de las instalaciones.

D. Riesgos de Operación y Mantenimiento

11. Incumplimiento total o parcial, tardío o defectuoso $\bullet$ Penalidad: $3 \mathrm{M} \$$

de un Mandato de conexión por Osinergmin o Autoridad Competente, cuando este fuere firme en

- Si las sanciones no son abonadas se ejecutará la sede administrativa y se hubiese interpuesto el garantía de $3 \mathrm{M} \$$ recurso contencioso en sede judicial. (Cláusula 10.10a)

12. Actos de abuso de posición de dominio en el $\bullet$ Penalidad: $3 \mathrm{M} \$$

mercado eléctrico o que limitan, restrinjan o $\bullet$ Si las sanciones no son abonadas se ejecutará la distorsionen la libre competencia declarada por la Autoridad competente, cuando este fuere firme en sede administrativa y se hubiese interpuesto el recurso contencioso en sede judicial. (Cláusula garantía de $3 \mathrm{M} \$$ $10.10 \mathrm{~b})$ 


\begin{tabular}{|c|c|}
\hline $\begin{array}{l}\text { 13. Incumplimiento o el cumplimiento parcial, tardío o } \\
\text { defectuoso, de lo dispuesto en el laudo generado } \\
\text { por una controversia a lo dispuesto en la cláusula } \\
5.12 \text { del contrato, referido a refuerzos a ejecutarse } \\
\text { de acuerdo con lo dispuesto por el artículo } 22 \text { de la } \\
\text { Ley } 28832 \text {. (Cláusula 10.10c) }\end{array}$ & $\begin{array}{l}\text { - Penalidad: } 3 \mathrm{M} \$ \\
\text { - Si las sanciones no son abonadas se ejecutará la } \\
\text { garantía de } 3 \mathrm{M} \$\end{array}$ \\
\hline $\begin{array}{l}\text { 14. Dejar de operar la línea eléctrica, sin causa } \\
\text { justificada, por } 180 \text { horas, continua o no, en un } \\
\text { año. (Cláusula } 12.2 \mathrm{~d} \text { ). }\end{array}$ & - Resolución del Contrato. \\
\hline $\begin{array}{l}\text { 15. Persistencia en el incumplimiento de prestación } \\
\text { del servicio en los plazos y según las normas } \\
\text { técnicas y de seguridad y estándares de calidad, } \\
\text { tras la sanción administrativa de Osinergmin } \\
\text { (firme en sede administrativa y sede judicial, de } \\
\text { ser el caso). (Cláusula 12.2 e) }\end{array}$ & $\begin{array}{l}\text { - Resolución del contrato si no se subsana en un plazo } \\
\text { de } 60 \text { días. }\end{array}$ \\
\hline 16. Fallas de Equipos & - Penalidades por indisponibilidad d \\
\hline $\begin{array}{l}\text { 17. Dificultades en el mantenimiento de las Líneas y } \\
\text { caminos de acceso, por accidentes geográficos de } \\
\text { la zona }\end{array}$ & $\begin{array}{l}\text { - } \text { Mayores costos } \\
\text { - } \\
\text { - }\end{array}$ \\
\hline $\begin{array}{l}\text { 18. Cambios en la topografía del terreno debido a } \\
\text { derrumbes, huaicos, cambio de cauces de ríos, etc. }\end{array}$ & $\begin{array}{l}\text { Gastos y costos no considerados en la operación y } \\
\text { mantenimiento } \\
\text { - }\end{array}$ \\
\hline 19. Vandalismo y robo contra la L.E. y/o S.E. & - Indisponibilidad del servicio \\
\hline $\begin{array}{l}\text { 20. Incremento en el Costo de Operación y } \\
\text { Mantenimiento (CO\&M, SPE, Capex, provisiones, } \\
\text { etc.) respecto del considerado en el modelo } \\
\text { financiero. }\end{array}$ & - Menor retorno \\
\hline $\begin{array}{lll}\text { Eiesgos Macroeconómicos, legales y } \\
\text { ambientales de Perú }\end{array}$ & \\
\hline $\begin{array}{l}\text { 21. Cambios en la política macroeconómica del } \\
\text { Gobierno de Péru (en cuanto a política monetaria, } \\
\text { cambiaria, fiscales, etc). }\end{array}$ & - Afectación de las Base Tarifaria y Costos \\
\hline 22. Cambios en las leyes tributarias & - Se pueden afectar la caja de la empresa \\
\hline $\begin{array}{l}\text { 23. Perdida de los permisos ambientales y } \\
\text { arqueológicos } \\
\text { Certificado de Intudio de Impacto Ambiental, } \\
\text { Arqueológicos). }\end{array}$ & $\begin{array}{l}\text { - Incrementos de costos del proyecto para gestionar } \\
\text { nuevamente los permisos. } \\
\text { - Posible pérdida de la concesión }\end{array}$ \\
\hline $\begin{array}{llll}\text { 24. Incumplimiento } & \text { en } & \text { las } & \text { regulaciones } \\
\text { medioambientales } & & & \\
\end{array}$ & $\begin{array}{l}\text { - Posibles multas } \\
\text { - Descontento social, huelgas. }\end{array}$ \\
\hline
\end{tabular}

